\title{
PRINCIPLES OF OPERATION AND DATA REDUCTION TECHNIQUES FOR THE LOFT DRAG DISC TURBINE TRANSDUCER
}

\author{
SANDOR SILVERMAN
}

September 1977

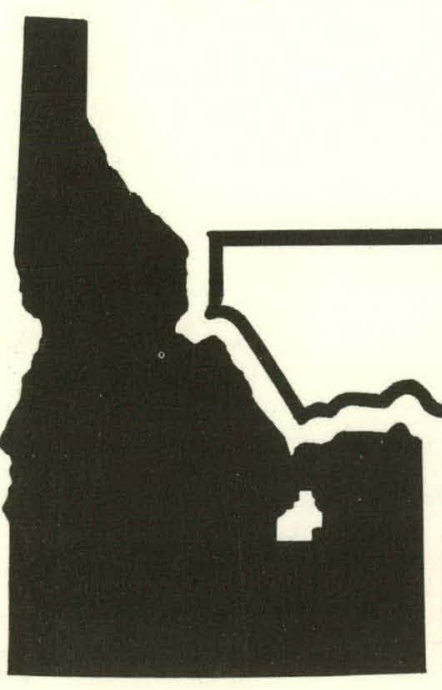

$\prod_{F} E \boldsymbol{E} \boldsymbol{G}$ Idaho, Inc.

IDAHO NATIONAL ENGINEERING LABORATORY

\section{ENERGY RESEARCH AND DEVELOPMENT ADMINISTRATION}




\section{DISCLAIMER}

This report was prepared as an account of work sponsored by an agency of the United States Government. Neither the United States Government nor any agency Thereof, nor any of their employees, makes any warranty, express or implied, or assumes any legal liability or responsibility for the accuracy, completeness, or usefulness of any information, apparatus, product, or process disclosed, or represents that its use would not infringe privately owned rights. Reference herein to any specific commercial product, process, or service by trade name, trademark, manufacturer, or otherwise does not necessarily constitute or imply its endorsement, recommendation, or favoring by the United States Government or any agency thereof. The views and opinions of authors expressed herein do not necessarily state or reflect those of the United States Government or any agency thereof. 


\section{DISCLAIMER}

Portions of this document may be illegible in electronic image products. Images are produced from the best available original document. 
Printed in the United States of America Available from

National Technical Information Service

U.S. Department of Commerce

5285 Port Royal Road

Springfield, Virginia 22161

Price: Printed Copy $\$ 6.75$; Microfiche $\$ 3.00$

$$
8,20
$$

"The NRC will make available data tapes and operational computer codes on research programs dealing with postulated loss-of-coolant accidents in light water reactors. Persons requesting this information must reimburse the NRC contractors for their expenses in preparing copies of the data tapes and the operational computer codes. Requests should be submitted to the Research Applications Branch, Office of Nuclear Regulatory Research, Nuclear Regulatory Commission, Washington, D.C. 20555."

\section{NOTICE}

This report was prepared as an account of work sponsored by the United States Government. Neither the United States nor the Energy Research and Development Administration, nor the Nuclear Regulatory Commission, nor any of their employees, nor any of their contractors, subcontractors, or their employees, makes any warranty, express or implied, or assumes any legal liability or responsibility for the accuracy, completeness or usefulness of any information, apparatus, product or process disclosed, or represents that its use would not infringe privately owned rights. 
TREE-NUREG-1109

\section{PRINCIPALS OF OPERATION AND DATA REDUCTION TECHNIQUES FOR THE LOFT DRAG DISC \\ TURBINE TRANSDUCER}

Approved:
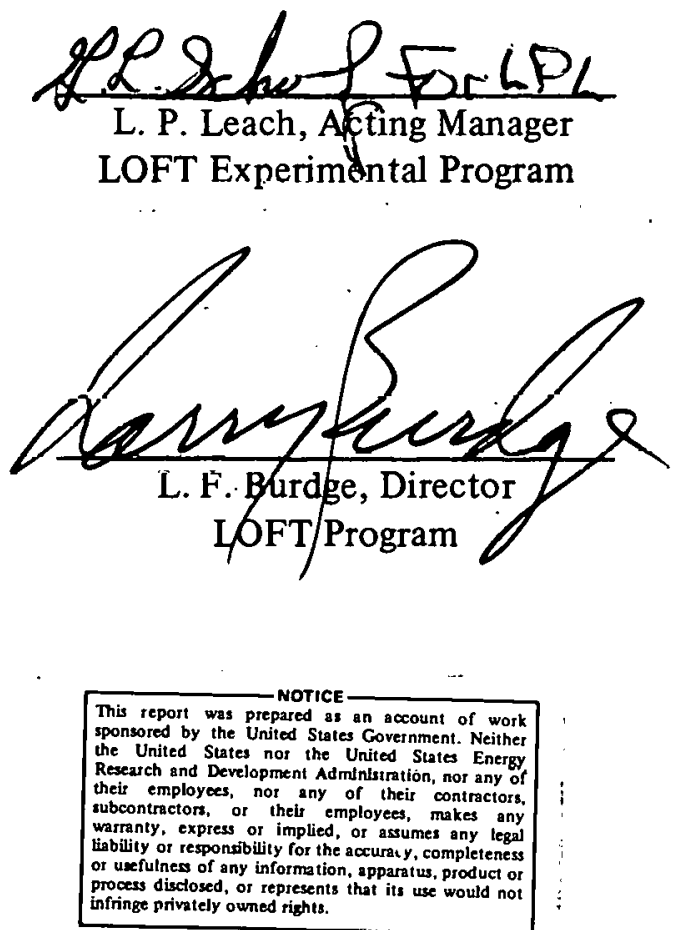

infringe privately owned rights. 
TREE-NUREG-1 109

Distributed Under Category:

NRC-2

Water Reactor Safety Research

Systems Engineering

\title{
PRINCIPLES OF OPERATION AND DATA REDUCTION TECHNIQUES FOR THE LOFT DRAG DISC. \\ TURBINE TRANSDUCER
}

by

Sandor Silverman

EG\&G IDAHO, INC.

September 1977

\author{
PREPARED FOR THE \\ U.S. NUCLEAR REGULATORY COMMISSION AND \\ ENERGY RESEARCH AND DEVELOPMENT ADMINISTRATION \\ IDAHO OPERATIONS OFFICE \\ UNDER CONTRACT NO. EY-76-C-07-1570
}




\begin{abstract}
An analysis of the single- and two-phase flow data applicable to the loss-of-fluid test (LOFT) is presented for the LUF'I drag turbine transducer. Analytical models which were employed to correlate the experimental data are presented.
\end{abstract}




\section{ACKNOWLEDGMENTS}

The author wishes to acknowledge the beneficial discussions and criticisms of R. K. Fujita, Energy Incorporated; B. Legrand, CEA of France working on a Power Burst Facility assignment; G. W. Cawood of Aerojet Solid Rockets Division, L. D. Goodrich, G. D. Lassahn, and C. F. Carmichael of EG\&G Idaho, Inc.; H. W. Heiselmann, Measurements Incorporated; and A. E. Arave, EG\&G Idaho, Inc.; who were most helpful in recalling details of the Auxiliary Reactor Area (ARA) and Westinghouse Canada Ltd. (WCL) test series. All of the reduced test data and the numerical results predicted by the various models were obtained by Betty Wong using the HP9830 calculator. Enough cannot be said about the data reduction by Ms. Wong as it is of the highest quality. Odo Göetzmann, Gesellschaft fur Kernforschung $\mathrm{MbH}$ of the Federal Republic of Germany, translated the German edition of "Wind Forces on Flat and Cambered Plates" for the needed information. The quality editorial guidance provided by Renee Gill and Cheryl Coppin (EG\&G Idaho, Inc.) is sincerely appreciated. 


\section{CONTENTS}

ABSTRACT $\ldots \ldots \ldots \ldots \ldots \ldots \ldots \ldots \ldots \ldots \ldots \ldots \ldots$ ii

ACKNOWLEDGMENTS $\ldots \ldots \ldots \ldots \ldots \ldots \ldots$ iii

I. INTRODUCTION $\ldots \ldots \ldots \ldots \ldots \ldots \ldots \ldots \ldots$

1. DISCUSSION $\ldots \ldots \ldots \ldots \ldots \ldots \ldots \ldots$

2. SUMMARY OF THE PROBLEMS $\ldots \ldots \ldots \ldots \ldots$

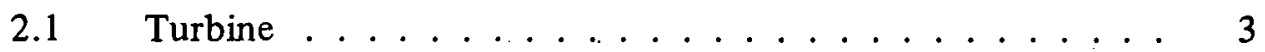

2.2 Drag Disc . . . . . . . . . . . . . 5

2.3 Point Versus Average Measurement for LOFT _ . . . . . 11

II. TURBINE TRANSDUCER IN SINGLE-PHASE FLOW $\ldots \ldots \ldots \ldots$

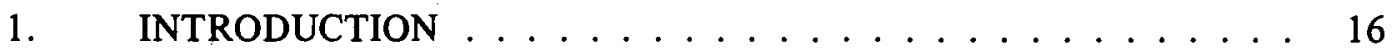

2. AUXILIARY REACTOR AREA TESTS PRE-WESTINGHOUSE CANADA LTD $\ldots \ldots \ldots \ldots$

3. WCL ALL-WATER, FREE FIELD TESTS $\ldots \ldots \ldots \ldots$

4. WYLE CALIBRATION $\ldots \ldots \ldots \ldots \ldots \ldots$

5. ARA TESTS, POST-WYLE $\ldots \ldots \ldots \ldots \ldots$

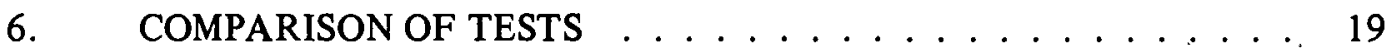

7. TURBINE METER DYNAMIC RESPONSE $\ldots \ldots \ldots \ldots$

III. TURBINE TRANSDUCER IN TWO-PHASE STEAM-WATER $\ldots \ldots \ldots 23$

1. INTRODUCTION . . . . . . . . . . . . . . 23

2. AYA'S THEORY $\ldots \ldots \ldots \ldots \ldots \ldots \ldots \ldots$

$2.1 \quad$ Introduction $\ldots \ldots \ldots \ldots \ldots \ldots$

2.2 Theory . . . . . . . . . . . . . . 24

2.3 Procedure for Application of Aya's Model . . . . . . . 28




4. VOLUMETRIC FLOW THEORY $\ldots \ldots \ldots \ldots \ldots \ldots \ldots$

5. FLOW MAP DATA FOR WCL FULL FLOW TESTS $\ldots \ldots \ldots$

6. COMPARISON OF THE THREE TURBINE MODELS WITH EXPERIMENTS . . . . . . . . . . . . . 36

7. SLIP AND VOID FRACTION SENSITIVITY STUDY $\ldots \ldots \ldots . .44$

IV. DRAG DISC IN SINGLE- AND TWO-PHASE FLOWS $\ldots \ldots \ldots \ldots$



2. ANALYSIS OF THE DRAG DISC $\ldots \ldots \ldots \ldots \ldots$

3. COMPARISON OF THEORY WITH EXPERIMENT $\ldots \ldots \ldots$

4. DYNAMIC RESPONSE OF THE DRAG DISC $\ldots \ldots \ldots$

5. WEIGHT CALIBRATION $\ldots \ldots \ldots \ldots \ldots . \ldots \ldots$

V. APPLICATION OF TURBINE AND DRAG DISC

DATA TO TWO-PHASE FLOW . . . . . . . . . . . . . . . . 64

VI. RESULTS, CONCLUSIONS, AND RECOMMENDATIONS . . . . . . . . 67

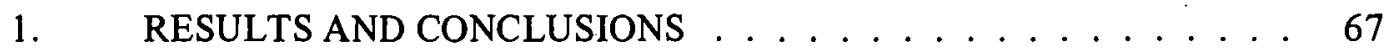

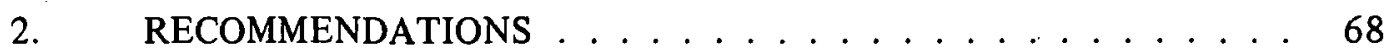

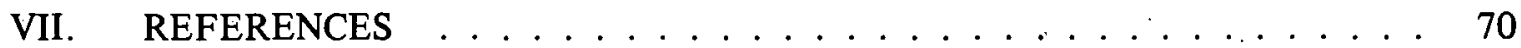

APPENDIX A - REDUCED DATA

FOR WCL FULL FLOW TESTS . . . . . . . . . . . . . . . . . . 73

APPENDIX B - LEGRAND/SILVERMAN THEORY FOR A TURBINE

IN STEADY DISPERSED, TWO-PHASE FLOW $\ldots \ldots \ldots \ldots$

APPENDIX C - ARA TESTS, PRE-WCL $\ldots \ldots \ldots \ldots \ldots \ldots \ldots$

APPENDIX D - EQUIVALENCY BETWEEN WYLE AND WCL

TURBINE VOLTS . . . . . . . . . . . . . . . . 93

APPENDIX E - WCL ALL-WATER FREE FIELD TESTS $\ldots \ldots \ldots \ldots \ldots$ 
APPENDIX F - ARA TESTS, POST-WCL, AND

COMPARISONS WITH WYLE $\ldots \ldots \ldots \ldots \ldots \ldots$

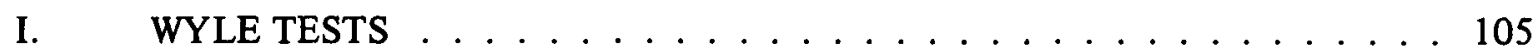

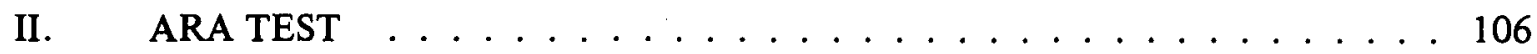

III. MODIFICATION OF ARA AND WYLE VELOCITIES . . . . . . . . . 107

IV. COMPARISON OF WYLE AND ARA DATA $\ldots \ldots \ldots \ldots$

APPENDIX G - FLOW MAP FOR WCL FULL FLOW TESTS $\ldots \ldots \ldots$

APPENDIX H - WEIGHT CALIBRATION OF DTT DRAG DISC $\ldots \ldots \ldots 131$

\section{FIGURES}

1. Drag disc turbine transducer (plenum



2. The effect of pipe size and fluid phase on turbine output $\ldots \ldots \ldots \ldots \ldots \ldots$

3. Typical turbine meter calibration illustrating the scatter in the data $\ldots \ldots \ldots \ldots \ldots \ldots$

4. WCL free field turbine calibration after applying

Rouhani's theory, liquid velocity versus turbine volts, forward flow with all-water calibration $\ldots \ldots \ldots \ldots$

5. The effect of pipe size and liquid phase on drag disc output $\ldots \ldots \ldots \ldots \ldots \ldots \ldots$

6. Typical drag disc two-phase flow calibration illustrating the scatter in the data $\ldots \ldots \ldots \ldots \ldots$

7. $\dot{\mathrm{M}}_{\text {predicted }} \div \dot{\mathrm{M}}_{\text {experimental }}$ versus flow area of test $\ldots \ldots \ldots 12$

8. Mass calculation method comparison $\ldots \ldots \ldots \ldots \ldots$

9. Turbine calibration based on average velocity 1

for all-water tests $\ldots \ldots \ldots \ldots \ldots \ldots \ldots$

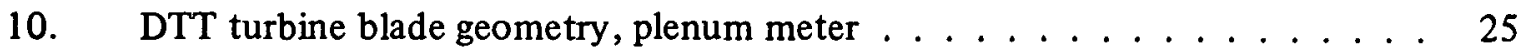


11. Velocity vectors for Aya's model _................ 26

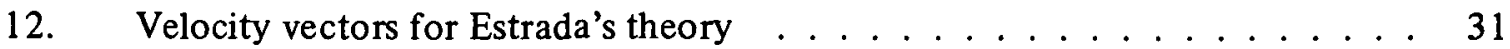

13. Flow regime map of Govier and Aziz for

WCL forward, full flow data . . . . . . . . . . . . . . . . 35

14. WCL free field turbine calibration after analyzing

Rouhani's theory ... . . . . . . . . . . . . 43

15. WCL free field, Rouhani model verses WCL data . . . . . . . . . 43

16. Schematic of the drag disc .................... 51

17. Schematic of forces on the drag disc ............. 52

18. Drag coefficient of a circular cylinder in a flow

normal to the axis as a function of Reynolds

number (Reference 26, Chapter III, Figure 29) . . . . . . . . . . . . . . . . 54

19. Drag coefficient of circular and square plates

(in normal flow) as a function of Reynolds number

(Reference 26, Chapter III, Figure 29)

20. Drag disc calibrations based on average velocity

for WCL tests, single- and two-phase flows

21. WCL free field, forward, two-phase flow,

summation of moments versus drag disc volts . . . . . . . . . . . . 58

22. WCL full flow, forward, two-phase flow,

momentum flux vcrsus drag disc volts . . . . . . . . . . . . . 59

23. WCL full flow, forward, two-phase flow,

summation of moments versus drag disc volts ... . . . . . . . 60

B-1. Velocity vectors for turbine blade and liquid ............ 81

B-2. Force vectors for turbine blade and liquid . . . . . . . . . . . . . 82

F-1. Average velocity versus turbine volts, ARA

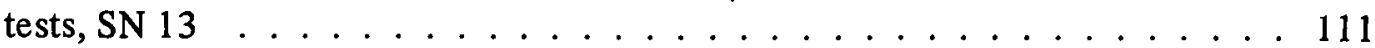

F-2. Average velocity versus turbine volts, ARA

tests, SN 14 
F-3. Average velocity versus turbine volts, ARA

tests, SN 15

F-4. Average velocity versus turbine volts, ARA tests, SN 16

F-5. Average velocity versus turbine volts, ARA tests, SN 18

F-6. Average velocity versus turbine volts, ARA tests, SN 55

F-7. Average velocity versus turbine volts, ARA tests, SN 50

F-8. Average velocity versus turbine volts, ARA tests, SN 57

F-9. Average velocity versus turbine volts, ARA tests, SN 58

F-10. Average velocity versus turbine volts, ARA tests, SN 59

F-11. Momentum flux using average velocity versus drag disc volts, ARA tests, SN 13, forward

F-12. Momentum flux using average velocity versus

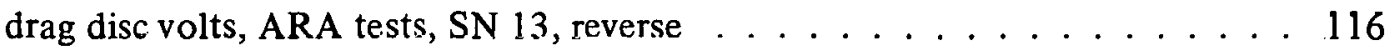

F-13. Momentum flux using average velocity versus dray disc volts, ARA tests, SN 14, forward

F-14. Momentum flux using average velocity versus drag disc volts, ARA tests, SN 14, reverse

F-15. Momontum flux using average velocity versus drag disc volts, ARA tests, SN 15, forward and reverse . . . . . . . 118

F-16. Momentum flux using average velocity versus drag disc volts, ARA tests, SN 16, forward

F-17. Momentum flux using average velocity versus drag disc volts, ARA tests, SN 16, reverse 
F-18. Momentum flux using average velocity versus drag disc volts, ARA tests, SN 18, forward and reverse . . . . . . . . . . . 119

F-19. Momentum flux using average velocity versus drag disc volts, ARA tests, SN 55, forward and reverse f . . . . . . . . 120

F-20. Momentum flux using average velocity versus drag disc volts, ARA tests, SN 56, forward . . . . . . . . . . . . . 120

F-21. Momentum flux using average velocity versus drag disc volts, ARA tests, SN 56 , reverse . . . . . . . . . . . . . . 121

F-22. Momentum flux using average velocity versus drag disc volts, ARA tests, SN 57, forward . . . . . . . . . 121

F-23. Momentum flux using average velocity versus drag disc volts, ARA tests, SN 57, reverse . . . . . . . . . . . . . 122

F-24. Momentum flux using average velocity versus drag disc volts, ARA tests, SN 58, forward

F-25. Momentum flux using average velocity versus drag disc volts, ARA tests, SN 58, reverse . . . . . . . . . . . . 123

F-26. Momentum flux using average velocity versus drag disc volts, ARA tests, SN 59, forward

F-27. Momentum flux using average velocity versus drag disc volts, ARA tests, SN 59, reverse

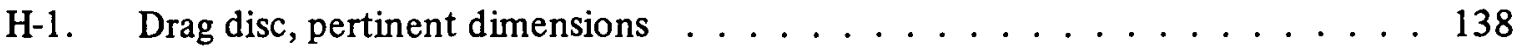

H-2. Drag disc volts versus momentum flux, from Wyle data and ARA weight calibration, SN 58

H-3. Drag disc volts versus momentum flux, from Wyle data and ARA weight calibration, SN 59

H-4. Drag disc volts versus momentum flux, from Wyle data and ARA weight calibration, SN 56

H-5. Drag disc volts versus momentum flux, from Wyle data and ARA weight calibration, SN 14

H-6. Drag disc volts versus momentum flux, from Wyle data and ARA weight calibration, SN 15 
H-7. Drag disc volts versus momentum flux, from

Wyle data and ARA weight calibration, SN 16, reverse . . . . . . . . . . . 142

H-8. Drag disc volts versus momentum flux, from

Wyle data and ARA weight calibration, SN 16, forward . . . . . . . . . . . 142

H-9. Drag disc volts versus momentum flux, from

Wyle data and ARA weight calibration, SN $18 \ldots \ldots . \ldots 143$

H-10. Drag disc volts versus momentum flux, from

Wyle data and ARA weight calibration, SN $19 \ldots \ldots$. . . . . . . . 143

\section{TABLES}

I. Ranges of the Test Variables . . . . . . . . . . . . . 36

II. Summary of Results for the Three Turbine Models,

WCL Free Field Tests . . . . . . . . . . . . . . . . 37

III. Summary of Results for the Three Turbine Models, WCL Full Flow tests . . 40

IV. Condensed Summary of Results for the Threc Turbine

Models, tree Field and Full Flow Tests . . . . . . . . . . . . . . . . . . 12

V. Rouhani Model with Slip Varied, LOFT Test I.1-2

Instrumentation Location BL-1, 8 sec After Bluwduwn . . . . . . . . . . . 46

VI. Rouhani Model with Void Fraction Varied, LOFT Test L1-2,

Instrumentation Location BL-1, 8 sec After Blowdown . . . . . . . . . 47

VII. Rouhani Model with Slip Varied, LOFT Test L1-2,

Instrumentation Location BL-1, $20 \sec$ After Blowdown . . . . . . . . . 48

VIII. Rouhani Model with Void Fraction Varied, LOFT Test L1-2, Instrumentation Location BL-1, 20 sec After Blowdown . . . . . . . . . . 49

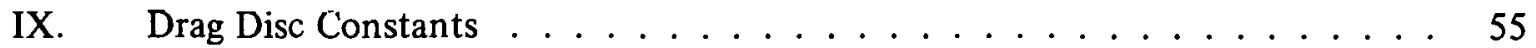

X. Mass Moments of Inertia and Stiffnesses for the DTT Disc _ . . . . . . 62

XI. Frequencies and Rise Times for the DTT Disc (Calculated) . . . . . . . 63

A-I. Reduced Data for WCL Full Flow Tests, Forward $\ldots \ldots \ldots$ 
A-II. Reduced Data for WCL Full Flow Tests, Reverse . . . . . . . . . . . . . . 77

C-I. ARA Tests, Pre-WCL, Full Flow, All-Water . . . . . . . . . . . . 90

D-I. Equivalent Turbine Volts Between ARA Tests

(Pre-WCL), WCL Tests, and Wyle Tests . . . . . . . . . . . . 96

E-I. WCL Free Field, All-Water (Pump Simulator Tests)

Forward (Drag Disc Upstream) and Reverse . . . . . . . . . . . . . . . . . 100

F-I. Comparison of ARA and Wyle Turbine Data . . . . . . . . . . 109

F-II. Comparison of ARA and Wyle Drag Disc Data _. . . . . . . . . . 110

G-I. WCL Full Flow Tests, Calculations for Flow Regime Map . . . . . . . . . . . 128

H-I. Forward Flow $(\mathrm{S} / \mathrm{N} 58) \ldots \ldots \ldots \ldots \ldots$

H-II. Reverse Flow $(\mathrm{S} / \mathrm{N} 58) \ldots \ldots \ldots \ldots \ldots \ldots$ 


\section{PRINCIPLES OF OPERATION AND DATA REDUCTION TECHNIQUES FOR THE LOFT DRAG DISC TURBINE TRANSDUCER}

\section{INTRODUCTION}

\section{DISCUSSION}

One of the basic quantities of interest during a loss-of-coolant experiment (LOCE) is the transient two-phase (steam-water) mass flow rate. Presently, there are no transducers commercially available which directly measure this parameter. Therefore, a transducer was designed at the Idaho National Engineering Laboratory (INEL) by EG\&G Idaho, Inc., which combines a drag disc and turbine into a single unit (see Figure 1). The combined meter is denoted as a drag disc turbine transducer (DTT). The basis for the design was that the drag disc would measure momentum flux $\left(\rho \mathrm{V}^{2}\right)$, the turbine would measure velocity, and the mass flow rate could then be calculated from the two quantities by knowing or assuming a flow profile. A development program was required before a meter was obtained which operated satisfactorily in the loss-of-fluid test (LOFT) environment. Early problems included turbine bearings and drag disc friction. Presently, the meter operates satisfactorily, but not perfectly.

For two-phase flow, the drag disc and turbine outputs are approximately proportional to momentum flux and velocity, respectively, but rather large errors can be expected under these assumptions. Evaluation of the experimental two- and single-phase calibration data has resulted in uncertainty estimates ${ }^{[a]}$ of $\pm 8 \%$ range for the turbine and $\pm 20 \%$ range for the drag disc ${ }^{[1]}$. In an effort to reduce the errors, further investigations were made to determine what the drag disc and turbine really measure.

The objectives of this report are as follows:

(1) Summarize the state-of-the-art for drag discs and turbines in single- and two-phase flow

(2) Summarize the experimental data available for the LOFT DTT

(3) Summarize the analytical investigations which were employed to correlate the experimental data.

It was hoped that the present investigations would result in a better evaluation of the DTT uncertainty. However, this cannot be accomplished until a detailed investigation has

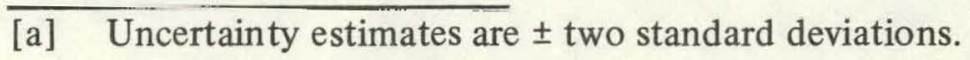




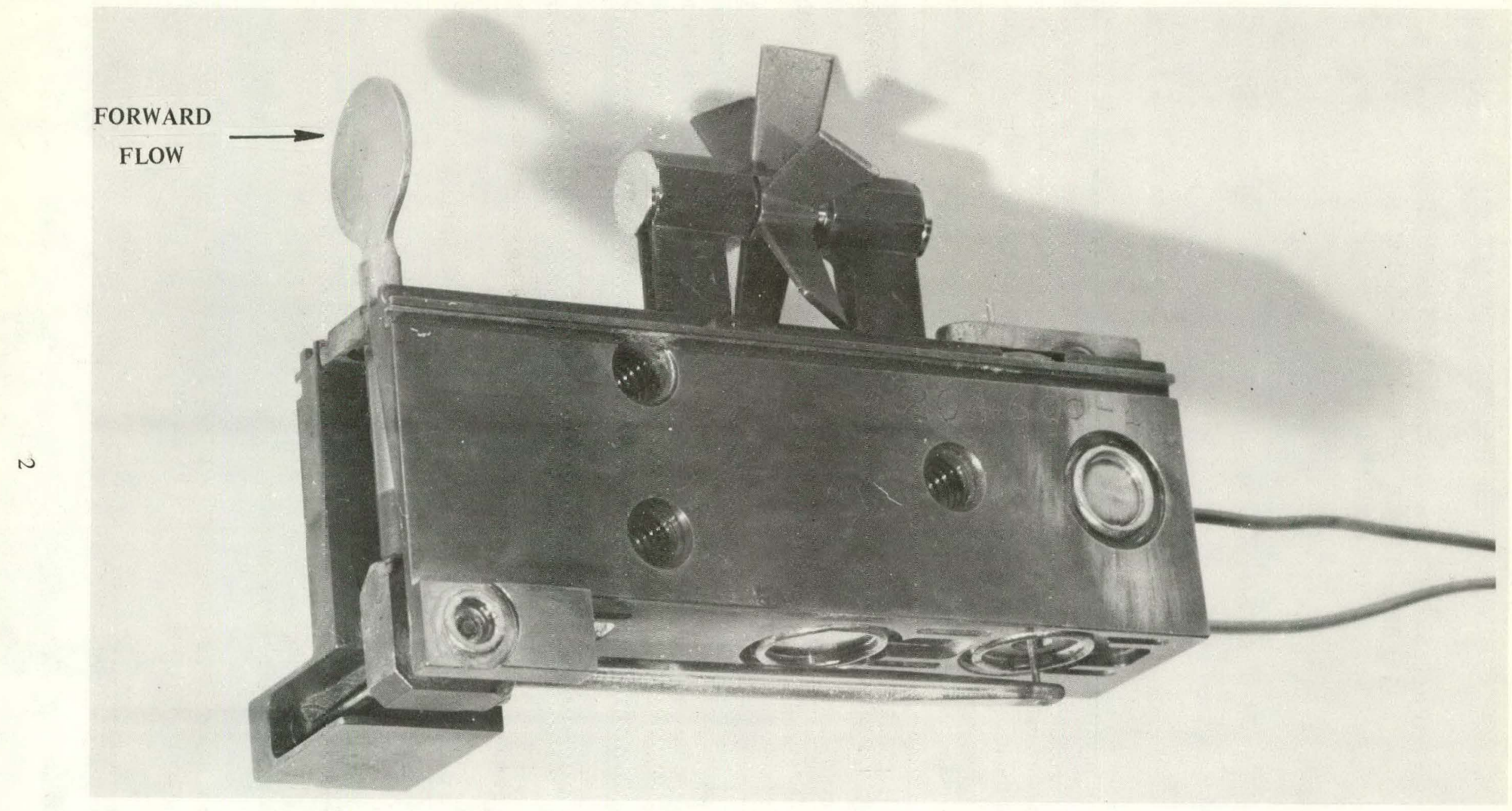

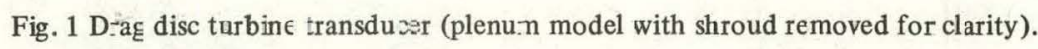


been conducted of the various techniques of predicting mass flow rate. Such an investigation for LOFT experiments L1-1, L1-2, L1-3, and L1-3A will be the subject of a future report.

The present investigation indicates that for the Westinghouse Canada Ltd. (WCL) steam-water tests in both the full flow ${ }^{[a]}$ and free field configurations, available turbine models yield reasonably good results. However, the question of the validity of these models for horizontal, transient flow conditions in the significantly larger LOFT-size pipe, remains to be answered. For LOFT, even if the models were perfect, the predicted mass flow could be in considerable error because more than three beams are required to understand the flow behavior over the pipe cross sections, particularly at the DTT location. If, for example, stratified flow is predominant with the turbine in steam, then an accurate value of slip must be known in order to obtain an accurate estimate of mass flow rate. This question of obtaining average flow quantities from point measurements is addressed briefly in Section I-2.3.

A summary of the contents of this report follows. In Section II, the available experimental data for the LOFT turbine in single-phase, all-water flow are summarized. The turbine dynamic response in all steam and in all water is also considered. The three available turbine meter models for two-phase flow are reviewed in Section III. The results predicted by the models are compared with the available two-phase flow data. A flow map for the WCL full flow tests is presented. A new theory is presented in Appendix B, because of deficiencies in the various two-phase flow theories for the turbine. The drag disc in singleand two-phase flow is reviewed in Section IV. Theoretical predictions are compared with the available experimental data. In addition, the dynamic response and the weight calibration of the drag disc are considered. In Section V, methods are presented for applying the drag disc and turbine data to two-phase flow. Conclusions and recommendations are given in Section VI.

\section{SUMMARY OF THE PROBLEMS}

\subsection{Turbine}

In two-phase flow a large number of variables affect both the turbine and drag disc. A list of variables known to affect the turbine meter follows:

(1) State of knowledge of the measurement principles

(2) Temperature of fluid and DTT

(3) Pressure of fluid

[a] In the full flow configuration all flow passes through the DTT. For the free field, the DTT is in a probe configuration and, therefore, flow can either pass through or go around the meter. 
(4) Irradiation of DTT

(5) Mounting misalignment

(6) Hysteresis

(7) Pipe dynamics

(8) Fluid transients

(9) Electronics

(10) Fluid kinematic viscosily

(11) Flow pattern within meter

(12) Entrance flow pattern, especially swirl (sce Reference 2)

(13) Orientation of the meter, horizontal versus vertical

(14) Angular positions of the pickup

(15) Retarding forces, electromagnetic and bearing

(16) Dynamic response and vibration of the turbine blades and/or drag disc

\section{(17) Cavitation.}

This report primarily deals with itern (1), but (8) is also discussed. Calibration and item (1) together account for an uncertainty of $6 \%$ of range (see-Reference 1, Table 8-1): The effects of the remaining variables have not yet been thoroughly evaluated, but are estimated to cause an uncertainty of approximately $1.5 \%$ of range ${ }^{[a]}$. Thus, the subject of this report has a significant effect upon the uncertainty analysis.

For the turbine in two-phase flow, there are two major problems with understanding the meter output ${ }^{[b]}$ :

[a] It is felt that cavitation may prove to be a significant problem, even though no reliable quantitative data are presently available.

[b] Mechanical and electrical problems are not considered in this report. 
(1) Due to disruption of the velocity profile by the presence of the transducer, the turbine output for both single- and two-phase flow is dependent upon the geometry and size of the passage in which the meter is located

(2) For two-phase flow, the contribution of factors other than average fluid velocity to the turbine output is not thoroughly understood.

Figure 2, which contains single- and two-phase calibration data for flow in various sizes of pipes, illustrates the passage size problem. The nominal velocity plotted is based upon the mass flow rate and the area corresponding to the pipe ID and does not account for the obstruction due to the DTT and its support. It is seen that the calibrations differ by a factor of 1.7 .

Figure 3 contains WCL free field data for single- and two-phase flow and illustrates the problem of understanding what variables affect the meter output. If the correct parameters were plotted, the scatter would be significantly reduced. Further discussion is provided in Section III-2; particularly note Figure 4 which contains exactly the same raw data shown in Figure 3, but with Rouhani's theory applied ${ }^{[3]}$.

It should be noted that a turbine model which accurately describes two-phase flow will reduce the scatter in the data and accurately predict steam and liquid velocities. Both reduction in scatter and accurate prediction of phase velocities are necessary for a successful model. Since no instruments are available to separately measure the phase velocities, the method used to judge the accuracy of the models is to compare predicted and measured mass flow rates. This comparison is made in Section III-6.

\subsection{Drag Disc}

The drag disc problems are approximately the same as those of the turbine. Thus, the problems of the effects of passage geometry, passage size, and understanding the factors affecting meter response in two-phase flow are evident. Figure 5 contains single- and two-phase calibration data for flow in various size pipes. The slopes for the two-phase calibration differ by a factor of about four. Figure 6 contains WCL free field data for two-phase flow and illustrates the problem of understanding what variables affect the meter outpurt. If the correct parameters were plotted, then the scatter would be significantly reduced. Further discussion is provided in Section IV.

Figure 5 shows the effect of pipe size and liquid phase on the drag disc output. The quantities $\rho_{\mathrm{WCL}}$ and $\mathrm{V}_{\mathrm{WCL}}$ were computed by WCL as follows: 


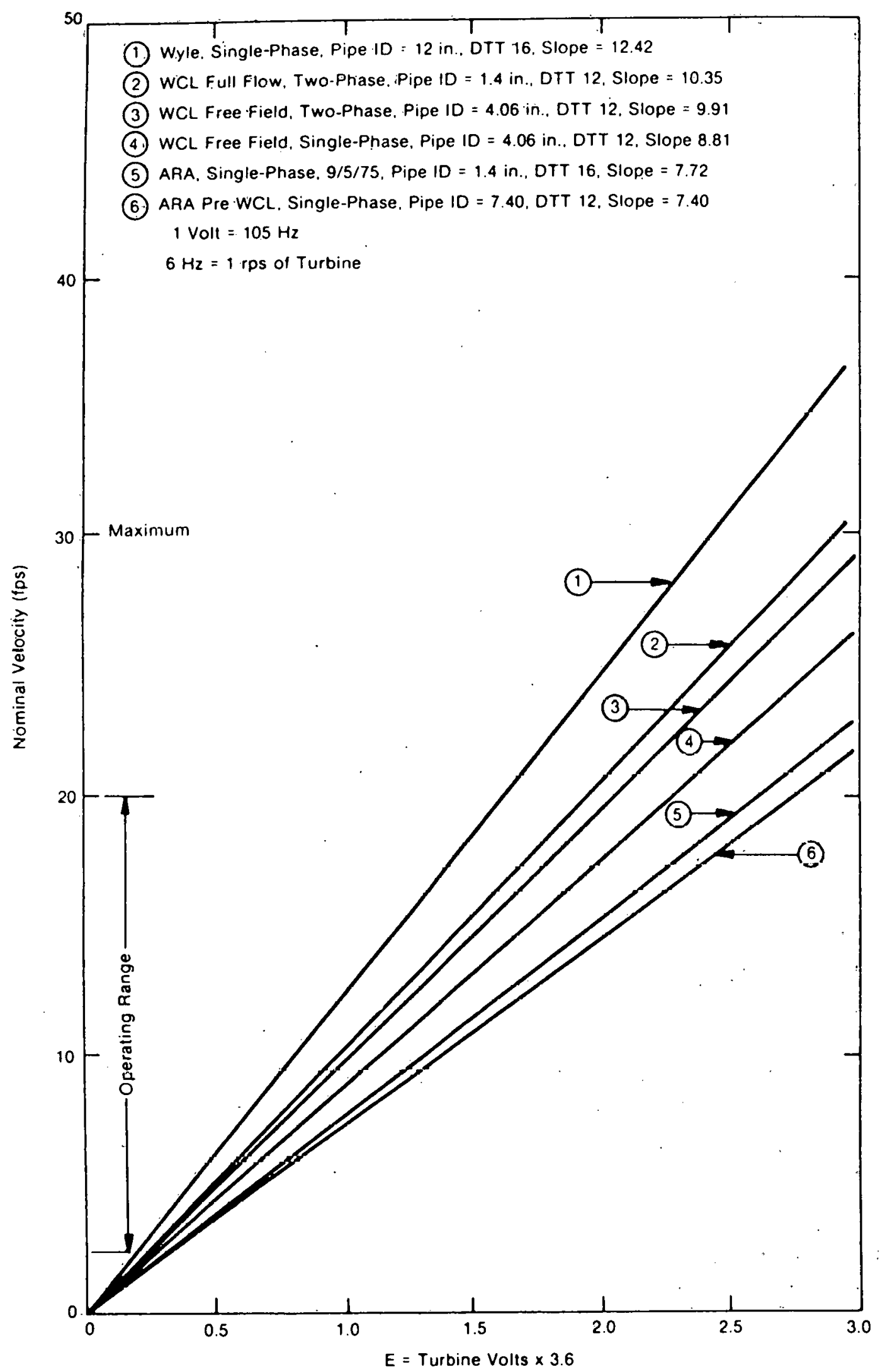

Fig. 2 The effect of pipe size and fluid phase on turbine output. 


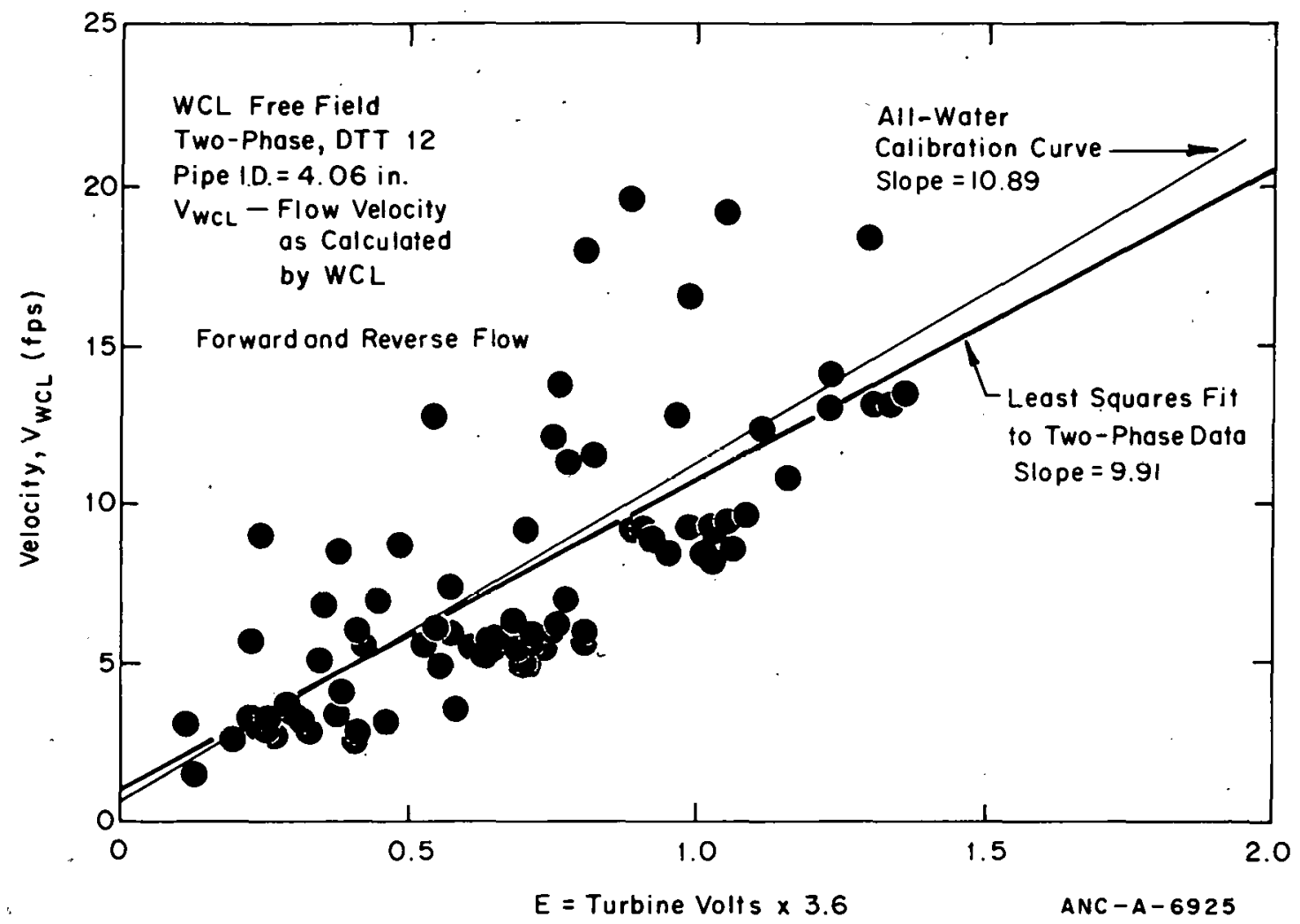

Fig. 3 Typical turbine meter calibration illustrating the scatter in the data.

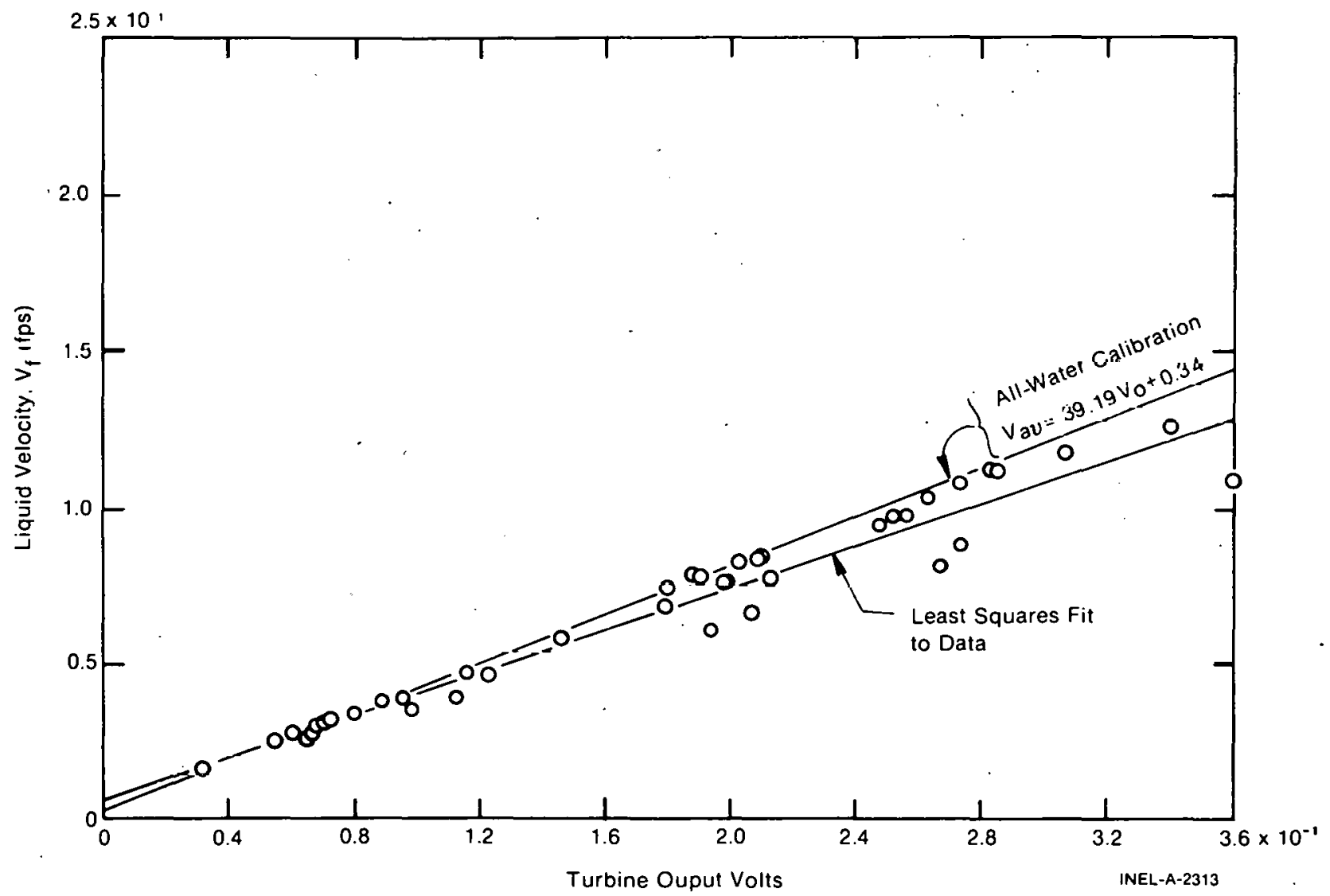

Fig. 4 WCL free field turbine calibration after applying Rouhani's theory, liquid velocity versus turbine volts, forward flow with all-water calibration. 


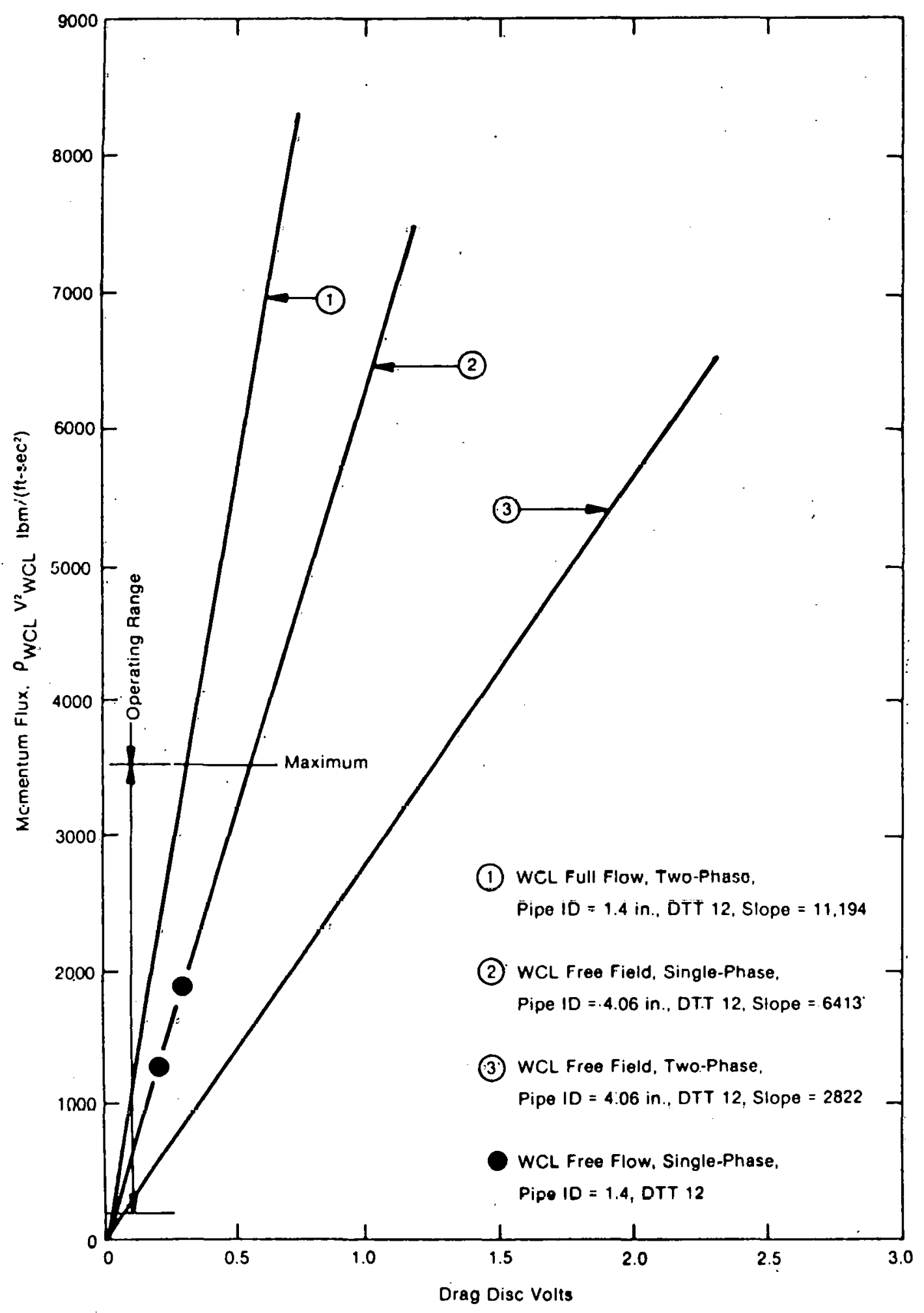

Fig. 5 The effect of pipe size and liquid phase on drag disc output. 


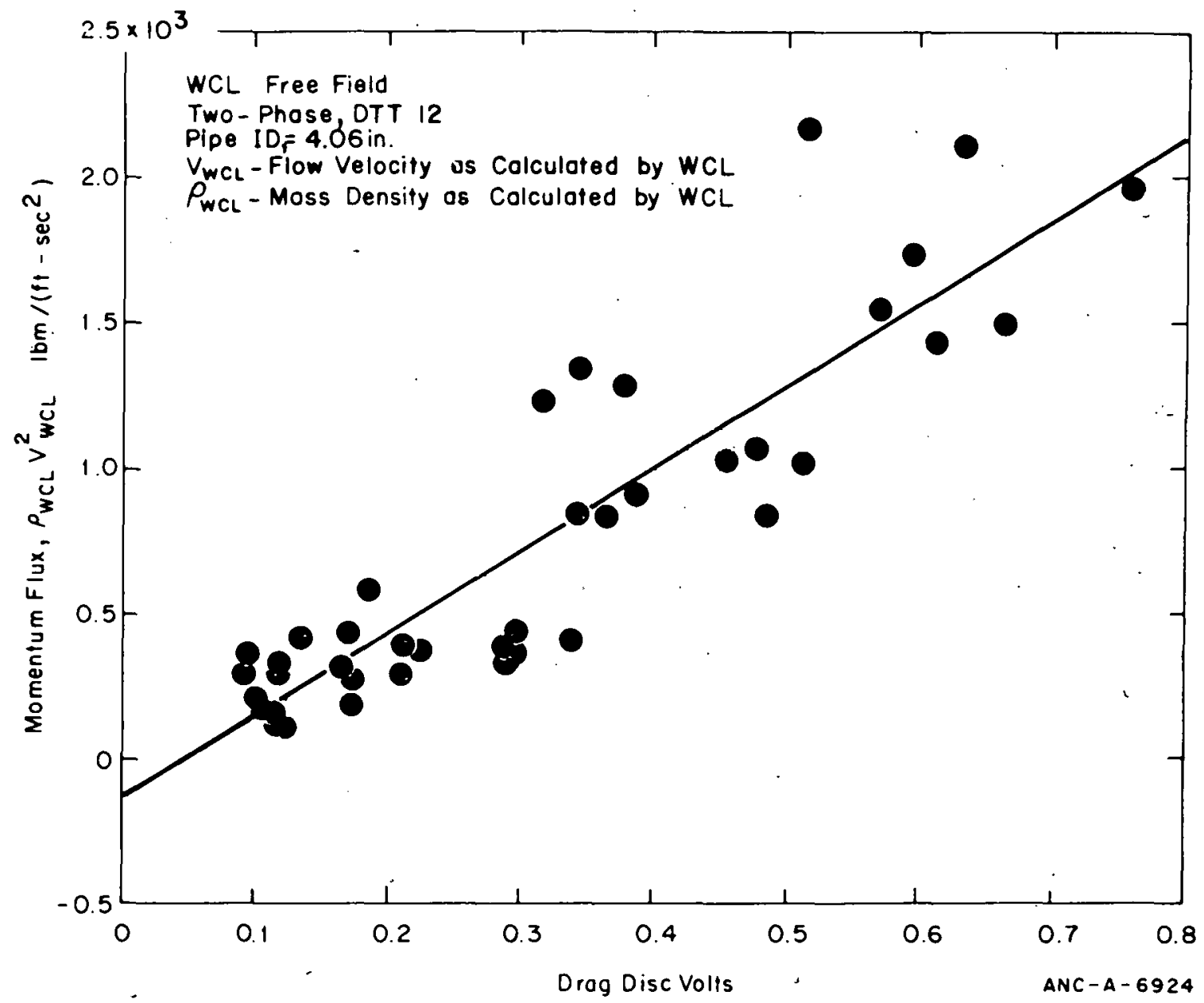

Fig. 6 Typical drag disc two-phase flow calibration illustrating the scatter in the data.

$$
\begin{aligned}
& \dot{m}_{20}=\frac{\dot{m}_{w}+\dot{m}_{s}}{h_{20}}=\frac{\dot{m}_{w} h_{w}+\dot{m}_{s} h_{s}}{\dot{m}_{20}} \\
& h_{20}=\frac{h_{20}-\Delta h}{x_{20}}=\frac{h_{20}-h_{f}}{h_{f g}} \\
& v_{20}=\left(1-x_{20}\right) v_{f}+x_{20} v_{\dot{g}}
\end{aligned}
$$

where

$$
\begin{array}{ll}
\rho_{\mathrm{WCL}}= & 1 / \mathrm{v}_{20} \\
\mathrm{~h}_{\mathrm{w}}= & \begin{array}{l}
\text { enthalpy of water from measured temperature } \\
\text { assumes saturation }(\mathrm{Btu} / \mathrm{lb})
\end{array}
\end{array}
$$




$$
\begin{aligned}
& \mathrm{h}_{\mathrm{s}}=\quad \text { enthalpy of steam from measured temperature and } \\
& \text { pressure }(\mathrm{Btu} / \mathrm{lb}) \\
& \mathrm{h}_{20}=\text { calculated two-phase fluid enthalpy (Btu/lb) } \\
& \Delta \mathrm{h}=\text { equivalent enthalpy as derived from heat loss tests } \\
& \text { (Btu/lb) } \\
& \mathrm{h}_{20}^{\prime}=\quad \text { calculated enthalpy at test section }(\mathrm{Btu} / \mathrm{lb}) \\
& \mathrm{h}_{\mathrm{f}} \quad=\quad \text { saturated liquid enthalpy at test section based on } \\
& \text { measured test section pressure }(\mathrm{Btu} / \mathrm{lb}) \\
& \mathrm{h}_{\mathrm{fg}}=\text { saturated vapor minus saturated liquid enthalpy at } \\
& \text { test section based on measured test section pressure } \\
& \text { (Btu/lb) } \\
& \mathrm{X}_{20}=\quad \text { fluid quality at test section inlet (decimal) } \\
& v_{f}=\quad \text { saturated liquid specific volume at test section inlet } \\
& \left(\mathrm{lb} / \mathrm{ft}^{3}\right) \\
& \mathrm{v}_{\mathrm{g}}=\quad \text { saturated vapor specific volume at test section inlet } \\
& \left(\mathrm{lb} / \mathrm{ft}^{3}\right) \\
& \mathrm{v}_{20}=\text { fluid specific volume at test section inlet }\left(\mathrm{lb} / \mathrm{ft}^{3}\right) \\
& \rho_{\mathrm{WCL}}=\quad \text { fluid density at test section inlet }\left(\mathrm{lb} / \mathrm{ft}^{3}\right) \text {. }
\end{aligned}
$$

The foregoing illustrates that significant differences in calibration can result if the various effects are not carefully accounted for.

For the purpose of investigating test data, an extremely useful technique for separating questionable ${ }^{[a]}$ turbine and/or drag disc data from good data is to first plot drag disc volts versus turbine volts. For single-phase flow, a smooth, second order curve usually results. Points falling off the curve are suspect. Generally, the questionable data are drag disc data, in which case a plot of $\rho \mathrm{V}^{2}$ versus drag disc volts will also show the bad data points, The data presented in this report incorporate the foregoing methods. Thus, obviously bad drag disc data were eliminated from the data reduction (no turbine data appeared bad).

It should be noted that a plot of drag disc volts versus turbine volts for two-phase flow results in significantly more scatter than the single-phase flow plots. For the case of two-phase flow with $5 \%$ or less steam quality, plots of drag disc versus turbine volts still

[a] The drag disc may be pegged or sticking while the turbine is operating satisfactorily. 
showed a large amount of scatter. This was true for the WCL free field and full flow two-phase flow data. It is concluded that even small amounts of steam drastically affect the drag disc and/or turbine meter outputs. It is felt that this information is useful, but presently it is not known exactly how to make use of it.

A single-phase steam calibration is required for understanding the meter response; this has not yet been conducted. The data reduction procedure reported in Section III indicates that a significant difference may exist between steam and water calibrations. Also, two-phase, free field horizontal flow data are needed, since no horizontal flow data exists for the DTT.

\subsection{Point Versus Average Measurements for LOFT}

This report is concerned mainly with available single- and two-phase flow data. The question remains: how to apply the knowledge obtained from these data to the transient, steam-water conditions in LOFT size pipes?

For steady, all-water flow, there is good argument that the turbine senses average flow velocity, i.e., volumetric flow divided by net flow area at the turbine. Data from the tests conducted at Wyle Laboratory in 12.0-in. ID pipe correlates well using average velocity with the data obtained in 1.5-in. pipe ${ }^{[a]}$. For the Wyle tests, velocity profiles taken with a pitot tube indicated a parabolic distribution over the cross section with average to maximum values on the order of 0.77 . The reasonably good correlation between the two series of tests is interpreted to mean the DTT disrupts the parabolic flow distribution sufficiently, such that the turbine senses average velocity. The drag disc data are not as well correlated by "average velocity" as the turbine data. Section II provides further discussion.

Transient, all-water flow is considered in Reference 4. For fluid accelerated from rest, it takes time to develop a laminar flow profile. For $\frac{\nu \mathrm{t}}{\mathrm{R}^{2}} \geqslant 0.15$ significant deviation from constant velocity occurs. For LOFT piping with water at $540^{\circ} \mathrm{F}$, this corresponds to a time of

$$
t=\frac{0.15 R^{2}}{u}=\frac{0.15}{0.0014} \times\left(\frac{11.2}{12}\right)=100 \mathrm{sec} .
$$

In addition to time, distance is required to develop laminar flow profiles. Liquid entering a pipe from a tank develops full laminar flow profiles downstream of the entrance.

From the foregoing discussion, throughout LOFT, velocity profiles are expected to be "flat" over the pipe for LOFT subcooled LOCEs. For two-phase, steam-water flow in LOFT, significant questions remain to be answered concerning what the drag disc and turbine sense, and how these measurements relate to the flow distribution over the cross section. The available steam-water calibration data are for flow areas of 1.19 in. ${ }^{2}$ (WCL full

[a] Sections II-4 and II-5 provide a discussion of the tests and Appendix F offers a comparison of the data. 
flow) and 10.62 in. $^{2}$ (WCL free ficld) while the LOFT flow area at the DTT location in the blowdown legs is $93.38 \mathrm{in} .^{2}$. Thus, the LOFT piping is a factor of 8.8 larger in flow area than the WCL free field tests.

The three turbine models yield reasonably good results for the WCL tests, but it cannot be concluded that the models remain valid for nearly an order of magnitude increase in flow area as occurs in LOFT. If the accuracies obtained with the WCL data are linearly extrapolated to LOFT, then predicted mass flow from the turbine models will be about 3.5 times higher than the experimental values. This is illustrated in Figure 7. Also shown is the "roll-off," which is conjectured buit cannot be verified, except through tcsts or perhaps more accurate modeling.

There has been a significant amount of analytical investigation of two-phase flow in pipes, with Reference 5 being a particularly good summary. The problem of understanding the flow is cxtrcmely difficult. Usually. the two-phasc system is treated as a continuous medium [b].



Fif. $7 \dot{\mathrm{M}}_{\text {predicted }} \dot{\mathrm{M}} \dot{\mathrm{M}}_{\text {experimential }}$ versus flow aiea of lesil.

This is probably accurate for dispersed type flow regimes, but is not appropriate for the stratificd regime, which appears from LOFT tests conducted to data to be the predominant regime during LOFT LOCE. It is noted that differences can exist between local and average velocities of the two phases. Local slip can be nearly 1.0 while average slip can be quite different. This may occur, for example, with stratified flow. Each phase may have dispersed within it the other phase. Thus, the bottom liquid stratification and the steam dispersed within it may move at about the same velocity, while the top steam stratification and the water dispersed within it may move at another velocity, which is different from the 
velocity of the bottom stratification. Local slip within each phase is about 1.0 , but since the two stratified phases move at different velocities, the average slip is different from 1.0. Further discussion concerning average velocities, a weighted mean velocity, and local relative velocities may be found in Reference 7 .

Presently, the state-of-the-art is such that two problems exist. The first, discussed above, relates to interpreting what point measurements, such as the drag disc and turbine, measure in LOFT size piping. The second relates to understanding the flow behavior over the cross section, even if centerline activity is known exactly. One method of understanding the fluid behavior is to predict the three dimensional behavior of the two-phase fluid from the first principles of fluid mechanics. To date, the governing equations have not been solved. Another method is to employ similitude studies to predict the behavior of the fluid. Flow regime maps, based on the principles of similitude, have been developed. Reference 8 is the most recent map and probably the most accurate. Unfortunately, the maps are only valid for fully developed steady flow in straight pipes, which is not the situation on LOFT where, for example, 45 degree bends are a short distance upstream from the instrument locations in the blowdown legs.

Thus, for tests such as LOFT, involving transient two-phase flow in large pipes containing point instruments, at best only crude estimates can be made of the velocity and density distributions. For. LOFT tests L1-1 through L1-3A, the values reported for velocity, density, and momentum flux are based on the all-water calibration data. To verify that the data obtained were being interpreted correctly for the two-phase blowdown, the data were employed to predict mass flow exiting from the blowdown pipes as a function of time. The simplified methods discussed in Section $\mathrm{V}$ were employed and the results were compared with the experimentally measured value obtained by means of differential pressure gauges in the suppression tanks. The predicted value varied, from about $25 \%$ underprediction to about $50 \%$ overprediction. Typical results may be seen for LOFT test L1-2 in Figure 8.

Efforts are presently underway to improve the agreement. The three-beam gamma densitometer output is being evaluated, with the results being an estimate of the density distribution in the pipe. The velocity distribution is either calculated or estimated. An alternative is to assume or calculate a momentum or momentum flux distribution in the pipe. Once the flow distribution in the pipe is known, then the mass flow can be computed and compared with the experimentally measured mass flow. The results have not been obtained.

Preliminary investigation of LOFT data for Tests L1-1, L1-2, and L1-3 has raised the following additional unanswered questions about what the DTT. senses in transient, two-phase flow:

(1) What does the turbine meter sense in stratified flow when, for example, only half the turbine is immersed in water?

(2) What are the effects on the drag disc and turbine nneter outputs of transient temperatures? The meter offscts may be especially sensitive to temperature. 


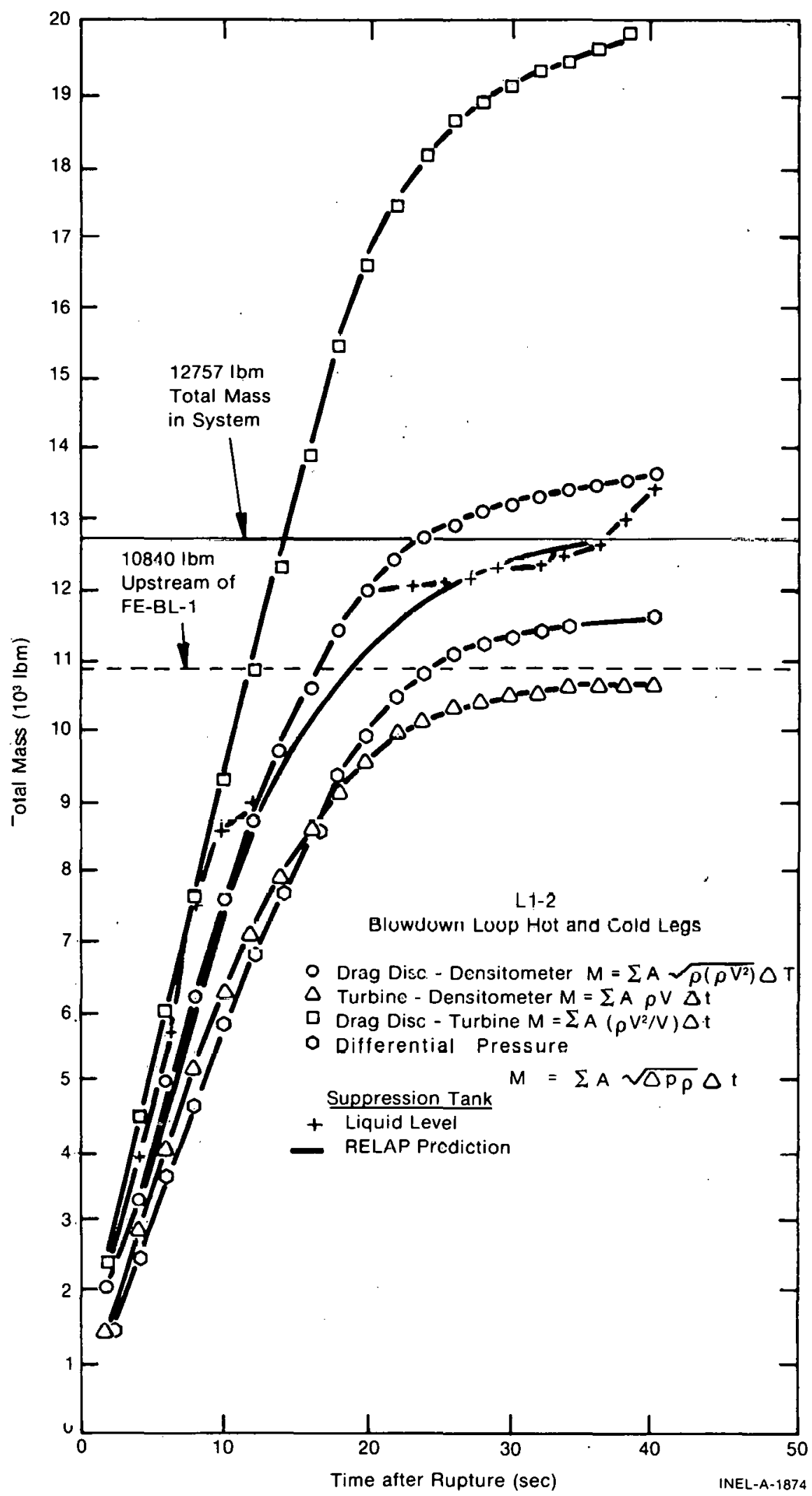

Fig. 8 Mass calculation method comparison. 
(3) What is the flow distribution and how is it affected by the DTT for the LOFT system?

(4) : How is the DTT output for single-phase, all-water flow related to the output for two-phase flow? For the all-water flow data available, it is shown in this report that the turbine senses average liquid velocity as opposed to point velocity. However, for two-phase flow, the fluid can easily flow around the meter since the steam is compressible. Thus, it is not clear what the meter senses in two-phase flow and how it correlates with single-phase flow. 


\section{TURBINE TRANSDUCER IN SINGLE-PHASE FLOW}

\section{INTRODUCTION}

Comprehensive studies of the performance characteristics of flow meters in water have been conducted $[2,9,10]$. These papers and the discussions following the papers should be read by everyone interested in turbine meters. References 11,12 , and 13 also contain information. Meter performance in gas is considered in Reference 14 and also in the discussion following Reference 9. The transient response of turbine meters is discussed in References 15,16, and 17. A list of variables known to affect the turhine meter nutput may be tound in Section 1-2.

In the remainder of this section, the single-phase water test data will be presented, discussed, and compared. The data are compared on the basis of the minimum flow area at the turbine, rather than the nominal flow area of the pipe (Section II-6). In addition, a simplified analysis of the turbine meter response is presented.

\section{AUXILIARY REACTOR AREA} TESTS PRE-WESTINGHOUSE CANADA LTD.

Full flow, all-water tests with DTT serial number (SN) 12 were run at Auxiliary Reactor Area (ARA) prior to the WCL tests. The data are presented in Appendix C.. In order to compare with Wyle data, the ARA turbine volts are converted to equivalent Wyle volts by multinlying by $3.6^{[\mathrm{a}]}$.

A least squares fit to the data yields the following calibration equations ${ }^{[b]}$

$$
v_{a v}=\left\{\begin{array}{l}
-0.116+9.12 \frac{H}{100} \\
-0.116+34.47 V_{0}
\end{array}\right.
$$

[a]. This conversion is based upon the fact that for a given turbine rotational speed, the turbine gain was different for the Wyle and ARA tests. Appendix D provides the details.

[b] For all the calibration equations presented in this report, a straight line was fitted to the data using the least squares criteria. 
where $\mathrm{V}_{\mathrm{av}}$ is the average flow velocity based on a minimum flow area of 1.37 in. ${ }^{2}$ for the piping meter and 1.19 in. $^{2}$ for the plenum meter ${ }^{[a]}$. $\mathrm{H}$ is turbine, $\mathrm{H}_{\mathrm{z}}\left(6 \mathrm{H}_{7}=1 \mathrm{rps}\right.$ of turbine) and $\mathrm{V}_{\mathrm{O}}$ is turbine output volts for ARA tests. The average velocity is thus related to the flow by

$$
V_{a v}=\left\{\begin{array}{l}
0.26960 \text { plenum meters including DTT SN } 55 \text { and SN } 60 \\
0.23460 \text { piping meters }
\end{array}\right.
$$

where $Q$ is the flow in gpm.

\section{WCL ALL-WATER, FREE FIELD TESTS}

Free field, all-water tests were conducted at WCL with DTT $12^{[18]}$. The raw test data are presented in Appendix E for completeness [b]. To compare with Wyle data, the turbine pulses are divided by 105 (Appendix D). The actual flow area at the meter was 10.623 in. ${ }^{2}$, while the nominal flow area for the 4.0625-in. ID pipe was 12.965 . Thus, to convert the nominal velocity calculated by WCL $\left(\mathrm{V}_{\mathrm{WCL}}\right)$ to average velocity $\left(\mathrm{V}_{\mathrm{aV}}\right)$, multiply the WCL velocity by $\frac{12.965}{10.623}=1.22$

$$
V_{a v}=1.22 V_{W C L} \text {. }
$$

A least squares fit to the data yields the following calibration equations

$$
v_{a v}=\left\{\begin{array}{l}
0.64+10.24\left(\frac{H}{100}\right) \\
0.34+39.19 V_{0}
\end{array} .\right.
$$

where $\mathrm{H}$ is turbine hertz and $\mathrm{V}_{\mathrm{O}}$ is turbine output volts for the WCL all-water tests.

[a] In LOFT, two different turbines (one high speed and the other low speed) and two different drag discs (one low range and the other high range) were used. The plenum meter employed a low speed turbine and low range drag disc, while the piping meter employed a high speed turbine and high range drag disc. The minimum flow area occurred at the shroud for the piping meter and at the drag disc for the plenum meter. It was difficult to decide upon a single correct flow area to use, since the area varied along the length of the meter. It was thus decided to use the minimum flow area at any section within the meter.

[b] The raw data were not reported in Reference 18 . 


\section{WYLLECALIBRATION}

The Wyle calibration tests are described in Reference 19, and the reduced data are reported in Reference 20 . The tests employed room temperature water and horizontal flow in a 12-in. ID pipe. The data were further reduced and corrected in Reference 1, Table 5.5. The equations, reported in. Reference 20 , are based upon the flow velocity in the 12 -in. ID pipe at the radial location where the meter was installed (center of the pipe). The velocity was measured with a pitot tube and was found to have a parabolic distribution across the pipe $^{[a]}$. The maximum velocity at the pipe center was initially used to compute the flow velocity. The minimum flow area in the 12 -in. ID pipe, accounting for the blockage caused by the DTT and its support, was about 106.5 in. ${ }^{2[b]}$. The average velocity at the meter is given by

$$
v_{a v}=\frac{3.01}{10^{3}} Q, f p s
$$

where $Q$ is the flow in gpm. A study of the velocity data indicates that the ratio of $V_{a v}$, the average velocity, to the Wyle velocity is reasonably constant over the velocity range and has the value ${ }^{[c]}$

$$
\frac{-V_{a v}}{V_{\text {Wyle }}}=\left\{\begin{array}{l}
0.812, \text { plenum meters including DTT SN } 55 \text { and SN } 60 \\
0.122, \text { piping meters. }
\end{array}\right.
$$

The average velocity is less than the listed velocity because of the nearly parabolic velocity distribution in the pipe with $\mathrm{V}_{W y l e}$ being the maximum value: Equation (6) was employed to convert the data of Reference 20 to an average velócity, rather than recalculating the average velocities from Equation (5).

[a] The Wyle velocity profiles were abnormal in that as the flow rate increased, the profile changed from: relatively flat to more parabolic. All flows had Reynolds numbers in the $10^{5}$ to $10^{6}$ region so that the flow should have been turbulent with a relatively flat velocity profile. The water storage tank was pressurized with air so as to maintain a constant head. It is presently felt that air entrained in the water caused the observed abnormality.

[b] This area is valid for both plenum and piping meters.

[c] At the high and low ends of the velocity calibration, the values listed may differ by $\pm 15 \%$. 


\section{ARA TESTS, POST-WYLE}

City water containing chlorine was used in the Wyle tests with the results being corrosion $^{[\mathrm{a}]}$ of all the meters tested. New turbines were installed in DTT SNs 13, 54, and 57. New variable reluctance transducers (VRT) and cores were installed in DTT SNs 54, 57, and 60. A new drag disc was installed in DTT SN 60. The other meters were flushed of chlorides by operating in the ARA flow loop until they operated satisfactorily. To verify that the turbines were not affected by the corrosion and that the Wyle results were still valid, further tests were conducted at ARA. The tests were for a full flow condition with water in the range of 130 to $200^{\circ} \mathrm{F}$. The minimum flow area for the piping meter has a value of 1.37 in. ${ }^{2}$ and the plenum meter, a value of 1.19 in. ${ }^{2}$. The average velocity through the meter is given by

$$
V_{a v}=\left\{\begin{array}{l}
0.2696 Q \text { plenum meters including DTT SN } 55 \text { and SN } 60 \\
0.2346 \text { Q piping meters }
\end{array}\right.
$$

where $Q$ is the flow in gpm. Plots of the data are presented in Appendix F.

\section{COMPARISON OF TESTS}

In Figures 2 and 5, data from the various test series are plotted using nominal flow velocities. That is, the velocities employed are based on the ID of the pipe and do not account for the obstructions due to the meter and the meter support. These obstructions significantly reduce the flow area and thus, change the meter calibration. Other factors may also cause the differences in calibration which appear in Figures 2 and 5. For example, the free field configuration allows water to bypass the meter. The amount of water passing through the meter depends on the relative resistance of flow through the meter as compared to the flow around the meter. The present state of the technology is such that the percent of the total flow going through the meter cannot be computed. In an effort to understand the different calibration curves resulting from the different test series (Figure 2), the average velocity based upon the minimum flow area at the turbine was plotted versus turbine volts. The results for selected turbine meters may be seen in Figure 9, while the remainder of the data may be found in Appendix F. From an investigation of these data, it is evident that primarily, the turbine measures the average flow velocity. Under this assumption free field and full flow calibrations agree very closely. Even though other effects such as flow bypass are most likely present, average flow velocity seems to correlate the data very well.

[a] The chlorine reacted with the stainless steel components of the D'l"I'. 


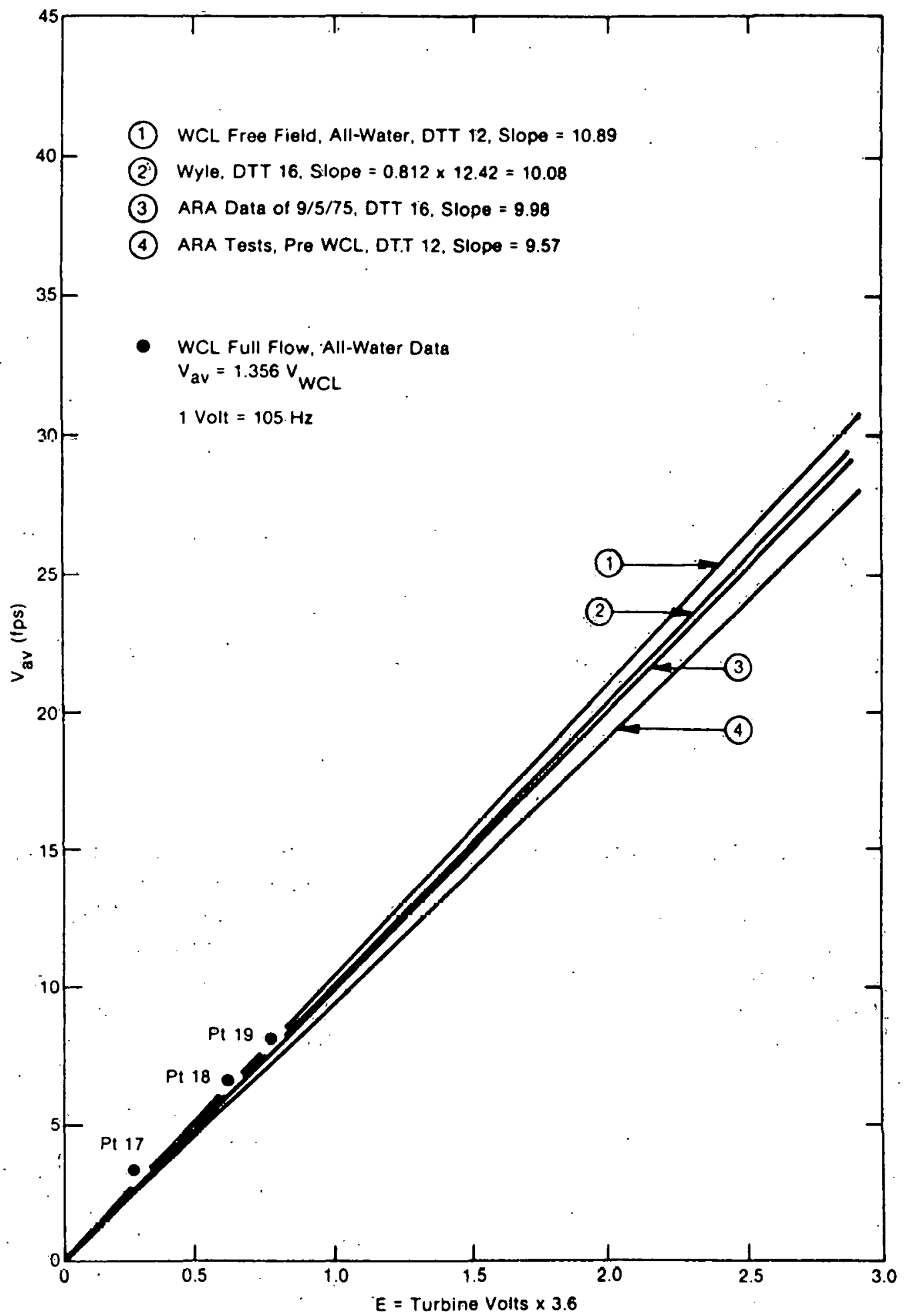

Fig. 9 Turbine calibration based on average velocity for all-water tests. 


\section{TURBINE METER DYNAMIC RESPONSE}

The response of a turbine meter is discussed in References 15, 16, and 17. An attempt was made to apply the theory of Reference 17 for a step change in fluid velocity to obtain the 10 to $90 \%$ rise time of the turbine. Unfortunately, numerical results could not be obtained. Therefore, the 10 to $90 \%$ rise time was estimated from the 0 to $63 \%$ rise time. From Reference 17, the governing equation used to calculate the 0 to $63 \%$ rise time is given by Equation (8). It is valid for water and steam, and for a given step change in velocity.

$$
t_{0-63}=\frac{1}{A \cos \alpha}
$$

where

$$
\begin{aligned}
& \mathrm{A}=\frac{\pi \eta \mathrm{U}_{2} \mathrm{NRC}^{2}\left(\mathrm{r}_{2} \mathrm{r}_{1}\right)}{\mathrm{I}(1+2 \eta / \mathrm{AR})} \\
& \alpha=\text { blade angle with pipe axis } 2.5 \text { to } 11.63 \text { degrees, use } 11.63 \\
& \text { degrees; piping } 7.5 \text { to } 31.7 \text { degrees, use } 31.7 \text { degrees, } \\
& \text { plenum } \\
& \eta \quad=\quad \text { blade airfoil efficiency } \simeq 0.9 \\
& \mathrm{~N}=\text { number of turbine blades }=6 \\
& \mathrm{C}=\text { chord of blade element }=0.25 \mathrm{in} \text {. } \\
& \mathrm{R}=\text { mean blade radius }=0.357 \mathrm{in} \text {. } \\
& \mathrm{r}_{1} \equiv \text { inside radius of hlade }=0.125 \mathrm{in} . \\
& \mathrm{r}_{2}=\text { outside radius of blade }=0.590 \mathrm{in} \text {. } \\
& \text { I }=\text { mass moment of inertia of turbine }=30.86 \times 10^{-7} \\
& \text { (lbf-sec }{ }^{2} \text {-in.) for plenum and piping meters } \\
& A R=\text { blade aspect ratio }=\frac{\left(r_{2}-r_{1}\right)^{2}}{\text { blade area }} \\
& \mathrm{U}_{2}=\text { magnitude of step change in fluid velocity. }
\end{aligned}
$$

For a purely exponential transient, the 10 to $90 \%$ and 0 to $63 \%$ rise times are related as

$$
t_{10-90}=2.2 t_{0-63}
$$


Substituting numerical values for the plenum meter yields typical results for LOFT conditions:

$$
t_{10-90}=\frac{2.2}{A \cos \alpha}=\left\{\begin{array}{l}
0.29 \mathrm{sec}, \text { water moving at } 20 \mathrm{in.} / \mathrm{sec}^{[a]} \\
11.9 \mathrm{sec}, \text { steam with } \rho=\frac{1}{6.6} \frac{1 \mathrm{bm}}{\mathrm{ft}^{3}} \\
\text { moving at } 20 \mathrm{in.} / \mathrm{sec}
\end{array} .\right.
$$

[a] The velocity of $20 \mathrm{in} . / \mathrm{sec}$ was chosen as an approximate minimum flow velocity. 


\section{TURBINE TRANSDUCER IN TWO-PHASE STEAM-WATER}

\section{INTRODUCTION}

Very little is known about what the turbine measures in two-phase flow. Simplified theories for the behavior in steady, two-phase flow are presented in References $3,21,22^{\text {[a] }}$, and 23. The concept of steam driving the turbine and liquid resisting, is utilized in Reference 21. (Aya's model). The forces are assumed to be due entirely to drag. Newton's law is employed in References 3 and 22, while the model of Reference 23 is based on the assumption that the turbine always measures volumetric flow.

Investigation of the various theories for the behavior of the turbine in two-phase flow indicates each has its shortcomings. Aya's theory [21] appears to be based upon intuition, and has merit in that the predicted results agree reasonably well with the experiment. However, it appears that both lift and drag forces should be considered and not just drag. Rouhani's theory [b] is based upon the change in momentum of the two-phase mixture as it passes through the turbine. One assumption in the analysis causes the total kinetic energy of the mixture to increase as it passes through the turbine. This occurs only if pressure energy is converted to velocity energy. The volumetric flow model suggested in Reference 23 appears to be an overly simplistic view of the turbine.

Based upon Aya's ideas, a new theory was derived by B. Legrand of CEA (France) and the author. The theory is presented in Appendix B. Unfortunately, the model is difficult to apply, and therefore, has not been applied to the two-phase flow data available. It is included for future reference.

Discussions with C. F. Carmichael of the Thermal Hydraulics Branch, EG\&G Idaho, Inc., indicate that Aya's model is not the approach normally employed by aerodynamicists. He advocated application of aerodynamics theory to the turbine much the same as presented in Reference 10, except that two-phase flow be considered. It is apparent to the author that further improvements in modeling should be based upon the more fundamental approach of aerodynamics, even though a significant amount of effort may be required.

Experimental data are available on the behavior of meters in two-phase flow. All the steady state two-phase flow experiments on the LOFT DTTs were conducted at WCL. At WCL, both full flow and free field data were taken with the DTTs being oriented vertically. The tests are discussed in Reference 24. The only test data available for horizontal flow were obtained at WCL by the Semiscale Project of EG\&G Idaho, Inc. ${ }^{[25]}$. A flow

[a] H. Estrada of MPR Associates independently derived the same results as that of Reference 21.

[b] In this report, the model derived in References 3 and 22 is termed the Rouhani model. 
Technology Corporation "turbine and a Ramapo Corporation drag disc were employed. The data were reduced using Aya's theory, but are not reported here. It was found that the mass flow rate predicted by Aya's theory did not agree as well with the experimentally determined mass flow rate as that obtained by using a weighted mass from the gamma densitometer and velocity from a turbine. It is tentatively concluded that Aya's model may not yield good results for horizontal flow.

Other two-phase flow data available pertain to the Bettis Flask tests reported in Reference 24. These data and LOFT data are the only transient two-phase data available for turbines. A detailed investigation of the LOFT data is underway.

The detailed investigations of the WCL data using Aya's theory [21], Rouhani's theory ${ }^{[3]}$ and the volumetric flow theory ${ }^{[23]}$ follow.

\section{AYA'S THEORY}

\subsection{Introduction}

The steady state behavior of the DTT in two-phase flow is sufficiently complex that extensive investigation is required to understand exactly what the transducer is sensing. The procedure described herein was developed for the turbine portion of the DTT and was applied to the free field and full flow tests described in Reference 24, The differences between the present procedure and previous results are that the model incorporates two-phase flow with slip between the phases. Previous investigation of the WCL data ${ }^{[24]}$ assumed homogeneous flow (no slip) and a turbine output proportional to some average flow velocity. The calibration curve resulting from the present procedure has considerably less scatter than the previous calibration. Predicted, mass flow rates using the new procedure compared surprisingly well with the experimentally determined mass flow rates,-indicating that 'Aya's model is heading in the right direction. The model.is based upon a force balance on the turbine blade between the steam and the liquid. The model remains valid for allsteam or all-liquid flow. The velocities determined for these two cases are those fluid vèlocities which put no force on the turbine blades.

\subsection{Theory}

A model of the behavior of a turbine meter was proposed by Izuo Aya formerly of Oak Ridge National Laboratory (ORNL) ${ }^{[21]}$. It is assumed the flow is dispersed with the steam moving faster than the water. The forces acting on the blade are visualized as a steam force acting on the upstream portion of the blade and a resisting water force acting on the downstream portion. The turbine is assumed to be turning at a nominal speed that corresponds to a fluid velocity, $\mathrm{V}_{\mathrm{t}}$. It is assumed that the steam is trying to drive the turbine into the water and the water on the other side of the blade resists this driving force. The derivation presented in Reference 21 is followed' below. 
The blade is shown in Figure 10. The tangential velocity at a point is $r \omega$, where $r$ is the radial distance from the axis to be the point and $\omega$ is the angular frequency of the blade.
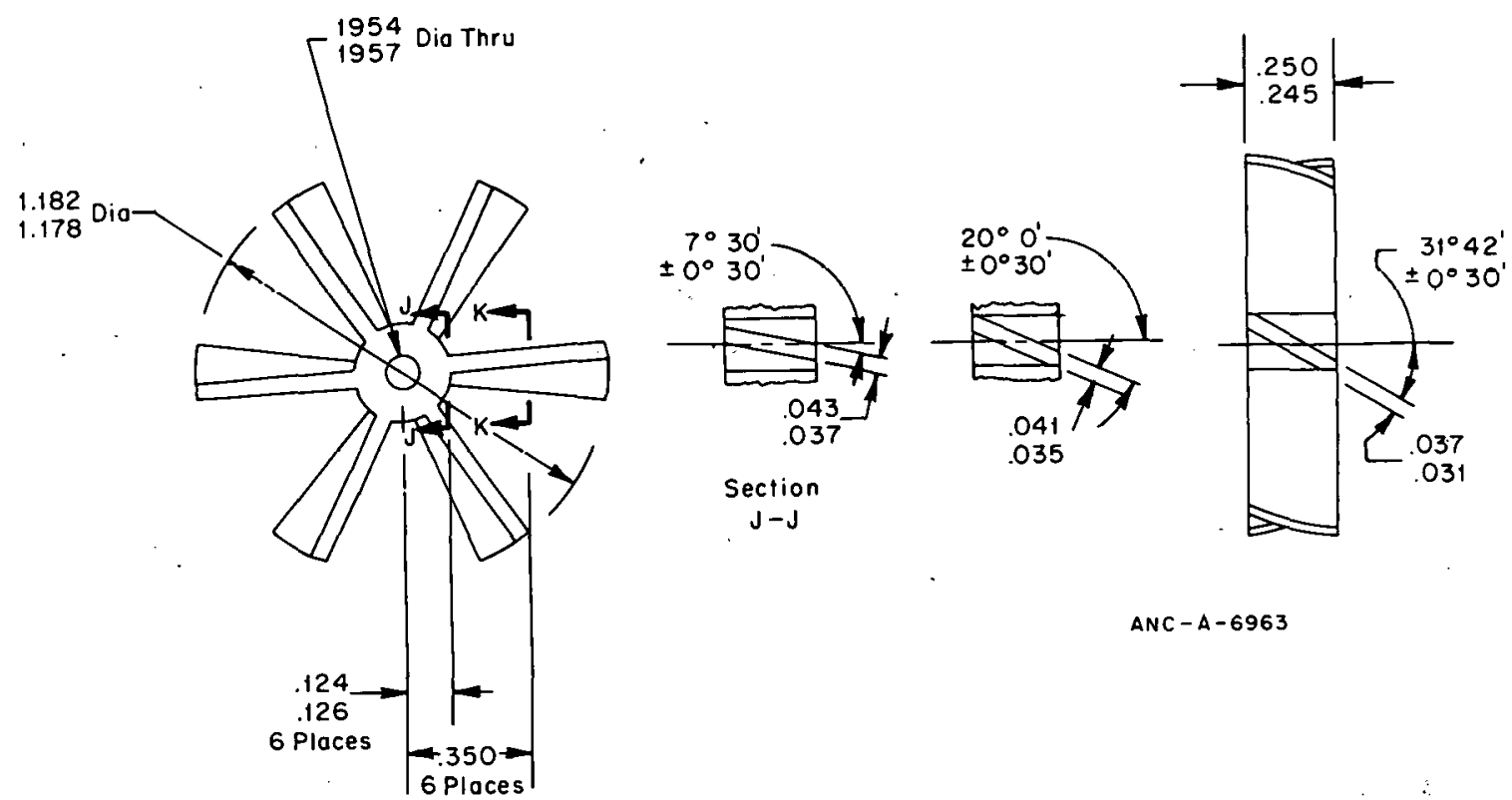

Fig. 10 DTT turbine blade geometry, plenum meter.

The blade is constructed such that ${ }^{[a]}$

$$
\frac{\tan \phi}{r}=\text { constant }
$$

The gas velocity is usually greater than or equal to the liquid velocity in two-phase flow. For steady state flow, the forces acting across the blade and normal to the turbine axis of rotation must be in equilibrium. Assuming that the forces acting normal to the blade have

[a] From Figure 10, this assumption can be verified.

For the plenum meter:

$$
\frac{\tan \phi}{r}=\left.\frac{\tan 7^{\circ} 30^{\prime}}{0.125}\right|_{j j}=\left.\frac{\tan 20^{\circ} 6^{\prime}}{0.350}\right|_{k k}=\left.\frac{\tan 31^{\circ} 42^{\prime}}{1.18 / 2}\right|_{\operatorname{tip}}
$$

and

$$
1.053 / j \mathrm{j} \cong 1.051 / \mathrm{kk} \cong 1.047 / \mathrm{tip} \text {, in. }{ }^{-1} \text {. }
$$

For the piping meter

$$
\frac{\tan \phi}{r}=\left.\frac{\tan 2.5}{0.125}\right|_{\mathrm{JJ}}=\left.\frac{\tan 6.97}{0.350}\right|_{\mathrm{KK}}=\left.\frac{\tan 11.63}{0.59}\right|_{\mathrm{LL}} \cong 0.349, \mathrm{in.}^{-1} .
$$


the form $(1 / 2) \rho \mathrm{V}^{2} \mathrm{CA}$, the equilibrium equation is as follows (viscous forces are neglected) (see Figure 11).

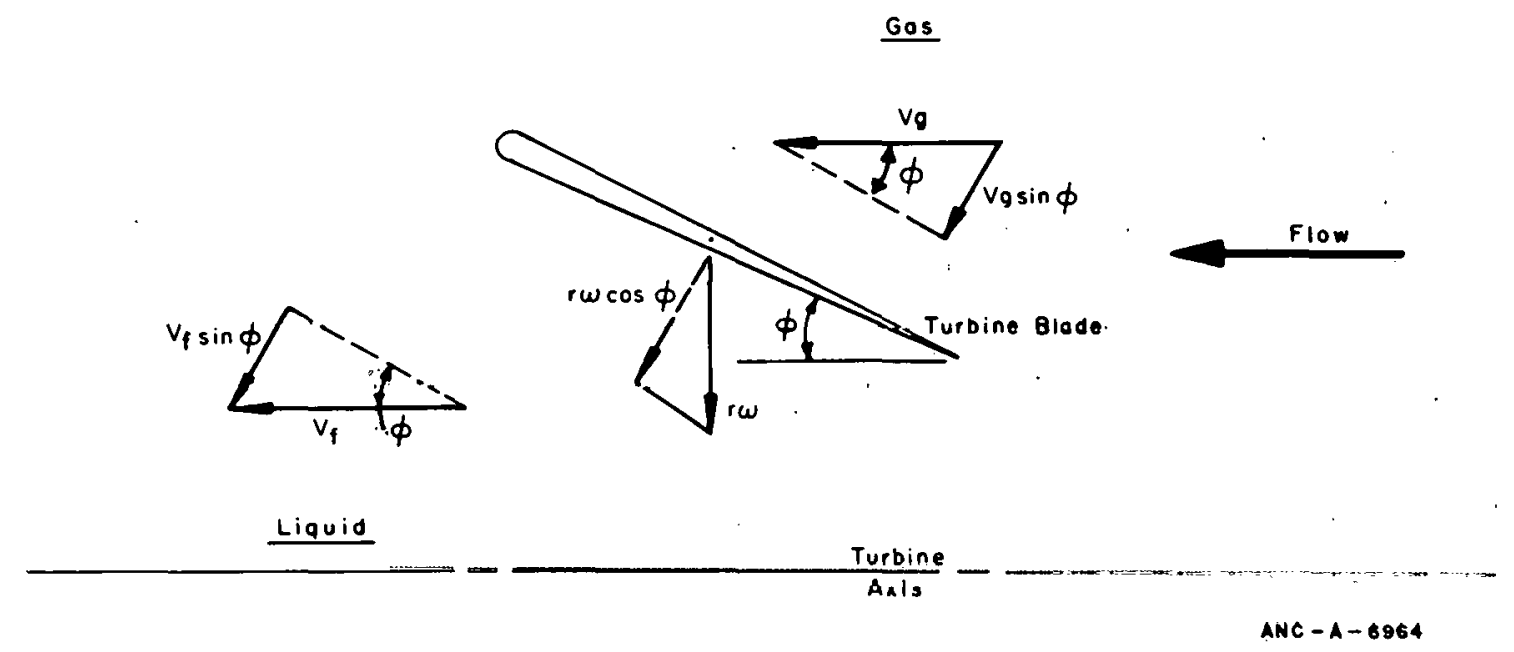

Fig. 11 Velocity vectors for Aya's model.

$$
(1 / 2) \rho_{g} c_{t g} A_{g}\left(v_{g}-v_{t}\right)^{2} \sin ^{2} \phi=(1 / 2) \rho_{f} c_{t f} A_{f}\left(v_{t}-v_{f}\right)^{2} \sin ^{2} \phi
$$

where

$$
v_{t}=\frac{\omega}{(\tan \phi / r)}
$$

This simplifies to

$$
\alpha \rho_{g}\left(v_{g}-V_{t}\right)^{2} c_{g}=(1-\alpha) \rho_{f} c_{f}\left(v_{t}-v_{f}\right)^{2}
$$

For the foregoing equations the following are defined:

$$
\begin{aligned}
& A_{\mathrm{g}}=\text { flow area occupied by the gas } \\
& \mathrm{A}=\text { total tlow area } \\
& \alpha=\frac{A_{\mathrm{g}}}{\mathrm{A}} \text { (void fraction) } \\
& \rho_{\mathrm{g}}=\text { mass density of gas }
\end{aligned}
$$




$$
\begin{aligned}
& \mathrm{V}_{\mathrm{g}}=\text { velocity of gas } \\
& \mathrm{C}_{\mathrm{tg}}=\text { drag coefficient for turbine blade in gas flow } \\
& \rho_{\mathrm{f}}=\text { mass density of liquid } \\
& \mathrm{V}_{\mathrm{f}}=\text { velocity of liquid } \\
& \mathrm{C}_{\mathrm{tf}}=\text { drag coefficient for turbine blade in liquid flow. }
\end{aligned}
$$

Dividing both sides of the equation by $V_{f}$ and rearranging yields:

$$
\left.\frac{\left(\frac{V_{g}}{V_{f}}-\frac{V_{t}}{V_{f}}\right)^{2}}{\left(\frac{V_{t}}{V_{f}}-1\right.}\right)^{2}=\frac{\rho_{f}}{\rho_{g}} \frac{1-\alpha}{\alpha} \frac{C_{f t}}{C_{t g}} .
$$

This is one equation with six parameters so further relations are required. Once five of these parameters are determined then Equation (14) can be solved for $V_{f}$, the fluid velocity.

The ratio $\mathrm{C}_{\mathrm{tf}} / \mathrm{C}_{\mathrm{tg}}$ should come from flow tests. However, an investigation of the drag coefficient for water and air indicates that there is little, if any, difference between the coefficients ${ }^{[26]}$. The drag coefficient depends on Reynolds number and the cavitation number and not the type of fluid. Assuming the ratio is one, introducing the slip ratio $\mathrm{S}=\mathrm{V}_{\mathrm{g}} / \mathrm{V}_{\mathrm{f}}$ and solving the quadratic equation yields

$$
V_{f}=\frac{\left[V_{t} \frac{\rho_{f}}{\rho_{g}}(1-\alpha)-\alpha\right]}{\left[(1-\alpha) \frac{\rho_{f}}{\rho_{g}}-\alpha S\right]+\left\{\left[\alpha S-(1-\alpha) \frac{\rho_{f}}{\rho_{g}}\right]^{2}-\left[(1-\alpha) \frac{\rho_{f}}{\rho_{g}}-\alpha\right]\left[(1-\alpha) \frac{\rho_{f}}{\rho_{g}}-\alpha S^{2}\right]\right\} 1 / 2} .
$$

Knowing the fluid velocity, the gas velocity can be calculated from the slip ratio. The mass flow rate can then be computed as

$$
\begin{aligned}
\dot{M}_{t} & =\dot{M}_{f}+\dot{M}_{g} \\
& =\rho_{g} v_{g} A_{g}+\rho_{f} V_{f} A_{f} \\
\dot{M}_{t} & =\left(\alpha \rho_{g} V_{g}+(1-\alpha) \rho_{f} V_{f}\right) A .
\end{aligned}
$$


The nondimensional cavitation number ' $\sigma$ is defined as

$$
: \sigma=\frac{P \cdots P_{0}}{(1 / 2) \rho v^{2}}
$$

where

$$
\begin{array}{lll}
\mathrm{p} & = & \text { fluid pressure } \\
\mathrm{P}_{\mathrm{O}} & = & \begin{array}{l}
\text { cavity pressure usually taken to be the fluid } \\
\text { vapor pressure }
\end{array} \\
(1 / 2) \rho v^{2}= & \begin{array}{l}
\text { fluid momentum nux or equivalently dynamic } \\
\text { pressure. }
\end{array}
\end{array}
$$

\subsection{Procedure for Application of Aya's Model}

The fluid velocity may be determined from Equation (15)once $\frac{\rho_{\mathrm{g}}}{\rho_{\mathrm{g}}}, \frac{\mathrm{V}_{\mathrm{g}}}{\cdot \mathrm{V}_{\mathrm{f}}}$ and $\mathrm{V}_{\mathrm{t}}$ are known. The ratio $\frac{\rho_{\mathrm{f}}}{\rho_{\mathrm{g}}}$ may be obtained from. Reference 27 once the fluid temperature is known, assuming saturation conditions. The slip ratio $\frac{\mathrm{V}_{\mathrm{g}}}{\mathrm{V}_{\mathrm{f}}}$ may be obtained : from Reference 28 , Figure 3 , where it is a function of the specific density ratio $\frac{\rho_{\mathrm{f}}}{\rho_{\mathrm{g}}}$ The void fraction, for which slip was accounted, may be obtained from a gamma densitometer or from the following relation, once the quality $x$ is known [Reference 29 , Equation (12-8)] .

$$
S=\frac{x}{1-x} \frac{i-\alpha}{\alpha} \frac{\rho_{f}}{\rho_{g} g}
$$

where $\chi$ is the flow quality defined by $\chi=\frac{\text { mass flow rate of gas }}{\text { total mass flow rate }}$. The quantity $V_{t}$ may be obtained from blade geometry and an air turbine calibration or preferably from an all-water calibration. For example, for DTT SN 12 prior to the Wyle tests, bench calibration at ARA yielded (blade turning in air)

$$
V_{0}=0.00252 \omega-0.000495
$$

where $\cdot V_{O}$ is the turbine output voltage, and $\omega$ is the rotational frcquency of the turbine.

From blade geometry for plenum meters

$$
\omega=\frac{\tan \phi}{r} v_{t} \cong 1.05 v_{t}, \frac{1}{i n .}
$$


Solving Equations (18a) and (18b) for $V_{t}$ yields

$$
V_{t}=0.0156+31.49 V_{0} \text {, fps . }
$$

To illustrate the application of an all-fluid calibration, consider the limits of Equation (15) as $\alpha \rightarrow 0$ (all-water) and $\alpha \rightarrow 1$ (all-gas). For these conditions, $V_{f / \alpha \rightarrow 0}=V_{t}$ and $\mathrm{V}_{\mathrm{g} / \alpha=1}=\mathrm{V}_{\mathrm{t}}$. The results from all-water tests for DTT SN 12 are

$$
v_{f}=v_{t}=\left\{\begin{array}{ll}
-0.116+34.47 v_{0} & \begin{array}{l}
\text { full flow tests } \\
\text { at ARA }
\end{array} \\
0.64+39.192 v_{0} \begin{array}{l}
\text { free field pump } \\
\text { simulator tests } \\
\text { at WCL }
\end{array}
\end{array} .\right.
$$

The experimental values for $V_{t}$ from the two all-water test series [Equation (20)] are larger than that predicted from blade geometry [Equation(19)]. Note the difference in calibration corresponding to the two flow areas. This difference is an indication of the accuracy of the assumption that the turbine measures average velocity.

For the WCL tests, the quality $\chi$ was known, so that $\alpha$ was obtained without employing a gamma densitometer. From Table 3-8-I, page 128 of Reference 24,

$$
v_{w}=v_{f}+x\left(v_{g}-v_{f}\right)
$$

where

$$
\begin{aligned}
& \mathrm{V}_{\mathrm{w}}=\text { the specific volume as calculated by WCL } \\
& \mathrm{V}_{\mathrm{g}}=\text { the specific volume of the gas at temperature } \\
& \mathrm{V}_{\mathrm{f}}=\text { the specific volume of the liquid at temperature. }
\end{aligned}
$$

Substituting $\chi$ from Equation (21) in Equation (17), and then solving Equation (17) for $\alpha$ yields

$$
\alpha=\frac{\rho_{f}-\rho_{w}}{S\left(\rho_{w}-\rho_{g}\right)+\left(\rho_{f}-\rho_{w}\right)} .
$$

The WCL data were reduced using Equation (22). 


\section{ROUHANI'S THEORY}

Both Rouhani ${ }^{[3]}$ and Estrada ${ }^{[22]}$ independently developed a theory relating turbine output to gas and liquid :velocities. The following derivation is taken directly from Reference 22.

The equation of motion for the blade is (Newton's law)

$$
F=\frac{d}{d t}(M V)
$$

where

$$
\begin{aligned}
& \mathrm{F}=\text { the force applied to the blade } \\
& \mathrm{M}=\text { the mass of the fluid flowing over the blade } \\
& \mathrm{V}=\text { the velocity of the fluid } \\
& \mathrm{t}=\text { time. }
\end{aligned}
$$

Assuming zero force acting on the blade (steady flow with no acceleration) and that no changes in phase occur, then Equation (23) becomes

$$
n=\dot{M}_{f} \wedge V_{f}+\dot{M}_{g} \wedge v_{g}
$$

where $\dot{\mathrm{M}}_{\mathrm{f}}$ and $\dot{\mathrm{M}}_{\mathrm{g}}$ are the mass flow rates of the liquid and steam, and $\Delta \mathrm{V}_{\mathrm{f}}$ and $\Delta \mathrm{V}_{\mathrm{g}}$ are the changes in velocity of the liquid and steam. The blade and velocity triangles are shown in Figure 12 from which

$$
\begin{aligned}
& \cos \phi=\frac{v_{3 x}}{w_{3}} \\
& v_{3 . y}=w_{3} \sin \phi-U=v_{3 x} \tan \phi-U
\end{aligned}
$$

where

$$
\begin{aligned}
& \mathrm{V}_{3 \mathrm{y}}=\text { the y component of the absolute velocity at the exit } \\
& \mathrm{U}=\text { the blade velocity } \\
& \phi \quad=\text { the blade angle } \\
& \mathrm{W}_{3}=\text { the velocity of gas and liquid relative to the blade. }
\end{aligned}
$$



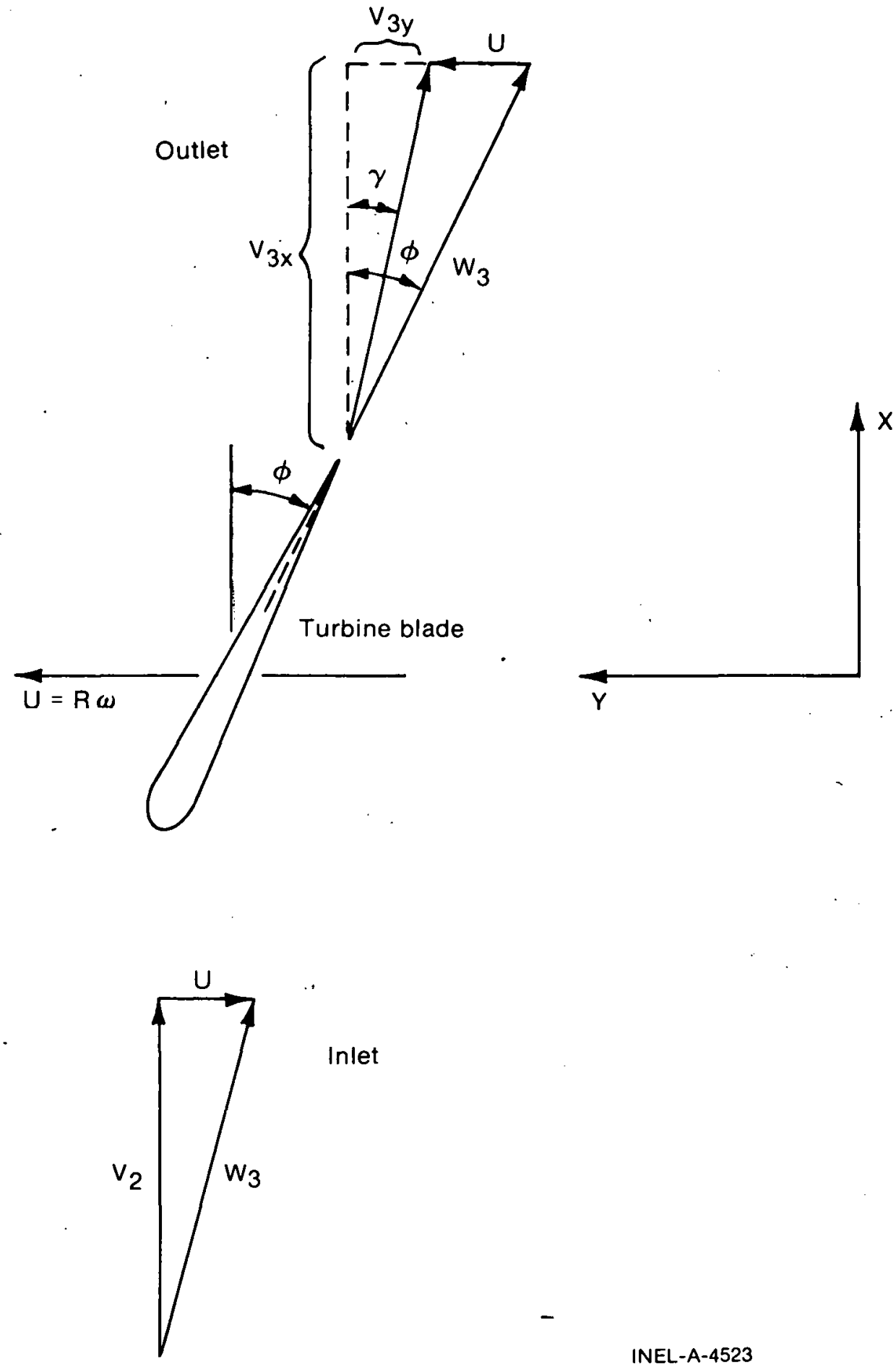

INEL-A-4523

Fig. 12 Velocity vectors for Estrada's theory. 
The mass flow rates are given by

$$
\begin{aligned}
& \dot{M}_{f}=V_{2 f} A(1-\alpha) \rho_{f} \\
& \dot{M}_{g}=V_{2 g} A \alpha \rho_{g}
\end{aligned}
$$

where

$$
\begin{array}{ll}
\mathrm{V}_{2 \mathrm{f}} \text { and } \mathrm{V}_{2 \mathrm{~g}}= & \begin{array}{l}
\text { the absolute velocities of liquid } \\
\text { and gas at the inlet }
\end{array} \\
\mathrm{A} & =\quad \text { the flow area } \\
\alpha & \text { the void fraction } \\
\rho_{\mathrm{f}} \text { and } \rho_{\mathrm{g}}= & \text { the mass densities of liquid and } \\
\text { steam. }
\end{array}
$$

Assuming $\mathrm{V}_{2}=\mathrm{V}_{3 \mathrm{x}}$, then

$$
\begin{aligned}
& \Delta V_{f}=V_{3 y f} \\
& \Delta V_{g}=V_{3 y g} .
\end{aligned}
$$

Substituting (25), (26), and (27) into Equation (24) yields

$$
\begin{aligned}
0 & =V_{2 f} A(1-\alpha) \rho_{f}\left(V_{2 f} \tan \phi-U\right) \\
& +V_{2 g} A \alpha \rho_{g}\left(V_{2 g} \tan \phi-U\right) .
\end{aligned}
$$

Solving Equation (28) for U yields

$$
U=\tan \phi \frac{(1-\alpha) \rho_{f} V_{2 f}^{2}+\alpha \rho_{g} V_{2 g}^{2}}{(1-\alpha) \rho_{f} V_{2 f}+\alpha v_{g} V_{2 g}}
$$

By employing the following relation between slip $S$, quality $\chi$ and void fraction [Reference 29, Equation (12-8)]

$$
S=\frac{V_{g}}{V_{f}}=\frac{x}{1-x} \frac{1-\alpha}{\alpha} \frac{\rho_{f}}{\rho_{g}} .
$$


Equation (29) becomes

$$
U=\tan \phi\left[(1-x) V_{2 f}+x V_{2 g}\right]
$$

Rearranging terms

$$
v_{g}=\frac{U S}{\tan \phi} \cdot\left[\frac{1}{1+(S-1) x}\right]
$$

Equation (32) can be written in terms of void fraction and nominal velocity by substituting for quality from Equation (30) and $\mathrm{V}_{\mathrm{t}}$ from Equation (18b):

$$
V_{f}=v_{t} \frac{\alpha S+(1-\alpha)\left(\rho_{f} / \rho_{g}\right)}{\alpha S^{2}+(1-\alpha)\left(\rho_{f} / \rho_{g}\right)}
$$

Effectively, the foregoing theory assumes that the turbine blade is in steady state equilibrium by means of the momentum changes of the liquid and gas. From Equation(24), $\dot{\mathrm{M}}_{\mathrm{f}}$ and $\dot{\mathrm{M}}_{\mathrm{g}}$ cannot be zero, therefore $\Delta \mathrm{V}_{\mathrm{f}}$ or $\Delta \mathrm{V}_{\mathrm{g}}$ must be negative. An examination of Figure 12 shows that under the assumption that $V_{3 x}=V_{2}$, the absolute velocity increases after it has passed through the turbine. This can occur only if pressure energy is converted to velocity energy. However, for small changes in direction of the velocities $\Delta V_{f}$ and $\Delta V_{g}$, the angle $\gamma$ is small (see Figure 12), and the foregoing equations are approximately valid.

\section{VOLUMETRIC FLOW THEORY}

A two-phase flow theory is derived for a turbine under the assumption that the turbine reads volumetric flow rate $Q$. The volumetric flow rate is given by

$$
Q=\alpha A V_{g}+(1-\alpha) A V_{f}
$$

where

$$
\begin{array}{lll}
\alpha & = & \text { void fraction } \\
\mathrm{A} & = & \text { turbine flow area } \\
\mathrm{V}_{\mathrm{g}}, \mathrm{V}_{\mathrm{f}} & = & \text { stcam and liquid vclocitics. }
\end{array}
$$


The steam and liquid velocities are related by the slip ratio $\mathrm{S}$ as

$$
s=\frac{v_{g}}{v_{f}} \text {. }
$$

Substituting Equation (35) into (34) yields

$$
Q=A V_{f}[1+\alpha(s-1)]
$$

The volumetric flow rate $Q$ can be obtained from all-water calibration data. Once $\alpha$ is obtained from a densitometer, Equation (36) can be solved for $V_{f}$ and Equation (35) for $\mathrm{V}_{\mathrm{g}}$. The mass flow rate can then be calculated from Equation (16).

'I'o illustrate the application of the theory, consider the all-water calibration al AKA prior to the WCL tests. From Equation (1) with $\mathrm{H} \times 3.6 \times 105=\mathrm{V}_{\mathrm{o}}$

$$
Q=A V_{a v}=\left(-0.116+34.47 V_{0}\right) A
$$

where $V_{o}$ is the turbine output test volts. Equating Equations (36) and (37) and solving for $V_{f}$ yields

$$
v_{f}=\frac{-0.11 \dot{6}+34.47 v_{0}}{1+\alpha(s-1)}
$$

\section{FLOW MAP DATA FOR WCL FULL FLOW TESTS}

To bctter understand the WCL full flow data ${ }^{[24]}$, an estimate of the flow regime was obtained. The flow regime map of Reference 30 for vertical pipe flow was used ${ }^{[a]}$. The calculations are presented in Appendix $G$ with the results being plotted in Figure 13. It may be seen that the majority of the data is within the annular mist region with a few points lying in the slug flow and froth regions. For the calculations, the following variables are defined

$$
\begin{array}{ll}
\mathrm{A}, \mathrm{ft}^{2}= & \text { nominal pipe flow area } \\
\mathrm{T},{ }^{\mathrm{o}} \mathrm{F}= & \text { temperature of liquid and gas at saturation } \\
\rho_{\mathrm{L}}, \frac{\mathrm{lbm}}{\mathrm{ft}^{3}}= & \text { mass density of liquid at saturation temperature }
\end{array}
$$

[a] For horizontal flow the flow regime information presented in Reference 8 is more accurate than that of Reference 30 , but it has only recently become available. Future investigations should employ the more recent data. 


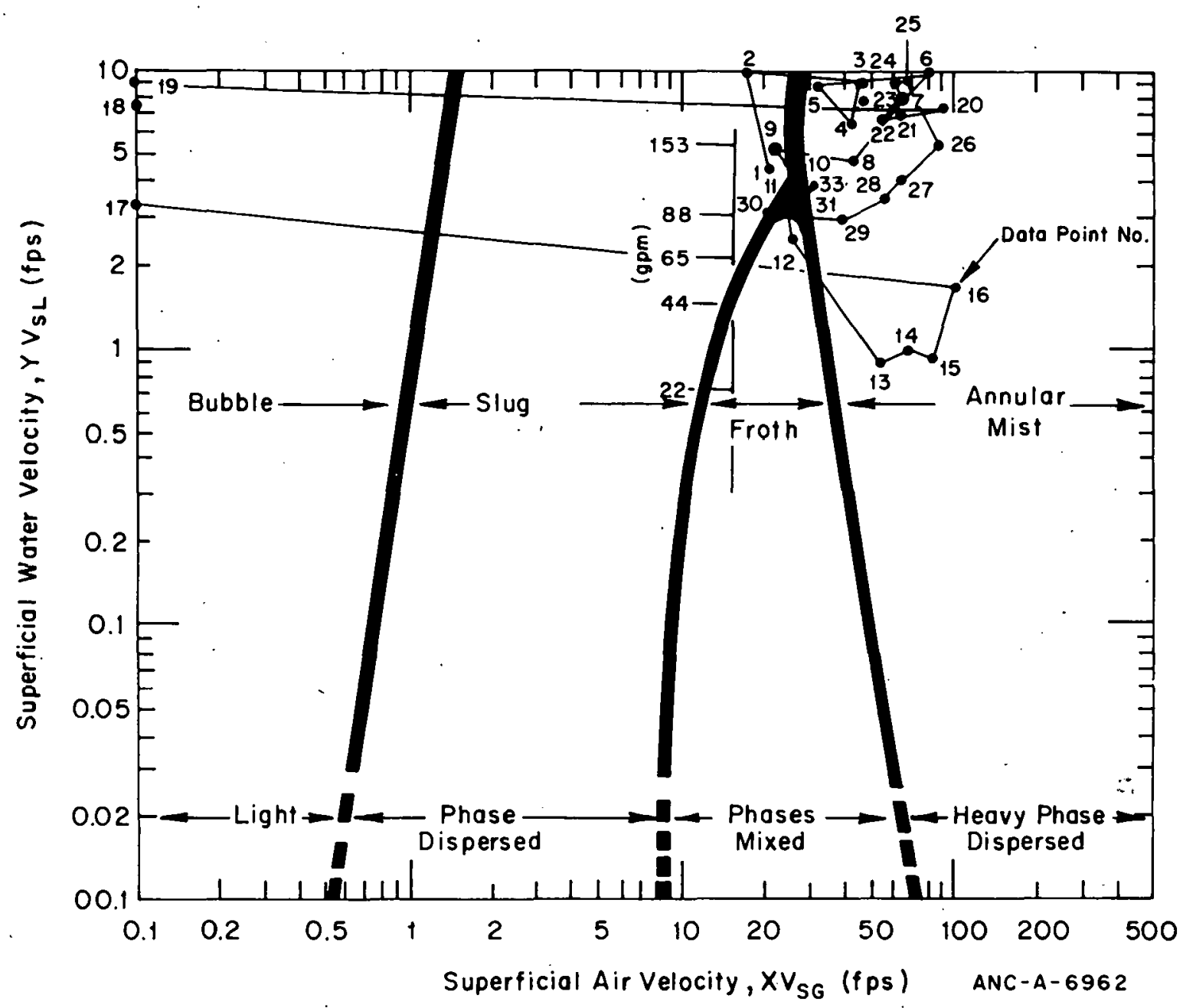

Fig. 13 Flow regime map of Govier and Aziz for WCL forward, full flow data.

\begin{tabular}{|c|c|c|}
\hline${ }^{0} \mathrm{WA}$ & & $\begin{array}{l}72.75 \frac{\text { dyne }}{\mathrm{CM}}=\text { surface tension between water and } \\
\text { air at } 20^{\circ} \mathrm{C}^{[31]}\end{array}$ \\
\hline$\sigma, \frac{\text { dyne }}{C M}=$ & $=$ & $\begin{array}{l}\text { surface tension between steam and water at } \\
\text { saturation temperature }{ }^{[32]}\end{array}$ \\
\hline$\rho_{\mathrm{G}}, \frac{\mathrm{lbm}}{\mathrm{ft}^{3}}=$ & & mass density of steam at saturation temperature \\
\hline$\dot{\mathrm{M}}_{\mathrm{G}}, \frac{\mathrm{lbm}}{\mathrm{hr}}=$ & & mass flow rate of gas \\
\hline$\dot{\mathrm{M}}_{\mathrm{L}}, \frac{\mathrm{lbm}}{\mathrm{l} \mathrm{Ir}}=$ & & mass flow rate of liquid \\
\hline $\mathrm{V}_{\mathrm{SG}}$ & $=$ & $\frac{\dot{\mathrm{M}}_{\mathrm{g}}}{\rho_{\mathrm{g}} \mathrm{A}}=$ superficial velocity of gas \\
\hline$=$ & $=$ & $\frac{\dot{\mathrm{M}}_{\mathrm{L}}}{\rho_{\mathrm{L}} \mathrm{A}}=$ superficial velocity of liquid \\
\hline
\end{tabular}




$$
\begin{aligned}
\rho_{\mathrm{W}} & =\quad 62.3 \frac{\mathrm{lbm}}{\mathrm{ft}^{3}}=\text { water density at } 70^{\circ} \mathrm{F} \\
\rho_{\mathrm{A}} & =\quad 0.071 \frac{\mathrm{lbm}}{\mathrm{ft}^{3}}=\text { air density at } 100^{\circ} \mathrm{F}, 14.7 \mathrm{psi} .
\end{aligned}
$$

\section{COMPARISON OF THE THREE TURBINE MODELS WITH EXPERIMENTS}

The three turbine models were used to investigate the WCL free field and full flow data for forward and reverse flow. For each model, exactly the same set of experimental data was employed. A summary of the ranges of the variables is presented in Table I. In addition, the Rouhani modol was cmployed to investigate the free field dala lu delenminte the effect on the predicted results of using a slip of 1.0. The free field data are summarized in Table II and the full flow data are summarized in Table III. These data are condensed for ease of comparison in Table IV. For the purpose of illustration, the results for the Rouhani model in forward flow as applied to the WCL free field data are presented in Figures 4, 14 and 15 .

\section{TABLE I}

\begin{tabular}{|c|c|c|c|c|c|c|c|c|c|}
\hline$\therefore$ & $\begin{array}{c}\text { Flow } \\
\text { Quality } \\
(x)\end{array}$ & $\begin{array}{l}\text { Nominal } \\
\text { Pressure } \\
\text { (psi) }\end{array}$ & $\begin{array}{c}\text { Nominal } \\
\text { Temperature } \\
\left({ }^{\circ} \mathrm{F}\right)\end{array}$ & $\begin{array}{c}\text { Void Fraction } \\
\text { Calculd ieu } \\
\text { from } \\
\text { Equation (17) } \\
\text { (a) }\end{array}$ & $\begin{array}{l}\text { Given of } / \circ \mathrm{g} \text { ' } \\
\text { Slip } \\
\text { idlculd teu } \\
\text { from } \\
\text { Reference } 28 \\
(5) \\
\end{array}$ & $\begin{array}{c}\varphi_{f} \\
\text { iuin/rt } \\
\text { Reference } 27 \\
\text { for Nominal } \\
\text { Temperature } \\
\end{array}$ & $\begin{array}{c}\text { "y } \\
\text { IDn/te?" } \\
\text { Reference } 27 \\
\text { for Nominal } \\
\text { Temperature }\end{array}$ & $\begin{array}{l}\text { Nominal } \\
\text { velocity } \\
\text { (fps) }\end{array}$ & $\begin{array}{c}\text { Number } \\
\text { of } \\
\text { Oata } \\
\text { Points }\end{array}$ \\
\hline \multicolumn{10}{|l|}{ Fuil Flaw, } \\
\hline Forward & Q to 0.52 & $300 \& 900$ & $420 \& 530$ & 0 to 0.94 & 1.0 to 2.3 & 47 to 55 & 0.37 to 2.0 & 2.3 to 30 & 32 \\
\hline Reverse & 0 to 0.27 & $300 \& 900$ & $390 \& 530$ & 0 to 0.85 & 1.0 to 2.3 & 47 to 54 & 0.46 to 2.0 & 3.0 to 25 & 45 \\
\hline \multicolumn{10}{|l|}{ Free Field, } \\
\hline Forward & 0 to 0.62 & $300 \& 900$ & $420 \& 530$ & 0 to 0.95 & 1.6 to 2.3 & 47 to 55 & 0.62 to 2.1 & 2.6 to 19 & 41 \\
\hline Keverse & $U$ to 0.98 & $300 \& 900$ & $340 \& 540$ & 0 to $\mathrm{i} .0$ & 1.6 to 3.1 & 47 to $56^{\prime}$ & 0.26 to 2.1 & 1.5 to 20 & 45 \\
\hline
\end{tabular}

\section{RANGES OF THE TEST VARIABLES}

Results from data (see Tables II, III, and IV):

(1) Forward and reverse flow velocities and mass flow rates for any given model agree within about $10 \%$. with the worst case being $21 \%$. This is true for free field and full flow data for all three models.

(2) Forward and reverse flow velocities and mass flow rates for the Rouhani and Aya models agree with each other within about $12 \%$. This is true for free field and full flow data. 


\section{TABLE II}

SUMMARY OF RESULTS FOR THE THREE TURBINE MODELS, WCL FREE FIELD TESTS

\begin{tabular}{|c|c|c|c|c|c|c|c|c|}
\hline Test Points & $\mathrm{B}_{0}$ & $\mathrm{~B}_{1}$ & $\sigma_{0}$ & $\sigma_{1}$ & $\sigma_{y x}$ & Direction & Mode 1 & Coordinates \\
\hline 41 & 0.586 & 34.35 & 0.235 & 1.194 & 0.674 & Forward & Rouhani & Liquid velocity versus turbine volts \\
\hline 19 & 1.208 & 52.43 & 0.659 & 3.144 & 1.249 & Forward & Rouhani & $\begin{array}{l}\text { Steam velocity versus turbine volts, } \\
\text { slip }=1.6\end{array}$ \\
\hline 22 & 1.047 & 79.21 & 0.520 & 2.820 & 1.110 & Forward & Rouhani & $\begin{array}{l}\text { Steam velocity versus turbine volts, } \\
\text { slip }=2.0,2.2,2.3\end{array}$ \\
\hline 41 & -0.186 & 1.215 & 0.871 & 0.0770 & 3.018 & Forward & Rouhani & Predicted versus measured mass flow \\
\hline 46 & 0.650 & 33.27 & 0.368 & 1.716 & $1: 051$ & Reverse & Rouhani & Liquid velocity versus turbine volts \\
\hline 24 & -0.753 & 66.76 & 1.466 & 6.084 & 2.664 & Reverse & Rouhani & $\begin{array}{l}\text { Steam velocity versus turbine volts, } \\
\text { slip }=1.6,1.8,1.9,2.0\end{array}$ \\
\hline 22 & 1.630 & 77.97 & 1.067 & 5.869 & 2.209 & Reverse & Rouhani & $\begin{array}{l}\text { Steam velocity versus turbine volts, } \\
\text { slip }=2.2,2.3,2.6,3.0,3.1\end{array}$ \\
\hline 46 & 1.573 & 1.092 & 0.852 & 0.0690 & 3.192 & Reverse & Rouhani & Predicted versus measured mass flow \\
\hline 41 & 0.509 & 25.19 & 0.331 & 1.686 & 0.952 & Forward & Volumetric Flow & Liquid velocity versus turbine volts \\
\hline 19 & 1.126 & 41.79 & 0.540 & 2.580 & 1.025 & Forward & Volumetric Flow & $\begin{array}{l}\text { Steam velocity versus turbine volts, } \\
\text { slip }=1.6\end{array}$ \\
\hline 22 & 1.314 & 50.38 & 1.115 & 6.041 & 2.378 & Forward & Volumetric. Flow & $\begin{array}{l}\text { Steam velocity versus turbine volts, } \\
\text { slip }=2.0,2.2,2.3\end{array}$ \\
\hline 41 & -0.648 & 1.033 & 0.523 & 0.0471 & 1.926 & Forward & Volumetric Flow & Predicted versus measured mass flow \\
\hline
\end{tabular}


TABLE II (continued)

\begin{tabular}{|c|c|c|c|c|c|c|c|c|}
\hline Test Points & $\mathrm{B}_{\mathrm{O}}$ & $B_{1}$ & ${ }_{-0}^{\prime \prime}$ & 3 & ${ }^{0} \mathrm{yx}$ & Direction & Model & Coordinates \\
\hline 46 & 1.317 & 20.34 & 0.361 & 1.680 & $1.02 \subseteq$ & Reverse & Volumetric Fl Jw & Liquid velocity versus turbine volts \\
\hline 24 & 1.628 & 41.77 & 0.822 & 3.408 & $1.49 c$ & Reverse & yolumetric Fluw & $\begin{array}{l}\text { Steam velocity versus turbine voits, } \\
\text { slip }=1.6,1.8,1.9,2.0\end{array}$ \\
\hline 22 & 3.504 & 42.57 & 1.710 & 9.404 & $3.53 \mathrm{C}$ & Reverse & Yolumetric Fluw & $\begin{array}{l}\text { Steam velocity versus turbine voits, } \\
\text { slip }=2.2,2.3,2.6,3.0,3.1\end{array}$ \\
\hline 46 & -0.327 & 1.324 & 0.434 & 0.035 & 1.62 & Reverse & Jolumetric $\mathrm{Fl}$ Jw & Predicted versus measured mass flow \\
\hline 41 & 0.497 & 32.97 & 0.168 & 0.857 & $0.48 \mathrm{c}$ & Forward & Aya & Liquid velocity versus turbine volts \\
\hline 19 & 0.964 & 51.78 & 0.404 & $1.9 \tilde{1}$ & 0.76 & Forward & Aya & $\begin{array}{l}\text { Steam velocity versus turbine volts, } \\
\text { slip }=1.6\end{array}$ \\
\hline 22 & 1.692 & 73.31 & 0.523 & $2.8 \div 3$ & 1.115 & Forward & Aya & $\begin{array}{l}\text { Steam velocity versus turbine volts, } \\
\text { slip }=2.0,2.2,2.3\end{array}$ \\
\hline 41 & -0.369 & 1.169 & 0.757 & $0.0 E 72$ & $2.62 \hat{\imath}$ & Forward & Aya & Predicted versus measured mass flow \\
\hline$\cdot .46$ & 0.803 & 30.87 & 0.269 & 1.255 & 0.769 & Reverse & Aya & Liquid velocity versus turbine volts \\
\hline 24 & -0.105 & 61.63 & 1.084 & $4.5 C 0$ & $1.97^{\circ}$ & Reverse & Aya & $\begin{array}{l}\text { Steam velocity versus turbine volts, } \\
\text { slip }=1.6,1.8,1.9,2.0\end{array}$ \\
\hline 22 & 2.020 & 70.80 & 1.118 & 6.148 & $2.31 c$ & Reverse & Aya & $\begin{array}{l}\text { Steam velocity versus turbine volts, } \\
\text { slip }=2.2,2.3,2.6,3.0,3.1\end{array}$ \\
\hline 46 & 1.202 & 1.071 & 0.713 & 0.0579 & 2.663 & Reverse & Aya & Predicted versus measured mass flow \\
\hline
\end{tabular}




\section{TABLE II (continued)}

\begin{tabular}{|c|c|c|c|c|c|c|c|c|}
\hline Test Points & $B_{0}$ & $\mathrm{~B}_{1}$ & $\sigma_{0}$ & $\sigma_{1}$ & $\sigma_{y x}$ & Direction & Model & Coordinates \\
\hline 41 & 0.344 & 39.19 & 0.0011 & 0.0055 & 0.003 & Forward & $\begin{array}{l}\text { Rouhani with } \\
\text { slip }=1.0\end{array}$ & Liquid velocity versus turbine volts, \\
\hline 71. & 0.0458 & 1.212 & 0.893 & 0.0793 & 3.093 & Forward & $\begin{array}{l}\text { Rouhani with } \\
\text { slip }=1.0\end{array}$ & Predicted versus measured mass flow \\
\hline
\end{tabular}




\section{TABLE III}

SUMMARY OF RESULTS FOR THE THREE TURBINE MODELS, WCL FULL FLOW TESTS

\begin{tabular}{|c|c|c|c|c|c|c|c|c|}
\hline 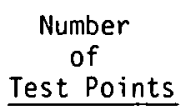 & Bo & $B_{1}$ & ${ }_{0}^{\circ}$ & $c_{1}$ & ${ }_{\mathrm{yx}}^{\mathrm{x}}$ & Direction & Model & Coordinates \\
\hline 32 & 0.632 & 29.42 & 0.255 & $0 . \overline{86}$ & 0.711 & Forward & Rouhani & Liquid velocity versus turbịne volts \\
\hline 15 & 1.363 & 44.12 & 0.698 & $2 . \triangleq 17$ & 1.349 & Forward & Rouhani & $\begin{array}{l}\text { Steam velocity versus turbine volts, } \\
\text { slip }=1.6\end{array}$ \\
\hline 13 & 1.158 & 70.70 & 0.475 & $1 . \equiv 00$ & 0.775 & Forward & Rouhani & $\begin{array}{l}\text { Steam velocity versus turbine volts, } \\
\text { slip }=2.3\end{array}$ \\
\hline 32 & 0.033 & 0.913 & 0.090 & 0.639 & 0.216 & Forward & Rouhani & Predicted versus measured mass flow \\
\hline 45 & 0.562 & 30.11 & 0.0995 & $0 . \approx 09$ & 0.324 & Reverse & Rouhani & Liquid velocity versus turbine volts \\
\hline 22 & 1.576 & 46.46 & 0.409 & 1. 185 & 0.898 & Reverse & Rouhani & $\begin{array}{l}\text { Steam velocity versus turbine volts, } \\
\text { slip }=1.6,1.9\end{array}$ \\
\hline 17 & 0.946 & 70.80 & 0.315 & 0.555 & 0.631 & Reverse & Rouhani & $\begin{array}{l}\text { Steam velocity versus turbine volts, } \\
\text { slip }=2.3\end{array}$ \\
\hline 45 & 0.303 & 0.778 & 0.219 & 0.105 & 0.477 & Reverse & Rouhani & Predicted versus measured mass flow \\
\hline 32 & 1.863 & 17.30 & 0.417 & $\mathrm{i} . \Sigma 8 ?$ & 1.164 & Forward & Valumetric Flow & Liquid velocity versus turbine volts \\
\hline 15 & 1.758 & 34.17 & 0.613 & $i . \$ 41$ & 1.184 & Forward & Vclumetric Flow & $\begin{array}{l}\text { Steam velocity versus turbine volts, } \\
\text { slip }=1.6\end{array}$ \\
\hline 13 & 4.536 & 34.23 & 1.397 & 3.820 & 2.230 & Forward & Vclumetric Flow & $\begin{array}{l}\text { Steam velocity versus turbine volts, } \\
\text { slip }=2.3\end{array}$ \\
\hline 32 & -.0279 & 0.761 & 0.133 & 0.0570 & $n .311$ & Forward & Vclımetric Flow & Predicted versus measured mass flow \\
\hline
\end{tabular}


TABLE III (continued)

\begin{tabular}{|c|c|c|c|c|c|c|c|c|}
\hline 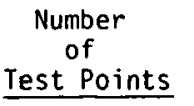 & $\mathrm{B}_{0}$ & $\mathrm{~B}_{1}$ & $\sigma_{0}$ & ${ }^{0} 1$ & $\sigma_{y x}$ & Direction & Model & Coordinates \\
\hline 45 & 1.785 & 18.19 & 0.366 & 1.135 & 1.191 & Reverse & Volumetric Flow & Liquid velocity versus tarbine volts \\
\hline 22 & 2.452 & 33.19 & 0.412 & 1.194 & 0.905 & Reverse & Volumetric Flow & $\begin{array}{l}\text { Steam velocity versus turbine volts, } \\
\text { slip }=1.6,1.9\end{array}$ \\
\hline 17 & 4.311 & 34.10 & 1.254 & 3.800 & 2.512 & Reverse & Volumetric Flow & $\begin{array}{l}\text { Steam velocity versus turbine volts, } \\
\text { slip }=2.3\end{array}$ \\
\hline 45 & 0.0169 & 0.747 & 0.195 & 0.093 & 0.424 & Reverse & Volumetric Flow & Predicted versus measured mass flow \\
\hline 32 & 0.713 & 27.54 & 0.168 & 0.518 & 0.468 & Forward & Aya & Liquid velocity versus turbine volts \\
\hline 15 & 0.951 & 44.14 & 0.444 & 1.406 & 0.858 & Forward & $\begin{array}{c}\text { Aya } \\
-\end{array}$ & $\begin{array}{l}\text { Steam velocity versus turbine volts, } \\
\text { slip }=1.6\end{array}$ \\
\hline 13 & 1.604 & 63.55 & 0.551 & 1.506 & 0.899 & Forward & Aya & $\begin{array}{l}\text { Steam velocity versus turbine volts, } \\
\text { slip }=2.3\end{array}$ \\
\hline 32 & $0.036=$ & 0.870 & 0.0829 & 0.0362 & 0.198 & Forward & Aya & Predicted versus measured mass flow \\
\hline 45 & 0.679 & 27.97 & 0.110 & 0.341 & 0.357 & Reverse & Aya & Liquid velocity versus turbine volts \\
\hline 22 & 1.397 & 44.60 & 0.329 & 0.953 & 0.722 & Reverse & Aya & $\begin{array}{l}\text { Steam velocity versus turbine volts, } \\
\text { slip }=1.6,1.9\end{array}$ \\
\hline 17 & 1.415 & 63.59 & 0.429 & 1.300 & 0.860 & Reverse & Aya & $\begin{array}{l}\text { Steam velocity versus turbine volts, } \\
\text { slip }=2.3\end{array}$ \\
\hline 45 & 0.248 & 0.765 & 0.203 & 0.0971 & 0.442 & Reverse & Aya & Predicted versus measured mass flow \\
\hline
\end{tabular}


TABLE IV

CONDENSED SUMMARY OF RESULTS FOR THE THREE TURBINE MODELS, FREE FIELD AND FULL FLOW TESTS

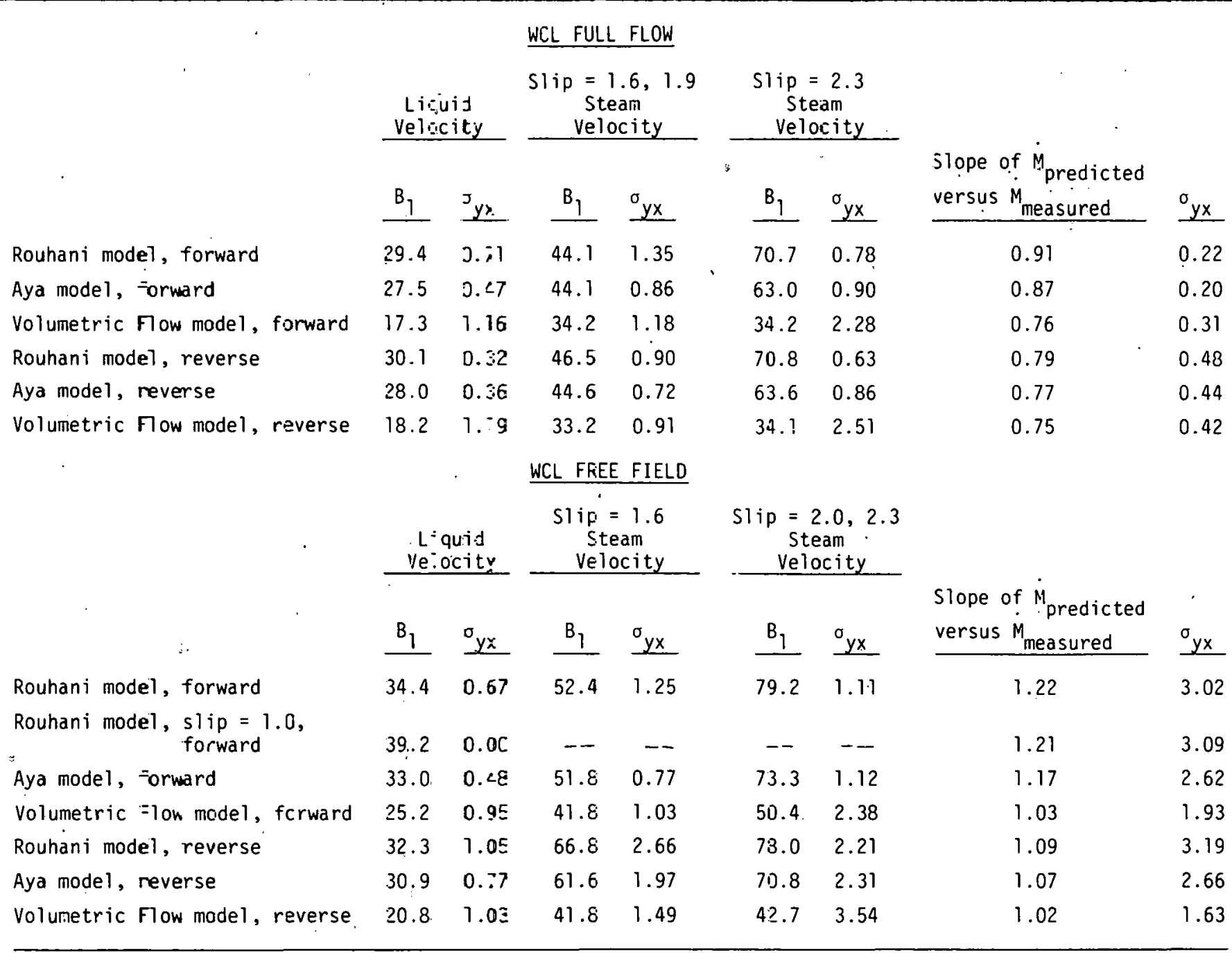




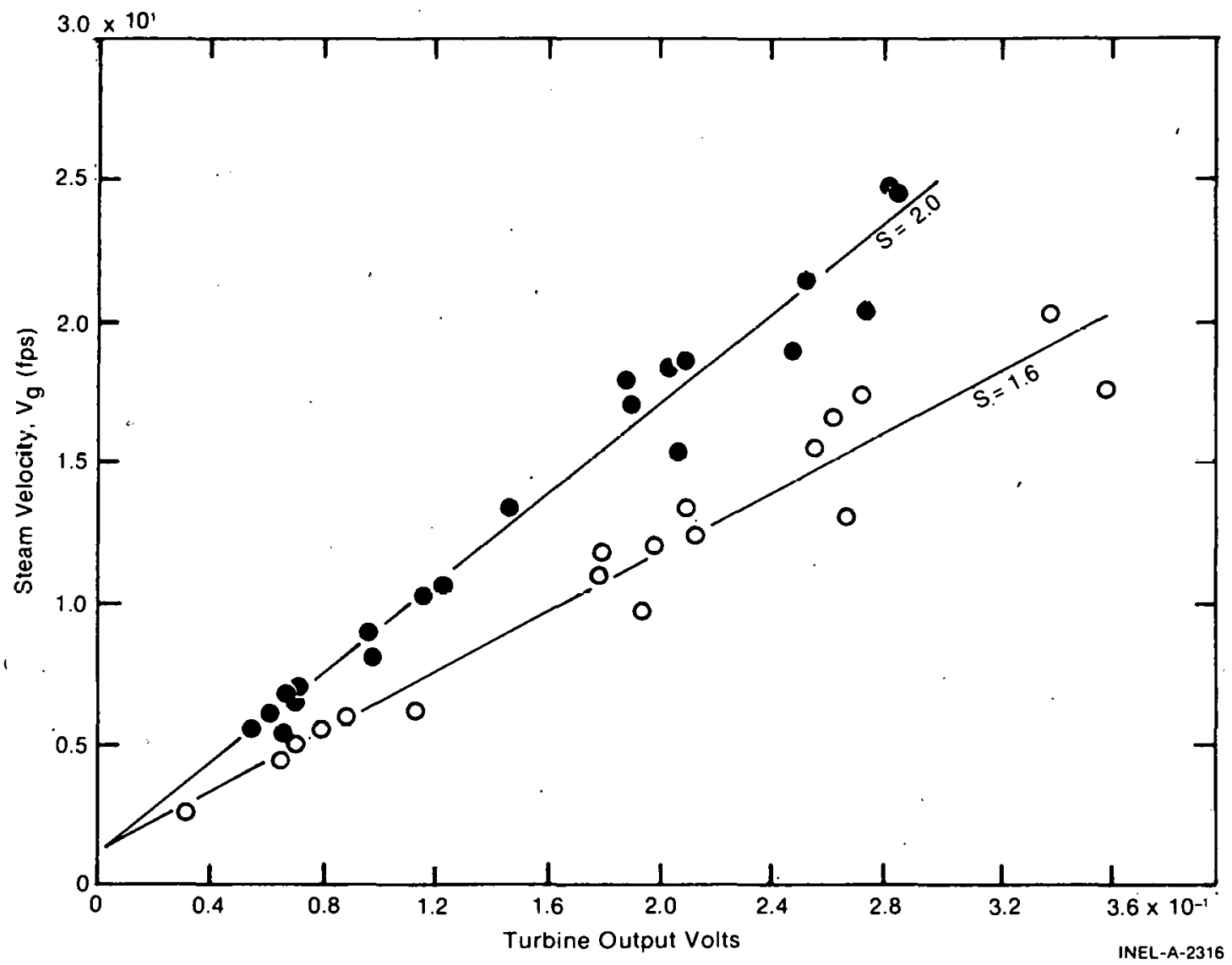

Fig. 14 WCL free field turbine calibration after analyzing Rouhani's theory.

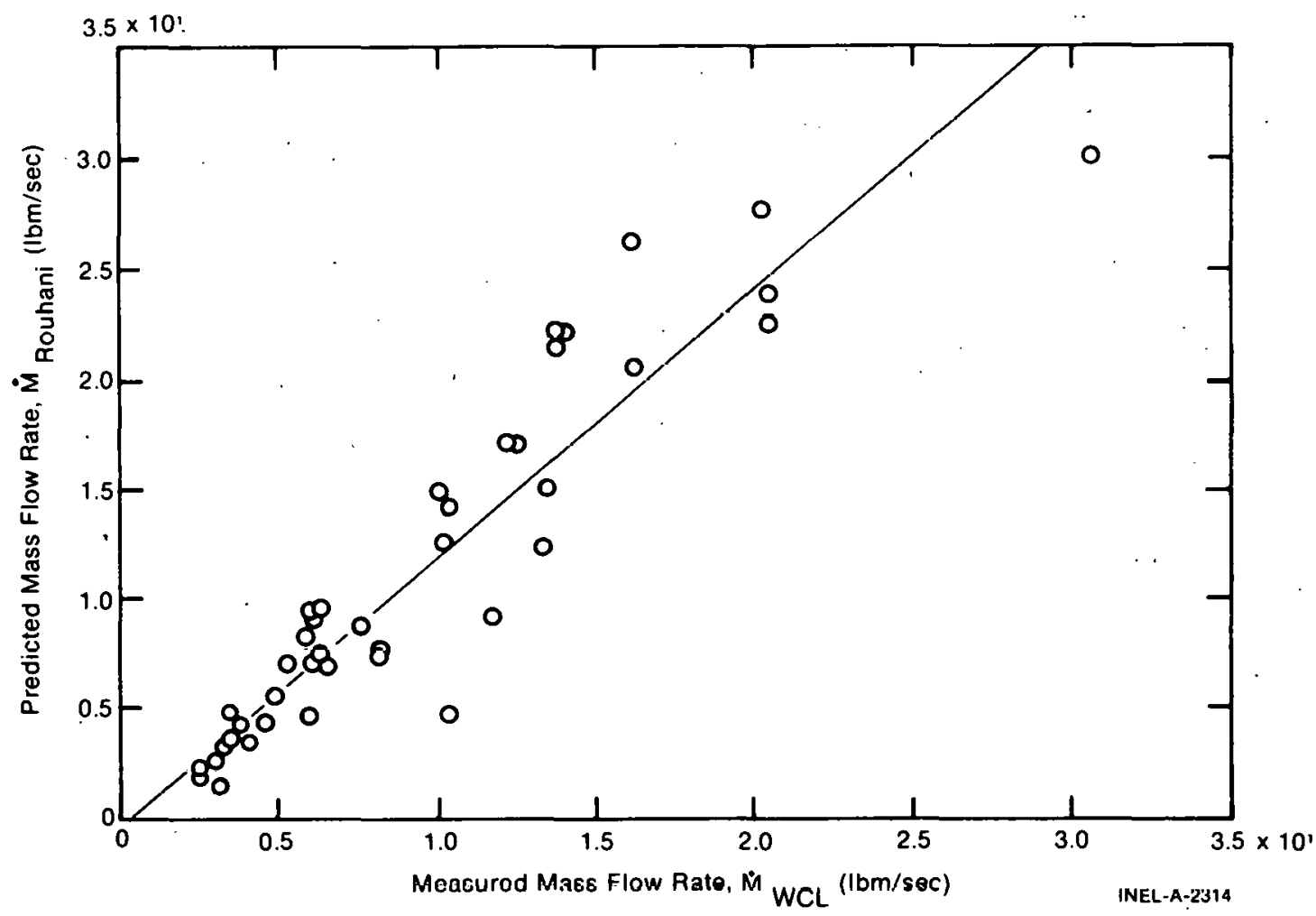

Fig. 15 WCL free field, Rouhani model versus WCL data. 
(3) For forward and reverse flow, the velocities predicted by the volumetric flow model are significantly less than those predicted by the Rouhani and Aya models. The maximum discrepancy, using the Rouhani model as a basis, is as large as $52 \%$. This is true for both free field and full flow data.

(4) The mass flow rates predicted by the volumetric flow model are less than those predicted by the other two models by about $16 \%$ for forward flow, and $7 \%$ for reverse flow.

(5) For the 16 conditions investigated in Table IV, nine of the worst correlations occurred for the volumetric flow model, while only three of the best correlations occurred for this model. The 16 conditions are for liquid velocity, two steam velocities, and one mass flow rate somparison for forward and reverse thow for hoth free field and full flow tests. The correlations are based on $0 \mathrm{yx}$.

(6) For the Rouhani standard error of estimate of $y$ on $x, \sigma_{y x}$, the model and the WCL free field tests in forward flow, the results for the "best estimate" of slip and slip equal to 1.0 agree closely.

(7) For all three models, one of the results is that the predicted gas velocity is dependent upon the slip ratio, whereas, the liquid velocity is independent of this ratio.

\section{SLIP $\Lambda$ ND VOID FR $\Lambda$ CTION SENSITIVITY STUDY}

It is of interest to obtain a feeling for how sensitive the turbine models are to variations in slip and void fraction. The Rouhani and Aya models were investigated for a slip range from 0.2 to 20 and void fractions from 0.1 to 1.0. LOFT data for blowdown L1-2 at instrument location BL-1 (blowdown hot leg.) for times after blowdown of 8 and $20 \mathrm{sec}$, were used as a basis for comparison. Equations and results for the Rouhani model are presented, but only the results for the Aya model are presented.

Upon rearranging Equation (33), the liquid velocity ratio $V_{f} / V_{t}$ is obtained.

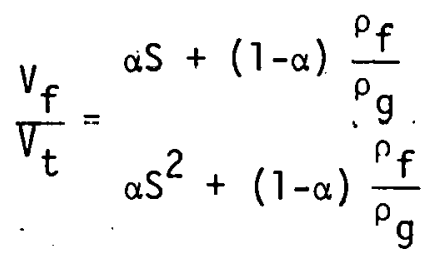


The steam velocity ratio is then

$$
\frac{v_{g}}{v_{t}}=s \frac{v_{f}}{v_{t}}
$$

The mass flow rate ratio can be obtained from Equation (16) by rearranging

$$
\frac{\dot{M}}{\rho_{g} A V_{t}}=\left[\alpha S+(1-\alpha) \frac{\rho_{f}}{\rho_{g}}\right] \frac{V_{f}}{V_{t}} .
$$

Equations (39), (40), and (41) were solved for variations in slip from 0.2 to .20 and variations in void fraction from 0.1 to 1.0. As a guide, data were used for LOFT blowdown L1-2 at instrumentation location BL-1 for times after blowdown of $8 \mathrm{sec}$ (Tables V and VI) and $20 \mathrm{sec}$ (Tables VII and VIII). Similar results obtained for the Aya model are not presented, but are briefly discussed.

It should be noted that the maximum flow rate always occurs at a slip of 1.0. For LOFT experiments, the maximum slip expected during LOCE is estimated to be 6.0 (based upon $\rho_{\mathrm{f}} / \rho_{\mathrm{g}}$ and Reference 28). Tables $\mathrm{V}$ and VII show that for slip values up to and including 8.0, the mass flow rate ratio decreased by about a factor of 2.3. As void fraction varied from 0.1 to 0.9 , the mass flow rate decreased by as much as a factor of 7.8 (Tables VI and VIII).

Similar results (not presented) were obtained with the Aya model. For slip values up to and including 8.0 , the mass flow rate ratio decreased by about a factor of 1.7. As void fraction varied from 0.1 to 0.9 , the mass flow rate decreased by as much as a factor of 7.6 .

In summary, predicted mass flow rate can vary by about a factor of two for the range of slips expected in LOFT, and about a factor of eight for the range of void fractions from 0.1 to 0.9 . 
TABLE $V$

ROUHANI MODEL WITH SLIP VARIED, LOFT TEST LI-2

INSTRUMENTATION LOCATION BL-1, 8 SEC AFTER BLOWDOWN ${ }^{[a]}$

\begin{tabular}{|c|c|c|c|c|c|}
\hline slip & $\begin{array}{l}\text { Liquid } \\
\text { Velocitis } \\
\text { Ratio } \\
\end{array}$ & V & $\begin{array}{l}\text { Steam } \\
\text { Velocity } \\
\text { Ratio } \\
\end{array}$ & \begin{tabular}{l}
\multicolumn{1}{c}{$\dot{M}^{\prime}$} \\
Mass Flow \\
Rate Ratio \\
\end{tabular} & $\frac{\dot{M}^{\prime}}{\dot{M}^{\prime} w / s l i p}=1.0$ \\
\hline 0.2 & 1.01 & & 0.20 & 13.04 & 0.98 \\
\hline 0.4 & 1.01 & & 0.40 & 13.18 & 0.99 \\
\hline 0.6 & 1.01 & & 0.61 & 73.28 & 0.99 \\
\hline 0.8 & 1.01 & & 0.80 & 13.33 & 1.0 \\
\hline 1.0 & 1.00 & & 1.00 & 13.35 & 1.0 \\
\hline 2.0 & 0.93 & & 1.87 & $12: 92$ & 0.97 \\
\hline 4.0 & 0.71 & & 2.85 & 10.59 & 0.79 \\
\hline 6.0 & 0.52 & & 3.09 & 8.16 & 0.61 \\
\hline 8.0 & 0.38 & & 3.01 & 6.34 & 0.47 \\
\hline 10.0 & 0.28 & & 2.85 & 5.08 & 0.38 \\
\hline 12.0 & 0.22 & & 2.68 & 4.20 & 0.31 \\
\hline 14.0 & 0.18 & & 2.52 & $3.5 \kappa$ & n. $? 7$ \\
\hline 16.0 & 0.75 & & 2.38 & 3.09 & 0.23 \\
\hline 18.0 & 0.13 & & 2.26 & 2.73 & 0.20 \\
\hline 20.0 & 0.11 & & 2.15 & 2.46 & 0.18 \\
\hline [a] & $\frac{\rho_{f}}{\rho_{g}}=25.56$ & $f^{=47.85}$ & Void & fraction $=0.497$ & \\
\hline
\end{tabular}


TABLE VI

ROUHANI MODEL WITH VOID FRACTION VARIED, LOFT TEST LI-2, INSTRUMENTATION LOCATION BL-1, 8 SEC AFTER BLOWDOWN ${ }^{[a]}$

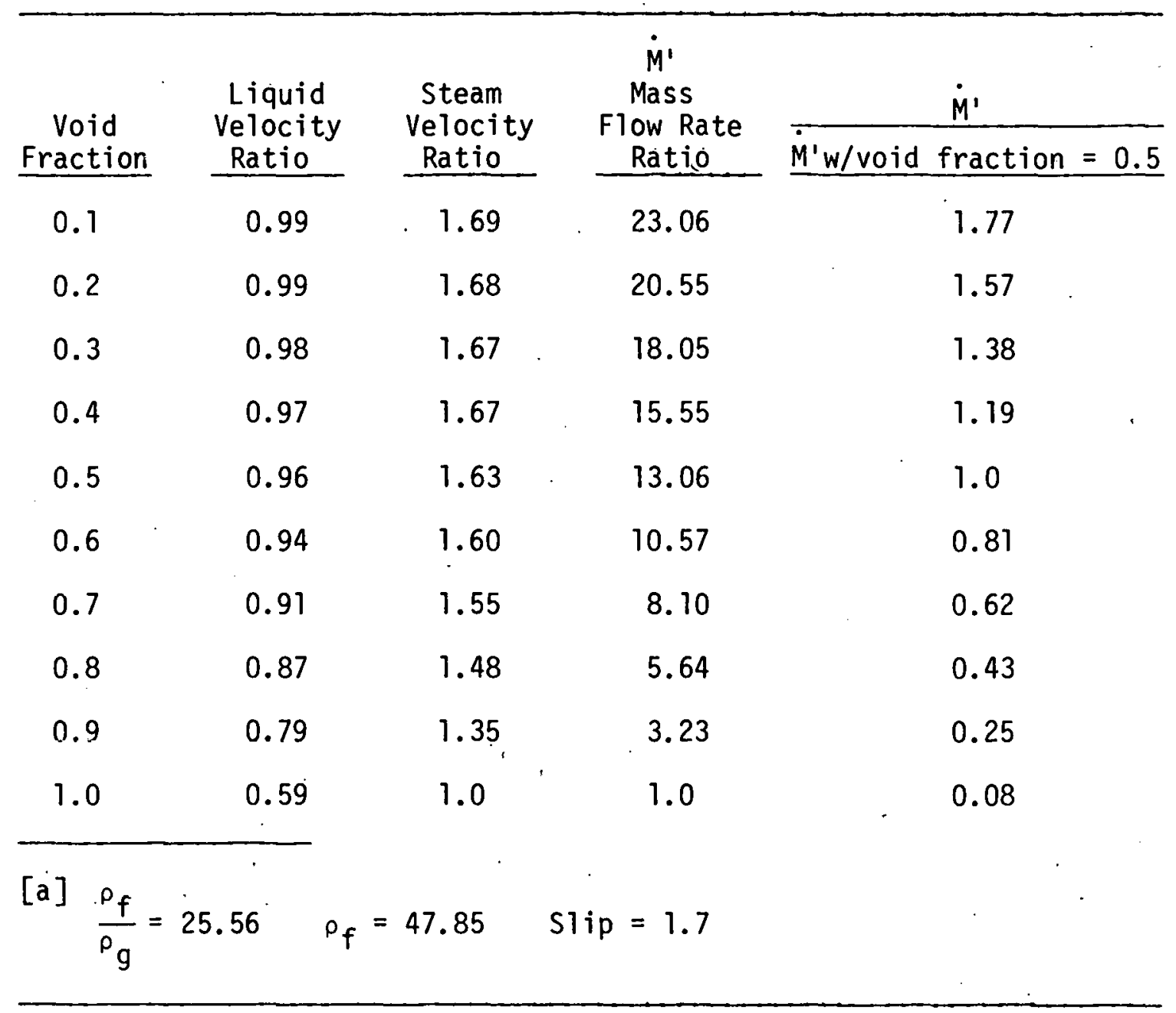




\section{TABLE VII}

ROUHANI MODEL WITH SLIP VARIED, LOFT TEST L1-2, INSTRUMENTATION LOCATION BL-1, 20 SEC AFTER BLOWDOWN ${ }^{\text {[a] }}$

\begin{tabular}{|c|c|c|c|c|c|}
\hline Slip & $\begin{array}{r}\text { Liquid } \\
\text { Velocity } \\
\text { Ratio } \\
\end{array}$ & $\begin{array}{l}\text { Steam } \\
\text { Velocity } \\
\text { Ratio } \\
\end{array}$ & $\begin{array}{c}\text { M' } \\
\text { Mass } \\
\text { Flow Rate } \\
\text { Ratio } \\
\end{array}$ & & $\frac{\dot{M^{\prime}}}{\left.\dot{M}^{\prime} w / s\right] i p}=1.0$ \\
\hline 0.2 & 1.05 & 0.27 & 3.30 & & 0.85 \\
\hline 0.4 & 7.07 & 0.43 & 3.56 & & 0.92 \\
\hline 0.6 & 1.07 & 0.64 & 3.75 & & 0.97 \\
\hline 0.8 & 1.01 & 0.83 & 3.85 & & 0.22 \\
\hline 1.0 & 1.00 & 1.00 & 3.87 & & 1.00 \\
\hline 2.0 & 0.72 & 1.45 . & 3.47 & & 0.90 \\
\hline 4.0 & 0.38 & 1.50 & .2 .49 & & 0.64 \\
\hline 6.0 & 0.24 & 1.41 & 1.99 & & 0.51 \\
\hline 8.0 & 0.17 & 1.34 & 1.72 & $\cdots$ & 0.44 \\
\hline 10.0 & 0.13 & 1.28 & 1.56 & & 0.40 \\
\hline 12.0 & 0.10 & 1.24 & 1.45 & s & 0.37 \\
\hline 14.0 & 0.086 & $1: 21$ & $1 . .37$ & & 0.35 \\
\hline 16.0 & 0.07 .4 & 1. 19. & 7.31 & & 0.34 \\
\hline 1.8 .0 & 0.065 & 1.17 & 1.26 & & 0.33 \\
\hline 20.0 & .0 .058 & 1.15 & 1.23 & & 0.32 \\
\hline [a] & $\frac{\rho_{f}}{\rho_{g}}=36.54$ & $\rho_{f}=50.09$ & Void Fraction $=0$ & .919 & \\
\hline
\end{tabular}




\section{TABLE VIII}

ROUHANI MODEL WITH VOID FRACTION VARIED,

LOFT TEST L1-2, INSTRUMENTATION LOCATION BL-1, 20 SEC AFTER BLOWDOWN [a]

\begin{tabular}{|c|c|c|c|c|}
\hline \multirow{2}{*}{$\begin{array}{c}\text { Void } \\
\text { Fraction } \\
\end{array}$} & \multirow{2}{*}{$\begin{array}{c}\text { Liquid } \\
\text { Velocity } \\
\text { Ratio } \\
\end{array}$} & \multirow{2}{*}{$\begin{array}{c}\text { Steam } \\
\text { Velocity } \\
\text { Ratio } \\
\end{array}$} & \multirow{2}{*}{$\begin{array}{c}\dot{M}^{\prime} \\
\text { Mass } \\
\text { Flow Rate } \\
\text { Ratio } \\
\end{array}$} & $\dot{M}^{\prime}$ \\
\hline & & & & $\dot{M}^{\prime} w /$ void fraction $=0.9$ \\
\hline 0.1 & 1.00 & 1.79 & 32.92 & 7.78 \\
\hline 0.2 & 0.99 & 1.78 & 29.31 & 6.93 \\
\hline 0.3 & 0.98 & 1.77 & 25.69 & 6.07 \\
\hline 0.4 & 0.98 & 1.76 & 22.08 & 5.22 \\
\hline 0.5 & 0.96 & 1.73 & 18.48 & 4.37 \\
\hline 0.6 & 0.95 & 1.71 & 14.88 & 3.52 \\
\hline 0.7 & 0.92 & 1.66 & 11.29 & 2.67 \\
\hline 0.8 & 0.88 & 1.59 & 7.73 & 1.83 \\
\hline 0.9 & 0.80 & 1.44 & 4.23 & 1.00 \\
\hline 1.0 & 0.50 & 1.00 & 1.00 & 0.24 \\
\hline ] $\frac{\rho_{f}}{\rho_{g}}$ & & 50.09 & Slip $=1.8$ & \\
\hline
\end{tabular}




\section{DRAG DISC IN SINGLE- AND TWO-PHASE FLOWS}

\section{INTRODUCTION}

The force acting on a given drag disc in both single- and two-phase flows depends upon the two-phase fluid density, two-phase fluid vapor pressure, two-phase fluid absolute pressure, two-phase fluid velocity, two-phase fluid viscosity, and the diameter of the target ${ }^{[26]}$. These variables can be combined into two dimensionless ratios denoted as Reynolds number and cavitation number. The force on the drag disc can then be written as

$$
\frac{F}{(1 / 2)_{H}, V^{2} A}=G\left(\frac{V d \rho}{\mu}, \frac{P-p_{0}}{(1 / 2) \mu v^{2}}\right)
$$

where

$$
\begin{aligned}
& \mathrm{F} \quad=\text { force on the drag disc } \\
& \mathrm{P}=\text { fluid pressure } \\
& \rho \quad=\text { fluid density } \\
& \mathrm{P}_{\mathrm{O}}=\text { cavity pressure usually taken to be the fluid vapor pressure } \\
& \mathrm{V}=\text { fluid velocity } \\
& \mu \quad=\text { fluid viscosity } \\
& \mathrm{d}=\text { diameter of drag disc } \\
& \mathrm{G}=\text { an unknown function } \\
& \mathrm{A}=\text { area of drag disc normal to flow. }
\end{aligned}
$$

Preliminary thought is that since the pressure during blowdown is very close to saturation, cavitation almost certainly occurs. Since it did not occur during calibration then rather large unpredicted differences in drag force are possible. Future investigations should address this question.

The experimental data cited in Sections II and III for the turbine are also available for the drag disc. Certain data are investigated in this section in an effort to better understand what the drag disc senses, and thus, reduce the scatter in the calibration data. The disc response to a step change in fluid velocity is determined, and weight calibration is discussed. 


\section{ANALYSIS OF THE DRAG DISC}

The drag disc is composed of a flat circular disc attached to a round rod, which in turn is connected to a torsion arm. Also attached to the torsion arm is a variable reluctance coil which is employed to sense the twist in the torsion arm (see Figure 16). Fluid forces acting on the disc and rod result in a moment about the torsion arm. Thus, the drag disc transducer output represents a moment about its torsion arm and not momentum flux. An analysis of the drag disc follows.

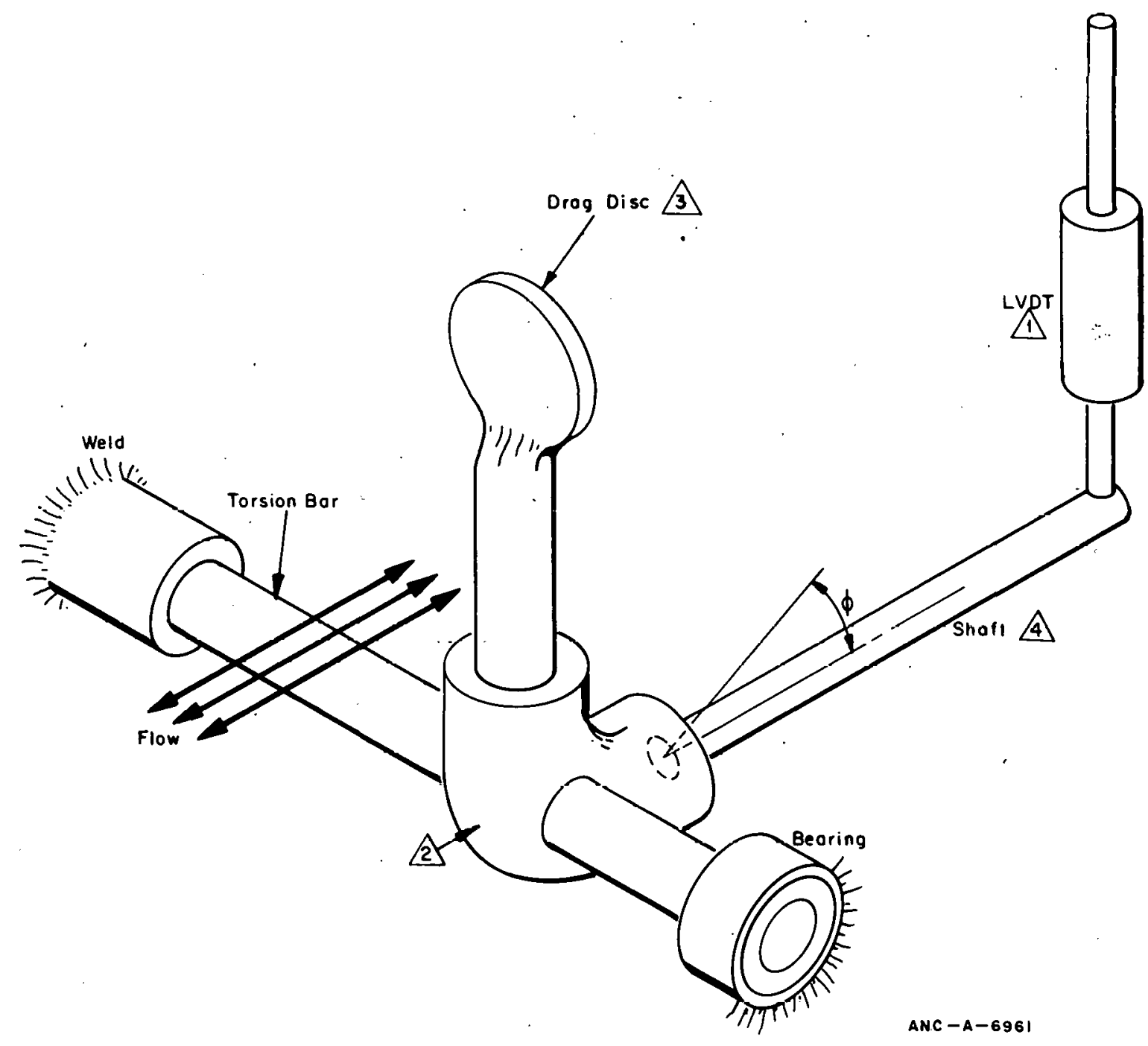

Fig. 16 Schematic of the drag disc. 
It is assumed that the two-phase flow is dispersed and that the flow forces acting on the disc and rod are uniformly distributed over the surfaces. It is also assumed that no cavitation occurs. The moment $M$ acting about the torsion arm is then (see Figure 17)

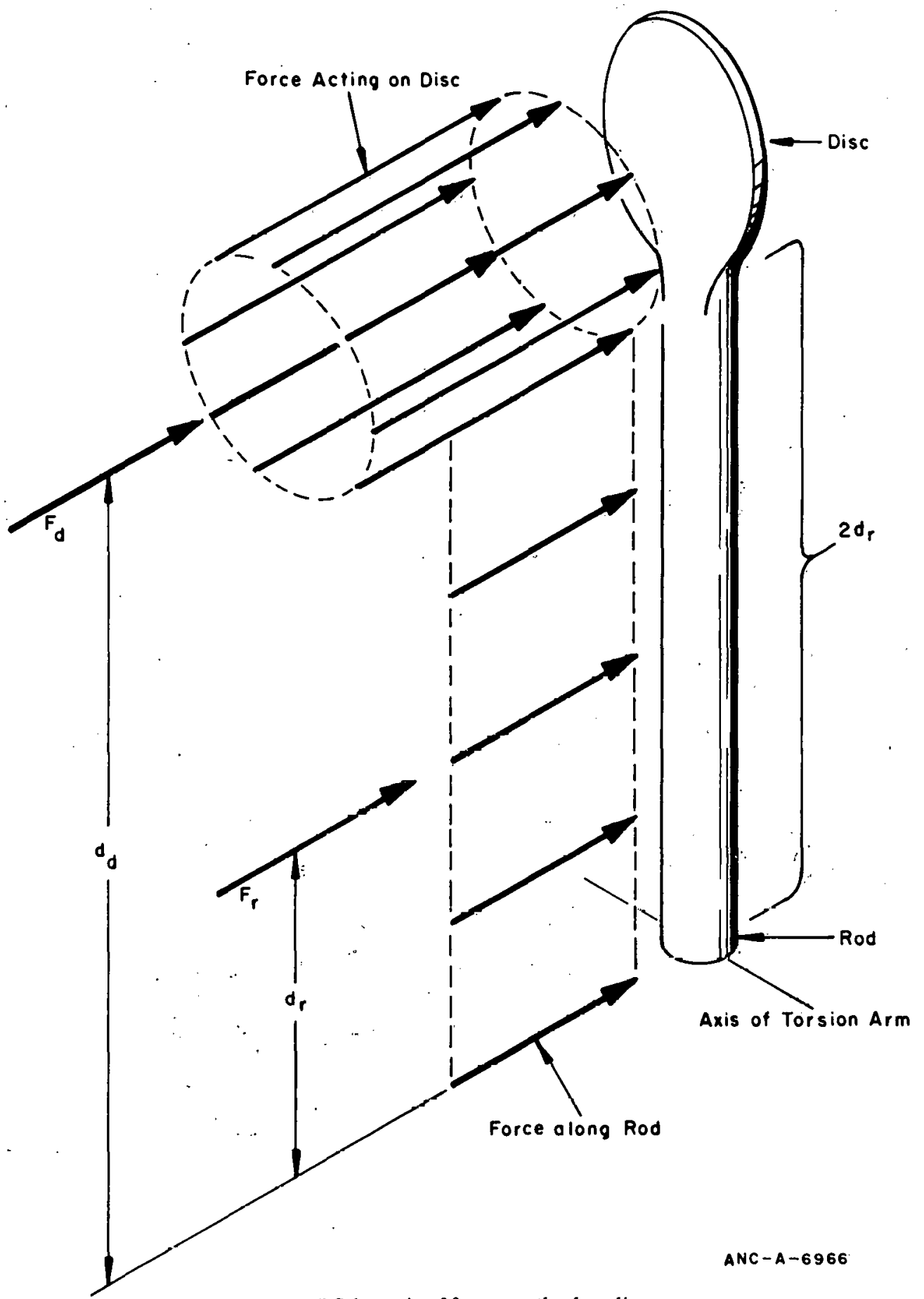

Fig. 17 Schematic of forces on the drag disc. 


$$
M=F_{d} d_{d}+F_{r} d_{f}
$$

where

$$
\begin{aligned}
& F_{r}=\text { the force acting on the rod } \\
& F_{d}=\text { the force acting on the disc } \\
& d_{r}=\begin{array}{l}
\text { the distance from the axis of the torsion arm to the } \\
\text { midpoint of the rod }
\end{array} \\
& d_{d}=\text { the distance from the axis of the torsion arm to the } \\
& \text { midpoint of the disc. }
\end{aligned}
$$

For two-phase flow, it is assumed that the forces are produced from steam and liquid. The forces may be written as ${ }^{[26]}$

$$
F=\left[(1 / 2) \rho V^{2} C A\right] \text { steam }+\left[(1 / 2) \rho V^{2} C A\right] \text { 1iquid }
$$

where

$$
\begin{aligned}
& \rho=\text { the mass density } \\
& \mathrm{V}=\text { the velocity } \\
& \mathrm{C}=\begin{array}{l}
\text { a drag coefficient which is assumed to depend upon } \\
\text { Reynolds number }
\end{array}
\end{aligned}
$$

A = the area over which the force is acting.

For two-phase dispersed flow, the expression for moment becomes

$$
\begin{aligned}
M & =(1 / 2) \rho_{g} V_{g}{ }^{2} C_{g d} A_{g d} d_{d}+(1 / 2) \rho_{f} V_{f}{ }^{2} C_{f d} A_{f d} d_{d} \\
& +(1 / 2) \rho_{g} V_{g}{ }^{2} C_{g r} A_{g r}{ }^{d}+(1 / 2) \rho_{f} V_{f}{ }^{2} C_{f r} A_{f r} d_{r}
\end{aligned}
$$

where subscripts $\mathrm{g}$ and $\mathrm{f}$ represent steam and liquid, and $\mathrm{r}$ and $\mathrm{d}$ represent rod and disc.

Since

$$
\alpha A=A_{g} \text { and }(1-\alpha) A=A_{f}
$$


where $\alpha$ is the void fraction, the foregoing equation becomes

$$
\begin{aligned}
M & =(1 / 2) \rho_{g} V_{g}{ }^{2} C_{g d} \alpha A_{d}{ }_{d}+(1 / 2) \rho_{f} V_{f}{ }^{2} C_{f d}(1-\alpha) A_{d} d_{d} \\
& +(1 / 2) \rho_{g} V_{g}{ }^{2} C_{g r} \alpha A_{r}{ }{ }_{r}+(1 / 2) \rho_{f} V_{f}{ }^{2} C_{f r}(1-\alpha) A_{r} d_{r}
\end{aligned}
$$

where $A_{d}$ and $A_{r}$ are the areas of the disc and rod.

The variation of the drag coefficient for discs and rods with Reynolds number may be seen in Figures 18 and 19. It should be noted that a drastic change in the drag coefficient occurs for the rod at a Reynolds number between $10^{5}$ and $10^{6}$. Equation (46) may be simplified by assuming that

$$
\begin{aligned}
& c_{\text {gr }}=\dot{C}_{f_{1}}-C_{p}=1.2 \\
& c_{\text {gd }}=c_{f d}=c_{d}=1.17 .
\end{aligned}
$$

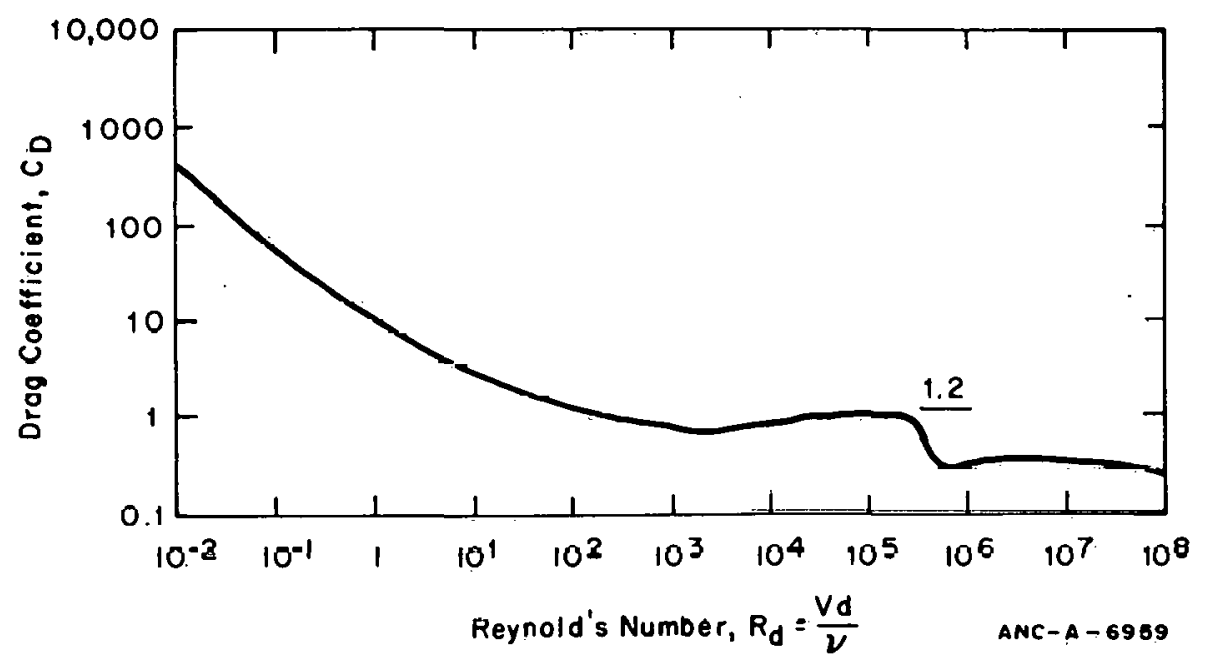

Fig: 18 Drag coefficient of a circular cylinder in a flow normal to the axis as a function of Reynolds number (Reference 26, Chapter III, Figure 29). 


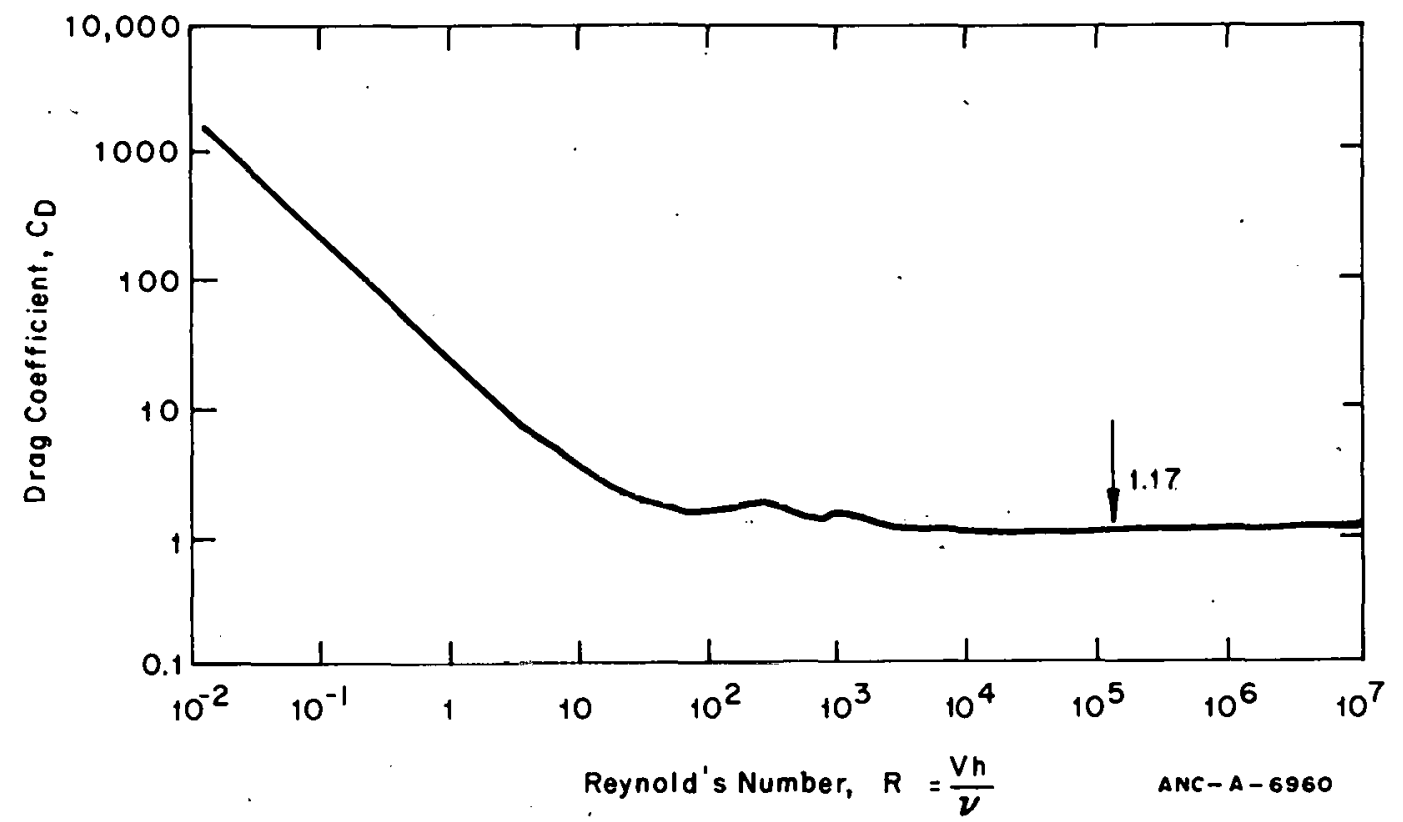

Fig. 19 Drag coefficient of circular and square plates (in normal flow) as a function of Reynolds number (Reference 26, Chapter III, Figure 29).

For the present LOFT design $A_{r}, A_{d}, d_{r}$, and $d_{d}$ are as shown in Table IX.

TABLE IX

DRAG DISC CONSTANTS

\begin{tabular}{|c|c|c|}
\hline Constant & $\begin{array}{l}\text { Plenum } \\
\text { Meter }\end{array}$ & $\begin{array}{l}\text { Piping } \\
\text { Meter } \\
\end{array}$ \\
\hline$A_{r}$, in. ${ }^{2}$ & 0.0436 & 0.070 \\
\hline$A_{d}$, in. ${ }^{2}$ & 0.2827 & 0.0707 \\
\hline$d_{r}$, in. & 1.31 & 1.45 \\
\hline $\mathrm{d}_{\mathrm{d}}$, in. & 1.85 & 1.85 \\
\hline
\end{tabular}

Then,

$$
\Sigma M=\left(k_{r}+k_{d}\right)\left[\rho_{g} V_{g}{ }^{2} \alpha+\rho_{f} V_{f}{ }^{2}(1-\alpha)\right]
$$

where 


$$
\begin{array}{r}
k_{r} \cong(1 / 2) C_{r} A_{r} d_{r}=\left\{\begin{array}{l}
\frac{1.983}{10^{5}} \mathrm{ft}^{3} \text { plenum meter } \\
\frac{3.524}{10^{5}} \mathrm{ft}^{3} \text { piping meter }
\end{array}\right. \\
k_{d} \cong(1 / 2) C_{d} A_{d} d_{d}=\left\{\begin{array}{l}
\frac{1.771}{10^{4}} \mathrm{ft}^{3} \text { plenum meter } \\
\frac{4.428}{10^{5}} \mathrm{ft}^{3} \text { piping meter }
\end{array}\right.
\end{array}
$$

and

$$
k_{r}+k_{d} \cong\left\{\begin{array}{l}
\frac{19.69}{10^{5}} \mathrm{ft}^{3} \text { plenum meter } \\
\frac{7.952}{10^{5}} \mathrm{ft}^{3} \text { piping meter. }
\end{array}\right.
$$

For the WCL full flow tests the above approximation is accurate for most of the data. From the above results [Equation (48)] it is seen that the drag disc senses a quantity which involves the momentum fluxes of gas and liquid and the void fraction. By employing a densitometer to obtain void fraction, steam tables to obtain densities (once temperature is known), and slip from Thom's paper ${ }^{[28]}$, Equation (48) can be solved for gas and liquid velocities. Mass flow rate can then be calculated from Equation (16).

The application of the foregoing model based upon a water calibration to two-phase flow data, is presented in Section $\mathrm{V}$, technique five. The procedure has been applied to both the WCL and LOFT blowdown data and appears to be worth further investigation.

\section{COMPARISON OF THEORY WITH EXPERIMENT}

Single-phase water drag disc data are available for the Wyle tests and all subsequent tests. In Figure 20, momentum flux based upon average velocity ${ }^{[a]}$ is plotted as a function of drag disc volts. A comparison of Figures 5 and 20 indicates that the use of average velocity did not result in better agreement among the various data. Based upon average velocity, further comparisons between Wyle and ARA tests may be found in Appendix F. It is seen that the agreement for these data is better than for the WCL data, but average velocity does not account for all of the differences. See Table F-I for a summary of the comparisons.

[a] See Section II for a discussion of average flow velocity. 


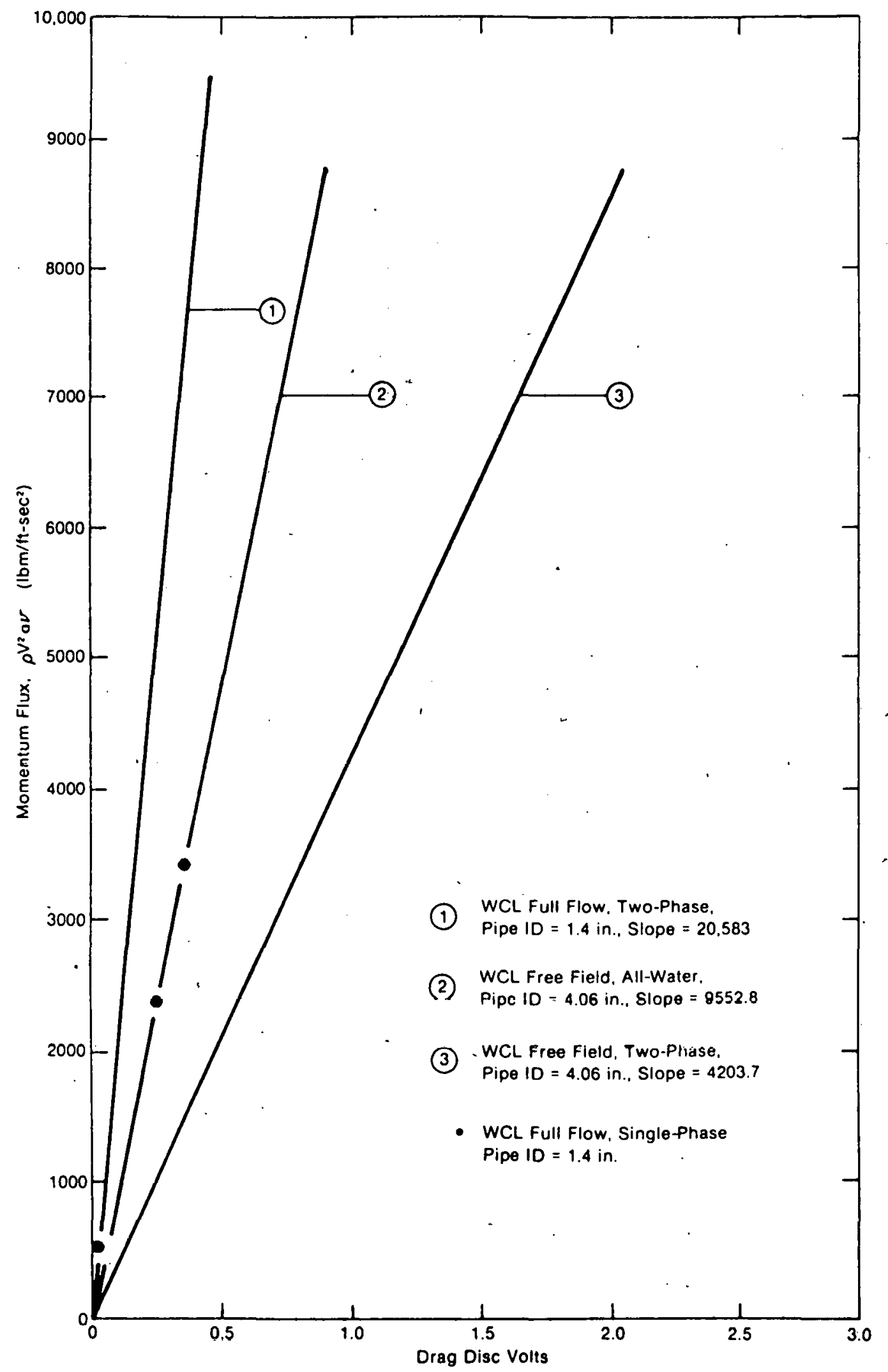

Fig. 20 Drag disc calibrations based on average velocity for WCL tests, single- and two-phase flows. 




Fig. 21 WCL free field, forward, two-phase flow, summation of moments versus drag disc volts.

WCL full flow and free field data for forward flow were employed to investigate the theory outlined in Section IV-2 for the drag disc. The reduced free field data may be seén in Figure 21 and compared with the basic momentum flux calibration data of Figure 6 . It is seen that for the free field data, the theory slightly increases the scatter in the calibration data. Basic calibration data for the WCL full flow condition may be seen in Figure 22 and compared with the reduced calibration data of Figure 23 . The reduced data has considerably less scatter in it than does the basic calibration data.

It is not possible to draw a conclusion about the theory of Section IV-2 from the foregoing information. The reduced data are better than the unreduced data for the full flow condition, but the reverse is true for the free field condition. Therefore, the theory is not the final answer as to what the drag disc senses in two-phase flow. 




Fig. 22 WCL full flow, forward, two-phase flow, momentum flux versus drag disc volts. 


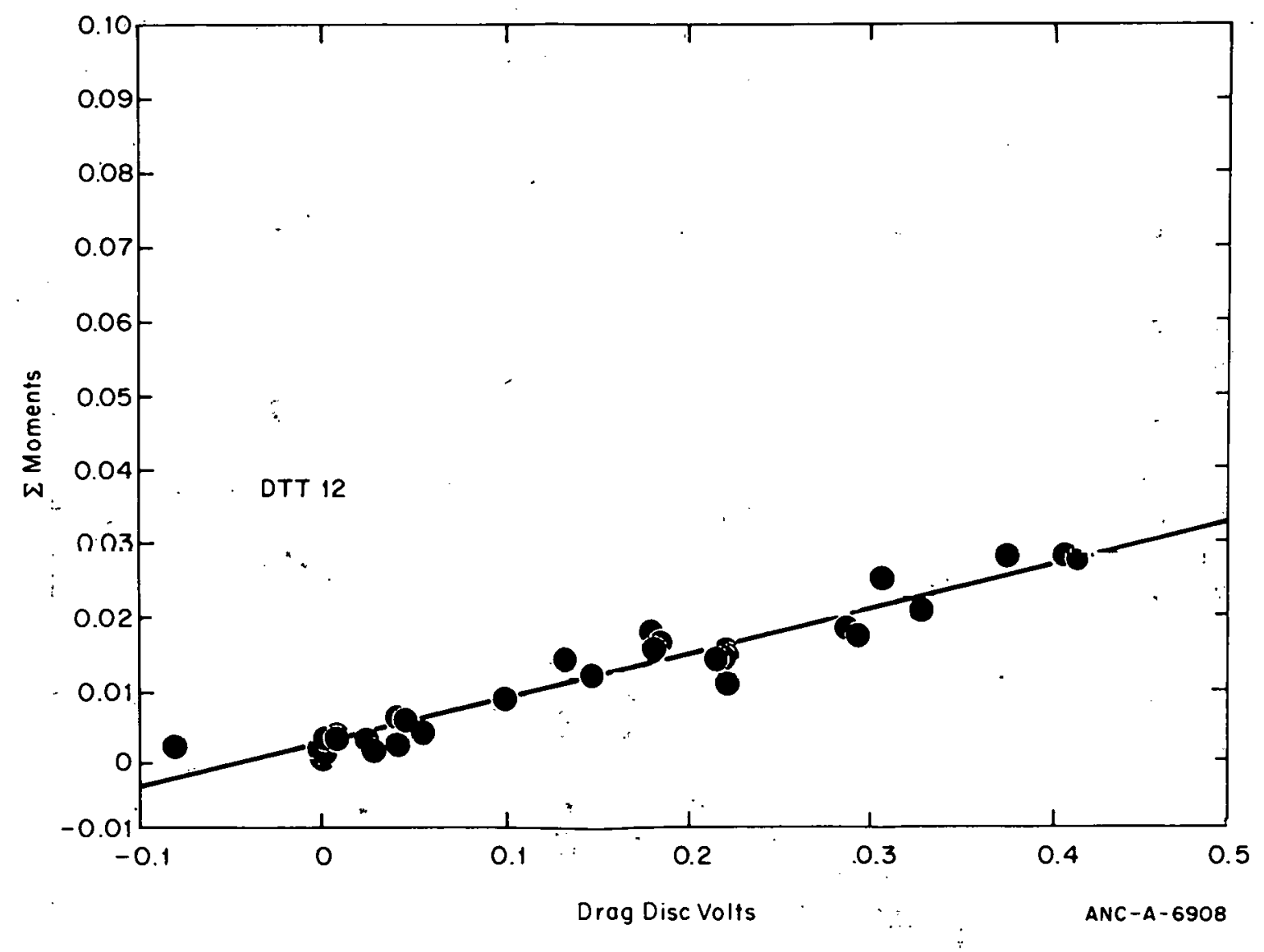

Fig. 23 WCL full flow, forward, two-phase flow, summation of moments versus drag disc volts.

\section{DYNAMIC RESPONSE OF THE DRAG DISC}

The response of the drag disc is limited by the electronics and the torsion arm support. Only the torsion support is considered herein, since the 10 to $9.0 \%$.rise time.for the electronics is estimated as $10 \mathrm{msec}$ (see Reference 1, page 40). The system is idealized as being a single degree of freedom system with zero damping, and the assumptions are:

(1) Friction from linear variable differential transducer (LVDT) motion is zero and does not affect the response

(2) Added mass coefficients calculated for harmonic oscillation in liquid are valid for transient motion in liquid

(3) Retarding force due to electromagnetic field is neglected.

A schematic of the drag disc may be seen in Figure 16. The equation of motion of the drag disc may be written as

$$
\ddot{I \phi}+\ddot{K \phi}=F(t)
$$


where
I = the mass moment of inertia of the moving components about the axis of rotation
$\mathrm{K}=$ the stiffness of the torsion arm
$\ddot{\Phi} \quad=\quad$ the angle of rotation
$F(t)=$ the forcing function.

From Reference 33, page 9,

$$
K=\frac{\pi d^{4} G}{32 L}
$$

where

$$
\begin{aligned}
& \mathrm{d}=\quad \begin{array}{l}
\text { the diameter of the torsion arm, and has a value of } 0.11 \mathrm{in} . \\
\text { for the piping meter and } 0.065 \mathrm{in} . \text { for the plenum meter }
\end{array} \\
& \mathrm{G}=\mathrm{E} /[2(1+\nu)] \\
& \mathrm{E}=25.1 \times 10^{6} \mathrm{psi} \text { is the modulus of elasticity at } 650^{\circ} \mathrm{F} \\
& \nu \quad=\quad 0.3 \text { is POISSON's ratio } \\
& \mathrm{L} \quad=\quad 0.7 \mathrm{in} \text { (plenum and piping) is the length of the torsion bar. }
\end{aligned}
$$

The mass moment of inertia is composed of the moment of inertia of the metal and the moment of inertia due to the resistance of the water. The resistance of the water is usually accounted for by adding an equivalent mass to the structure ${ }^{[a]}$. The values calculated for the various parts noted in Figure 16 are listed in Table X.

Substituting into the goveming equation for $\mathrm{K}$ and $\mathrm{I}$ yields the natural circular frequency squared $\omega_{n}{ }^{2}$ and the natural circular frequency (see Table XI). Using the data of Reference 34 , the 10 to $90 \%$ rise time of the drag disc in water is estimated as $1 \mathrm{msec}$ for the piping unit and $3 \mathrm{msec}$ for the plenum unit. The major assumption concerning the results is that friction is negligible. Experimental verification of the above frequency prediction has been done for the plenum unit. The natural frequency was determined to be $48 \mathrm{cps}$ in air versus a predicted value of $62 \mathrm{cps}$. This is considered to be a satisfactory agreement for the purposes of the present calculation.

[a] The values for the hydrodynamic (added) mass per unit length were obtained from Figure 3 and 4 of Reference 35. 


\section{TABLE $X$}

MASS MOMENTS OF INERTIA AND STIFFNESSES FOR THE DTT DISC

\begin{tabular}{|c|c|c|c|c|}
\hline \multirow[b]{2}{*}{ Component $^{[\mathrm{a}]}$} & \multicolumn{2}{|c|}{ Piping } & \multicolumn{2}{|c|}{ Plenum } \\
\hline & $\begin{array}{l}\text { Added Mass } \\
\text { Moment of } \\
\text { Inertia Due } \\
\text { to Water } \\
\end{array}$ & $\begin{array}{c}\text { Metal Mass } \\
\text { Moment of } \\
\text { Inertia } \\
\end{array}$ & $\begin{array}{l}\text { Added Mass } \\
\text { Moment of } \\
\text { Inertia Due } \\
\text { to Water } \\
\end{array}$ & $\begin{array}{l}\text { Metal Mass } \\
\text { Moment of } \\
\text { Inertia } \\
\end{array}$ \\
\hline & I" & I & $I^{\prime \prime}$ & I \\
\hline 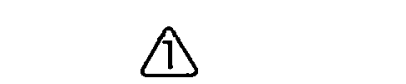 & $0.15 / 10^{5}$ & $3.47 / 10^{\overline{5}}$ & $0.15 / 10^{5}$ & $3: 47 \% 10^{5}$ \\
\hline 21 & $0.008 / 10^{5}$ & $0.06 / 10^{5}$ & $0.008 / 10^{5}$ & $0.06 / 10^{5}$ \\
\hline$\hat{3}$ & $1.56 / 10^{5}$ & $2.33 / 10^{5}$ & $5.39 / 10^{5}$ & $4.36 / 10^{5}$ \\
\hline 4 & $2.23 / 10^{5}$ & $5.52 / 10^{5}$ & $2.23 / 10^{5}$ & $5.52 / 10^{5}$ \\
\hline Sub Total & $3.95 / 10^{5}$ & $11.38 / 10^{5}$ & $7.78 / 10^{5}$ & $13.41 / 10^{5}$ \\
\hline $\begin{array}{l}\text { Total }{ }^{[a]} \\
\text { in water }\end{array}$ & 15 & 53. & . & \\
\hline Stiffness $[c], k$ & & & & \\
\hline [a] See Figure 16 & for compone & & & \\
\hline [b] Units are Ibf & $\sec ^{2}$ in. & . & . & \\
\hline [c] Units are lbf- & -in./radian. & & . & . \\
\hline
\end{tabular}


TABLE XI

FREQUENCIES AND RISE TIMES FOR THE DTT. DISC (CALCULATED)



\section{WEIGHT CALIBRATION}

To establish, without tlow testing, whether or not a drag disc is operating similarly to previously fabricated units, weight calibration was investigated (Appendix $\mathrm{H}$ ). It is shown in that reference that weight calibrations agree very well with Wyle all-water calibration data. If the Wyle data are corrected to reflect an average flow velocity, then the data are not in good agreement. Therefore, it appears that weight calibrations are valid and should agree reasonably well with uncorrected Wyle calibration data.

Friction problems with the weight calibrations cause the loading and unloading paths to be different if the DTT is not vibrated by taping during the calibration process. It appears that some vibrational technique during calibration should be used to settle the disc. 


\section{APPLICATION OF TURBINE AND DRAG DISC DATA TO TWO-PHASE FLOW}

Five methods of estimating the mass flow rate from the drag disc data, turbine data, and densitometer data are discussed in this section. All the methods involving the drag disc and turbine assume that the flow is uniform over the pipe cross section. Only method number two could be applied to the available two-phase flow data.

One method is to apply the all-water calibration to the test data. Turbine output voltage yields some average flow velocity, while drag disc volts yield some average momentum flux. Given the water calibrations

$$
\begin{gathered}
\text { Vel }=c_{1} V_{\text {ot }}+c_{2} \\
\rho(V e])^{2}=c_{3} V_{\text {oD }}+C_{4}
\end{gathered}
$$

where

$$
\begin{array}{ll}
\text { V.el } & \text { some average flow velocity } \\
\mathrm{C}_{1} \text { and } \mathrm{C}_{2}= & \text { the turbine calibration constants } \\
\mathrm{V}_{\text {ot }}= & \text { the turbine output during test in volts } \\
\mathrm{C}_{3} \text { and } \mathrm{C}_{4}= & \text { the drag disc calibration constants. } \\
\mathrm{V}_{\mathrm{OD}} & \text { the drag disc output during test in }
\end{array}
$$

The average mass flow rate can be estimatẻd as

$$
\dot{M}_{t}=\frac{\rho\left(V_{e l}\right)^{2}}{\left(V_{e} l\right)} \text {. }
$$

Substituting Equations (54) and (55) into (56) yields

$$
\dot{\bar{M}}_{\mathrm{t}}=\frac{C_{3} V_{\mathrm{ou}}+C_{4}}{C_{1} V_{o t}+C_{2}} A .
$$

A second technique is to apply one of the three turbine models presented in Section III. Drag disc data are not needed with this method. Required lest irformation for this model is slip, temperature, and void fraction or flowing quality. From Equation (17), once slip is known, quality may be replaced by void fraction which may be obtained from the densitometer. 
The third method employs the all-water turbine. calibration to obtain velocity and a gamma densitometer to obtain density. The mass flow rate is calculated as

$$
\dot{M}=(\rho V) \times A
$$

where $A$ is the flow area.

With the fourth technique, the drag disc and densitometer are employed to obtain the mass flow rate

$$
\dot{M}=A \sqrt{\rho \times\left(\rho V^{2}\right)} \text {. }
$$

The theory of Section IV-2 can be employed (fifth technique) in conjunction with an all-water drag disc calibration and a densitometer. From Equation (48)

$$
\left(K_{r}+K_{d}\right)\left[\rho_{g} V_{g}^{2} \alpha+\rho_{f} V_{f}^{2}(1-\alpha)\right]=A_{0}+A_{1} V_{d}
$$

where $A_{o}$ and $A_{1}$ are general calibration constants, and $V_{d}$ is the drag disc voltage output.

For an all-water test, the equation reduces to

$$
\rho_{f} v_{f}^{2}=\frac{\left(A_{0}+A_{1} V_{d}\right)}{\left(K_{r}+K_{d}\right)}
$$

The regular calibration for the drag disc has the form

$$
\rho_{f} v_{f}^{2}=c_{0}+c_{1} v_{d}
$$

By equating the two expressions for momentum flux

$$
A_{0} \equiv C_{0}\left(K_{r}+K_{d}\right) A_{1}=C_{1}\left(K_{r}+K_{d}\right) .
$$

The calibration equation is then

$$
\rho_{g} v_{g}^{2} \alpha+\rho_{f} v_{f}^{2}(1-\alpha)=c_{0}+c_{1} \cdot v_{d} .
$$


Noting that $\mathrm{S}=\frac{\mathrm{V}_{\mathrm{g}}}{\mathrm{V}_{\mathrm{f}}}$ the foregoing equation can be solved for $\mathrm{V}_{\mathrm{f}}$ to yield

$$
v_{f}=\sqrt{\frac{\left(C_{0}+C_{1} \cdot v_{d}\right)}{\rho_{g} s^{2} \alpha+\rho_{f}(1-\alpha)}} .
$$

The term in the numerator is the momentum flux as calculated from an all-water calibration. The mass flow rate can then be determined from Equation (16). 


\section{RESULTS, CONCLUSIONS, AND RECOMMENDATIONS}

\section{RESULTS AND CONCLUSIONS}

Based upon the investigation outlined in this report, the following results are obtained and conclusions drawn:

(1) For all-water flow in pipes up to and including 11-in. ID, the presence of the DTT disrupts the velocity profile to the extent . that the turbine meter output is proportional to average velocity. The drag disc output is approximately proportional to momentum flux calculated using average velocity. However, the available drag disc data are not correlated as well by this parameter as are the turbine data.

(2) For the test data analyzed (WCL free field and full flow tests in vertical, steady state flow), the three two-fluid models reduce the scatter as compared to a simple homogeneous model. The Aya and Rouhani models yield results which agree closely with each other. However, the predicted velocities from these models (steam and liquid) differ significantly from those predicted from the volumetric flow model. The ecatter in the data for the Aya and Rouhani models is generally less than that for the volumetric flow models. Predicted mass flow rates for the volumetric flow model are less accurate than the other two models for the full flow tests, but more accurate for the free field test. Thus, one model does not fit all the available data better than the other two models and there is little difference between the Aya and Rouhani models.

(3) For any given model, predicted steam and liquid velocities for forward flow agree closely with those for reverse flow. It is concluded from this that cavities and other flow distrubances caused by the drag disc do not significantly affect the turbine. For example, forward and reverse flow for the Rouhani model agree closely, similarly for the volumetric flow model. However, the two models do not yield results which agree with each other.

(4) For the Rouhani model applied to the WCL free field tests in forward flow, the results for the "best estimate" of slip and slip equal 1.0, agree very closely. This suggests that the turbine meter behavior in two-phase flow is primarily controlled by the liquid phase. If it is assumed that the Rouhani model is valid for the WCL tests, then the suggestion is logical since the slip ratios were 
low (less than 3.1 ) and the density ratios (liquid to steam) were high (22 to 147). Thus, the change in momentum of the liquid, rather than the change in momentum: of the steam, dominates the turbine meter behavior. This condition is expected to remain valid for LOFT tests since the slip ratio is not expected to exceed 6.0 .

(5) The turbine 10 to $90 \%$ rise time is estimated to be about $0.29 \mathrm{sec}$ in water and $11.9 \mathrm{sec}$ in steam. Unreported experimental data indicate that the response in water is approximately $.05 \mathrm{sec}$. The estimated response in steam is also too large, since simply blowing on the meter causes the meter to react within about 1 sec. Thus, the theoretical response estimates are not accurate enough for the turbine.

(6) The theory presented in Section IV-2 for the behavior of the drag disc in two-phase flow correlates the WCL full flow two-phase data but not the free field data.

(7) The drag disc has. a fast response with a 10 to $90 \%$ rise time in water being estimated as $3 \mathrm{msec}$ for the piping unit and $1 \mathrm{msec}$ for the plenum unit.

\section{RECOMMENDATIONS}

For the purpose of understanding the data obtained during LOFT tests. with the drag disc turbine transducers, the following recommendations are made.

(1) For the turbine and drag disc in two-phase flow, the effects of horizontal orientation, pipe size, and pipe geometry are felt to be significant and should be experimentally investigated. Cavitation may prove to be a problem and should also be investigated. Although some transient two-phase data are available for turbines, it is valid only for the full flow configuration in small pipes and is not applicable to LOFT tests. The renommended tests should answer questions like what do the turbine and drag disc measure when (a) stratified flow occurs with some portion of the turbine and disc being immersed in the flow and (b) slug flow occurs where the slug can either elongate or go around the DTT. The tests should also answer questions relating to interpreting the LOFT gamma densitometer readings.

(2) For LOFT, it is recommended that the drag disc turbine and densitometer be employed simultaneously to estimate the mass 
flow rate. Densitometer coverage is mandatory for tests conducted in large pipes with only a single DTT unit located within the pipe. A minimum of three beams is recommended with the more beams used, the greater the understanding of the flow regime at the DTT location. All three turbine models should be investigated as should the drag disc model. Theoretical predictions should then be compared with the experimentally measured values. When agreement is reached far greater confidence in the modeling will be obtained.

(3) The discrepancy in predicted velocities between the volumetric flow model and the Rouhani and Aya models should be resolved.

(4) A single point measurement in a large pipe is not sufficient for understanding the flow behavior over the cross section. Either many point measurements and/or full flow instrumentation are required since the flow distribution cannot be predicted from theory. It is recommended that a full flow turbine be considered for future tests. 


\section{REFERENCES}

1. S. Silverman, LOFT Drag Disc Turbine Uncertainty Analysis, TREE-NUREG-1102 (April 1977).

2. S. P. Hutton, "The Effect of Inlet Flow Conditions on the Accuracy of Flowmeters," Proceedings of the Conference on Component Interactions in Fluid Flow Systems London, England, March, 7, 1974, Institute of Mechanical Engineers, London, England, 1975.

3. Z. Rouhani, "Application of the Turbine Type Flowmeters in the Measurement of Steam Quality and Void," Symposium on In-Core Instrumentation, Oslo, June 15-19, 1974, CONF-640607, Paper D-6, p 3.

4. H. Schlichting, Boundary-Layer Theory, 6th edition, New York: McGraw-Hill, 1968.

5. R. T. Lahey, Jr., Two-Phase Flow in Boiling Water Nuclear Reactors, NEDO-13388 (July 1974).

6. S. Levy, "Prediction of Two-Phase Pressure Drop and Density Distribution from Mixing Length Theory," Transactions of the ASME, Journal of Heat .Transfer (May 1963) p 137.

7. N. Zuber and J. A. Findlay, "Average Volumetric Concentration in Two-Phase Flow Systems," Transactions of the ASME, Journal of Heat Transfer (November 1965) p 453 .

8. Y. Taitel and A. E. Dukler, "A Model for Predicting Flow Regime Transitions in Horizontal and Near Horizontal Gas-Liquid Flow," AIChE Journal 22, (1976) pp 47:55.

9. M. R. Shafer, "Performance Characteristics of Turbine Flowmeters," Journal of Basic Engineering (December 1962) pp 471-485.

10. R. L. Thompson and J. Gray, "Turbine Flowmeter Performance Model," Journal of Basic Engineering Trans. ASME, 92D (December 1970) pp 713-723.

11. W. O. Strohmeier, "Turbine Flowmeters, Past, Present, and Future," Flow, Its Measurement and Control in Science and Industry, I (Part Two) Pittsburg: Instrument Society of America, 1974, pp 687-693.

12. D. E. Stuart, "An Advanced Turbine Flowmeter System with Density Compensation," Flow, Its Measurement and Control in Science and Industry, I (Part Two) Pittsburg: Instrument Socicty of America, 1974, pp 695-700. 
13. I. Warshawsky et al, "Small Turbine Type Flowmeters for Liquid Hydrogen," Flow, Its Measurement and Control in Science and Industry, I (Part Two) Pittsburg: Instrument Society of America, 1974, pp 709-791.

14. W. F. Z. Lee and H. J. Evans, "Density Effect and Reynolds Number Effect on Gas Turbine Flowmeters," Journal of Basic Engineering, Trans. ASME (December 1965) p 1043.

15. G. H. Stevens, "Dynamic Calibration of Turbine Flowmeters," Instruments and Control Systems (April 1970) p 109.

16. D. J. Higson and J. Instrum, "The Transient Performance of a Turbine Flowmeter in Water," Science 41 (1964).

17. J. Grey, "Transient Response of the Turbine Flowmeter," Jet Propulsion (ARS J), 26 (1956) pp 98-100.

18. C. B. Parsons, ANC Pump Simulator and LOFT Flow Meter [sic] Tests, Mod-2, CWAPD-251 1-5 (July 1974).

19. Internal Report.

20. Private Communication.

21. I. Aya, A Model to Calculate Mass Flow Rates and Other Quantities of Two-Phase Flow in a Pipe with a Densitometer, a Drag Disc, and a Turbine Meter, ORNL TM-47591 (November 1975).

22. Private Communication.

23. J. E. Hench and D. Olivia, Turbine Flowmeter, Calibration, and Instrumented Fuel Assembly Pressure Drop Garigliano Development Program, GEAP-4954 (October 1965).

24. H. W. Heiselmann, A. E. Arave, L. D. Goodrich, L. C. Worley, Design Development and Testing Status of the LOFT Drag Disc Turbine Transducer, ANCR-1201, (August 1974).

25. Private Communication.

26. S. F. Hoerner, Fluid Dynamic Drag, Midland Park, New Jersey: S. F. Hoerner, 1958.

27. C. A. Meyer (ed.), 1967 ASME Steam Tables, 2nd edition, New York: American Society of Mechanical Engineers, 1967. 
28. J. R. S. Thom; "Prediction of Pressure Drop During Forced Circulation Boiling of Water," International Journal of Heat Mass Transfer, 7 (1964) pp 709-724.

29. M. M. El-Wakil, Nuclear Heat Transport, Scranton, Pennsylvania: International Textbook, 1971.

30. G. W. Govier and K. Aziz, The Flow of Complex Mixtures in Pipes, New York: Van Nostrand Reinhold, 1972.

31 C. D. Hodgman, R. C. Weast, S. M. Selby, Handbook of Chemistry and Physics, 39th edition, Cleveland, Ohio: Chemical Rubber Publishing Company, 1957.

32. Ernst Schmidt, Propertiés of Water and Steam in SI-Units, Berlin: Springer Verlag, 1969.

33. S. P. Timoshenko, Vibration Problems in Engineering, 3rd edition, Princeton, New Jersey: D. Van Nostrand Co., 1961.

34. A. D. Wood and R. Cohen, "Table of Related Characteristics for Second Order Systems," ISA-Journal (October 1962) p 63.

35. B. V. Korvin-Krouskovsky, Theory of Seakeeping, New York: The Society of Naval Architects and Marine Engineers, 1961. 


\section{APPENDIX A}

\section{REDUCED DATA FOR WCL FULL FLOW TESTS}


THIS PAGE

\section{WAS INTENTIONALLY LEFT BLANK}




\section{APPENDIX A \\ REDUCED DATA FOR WCL FULL FLOW TESTS}

This appendix contains reduced data (see Tables A-I and A-II) from the WCL full flow tests. The raw data are presented in Reference A-1. 


\section{TABLE A-I}

REDUCED DATA FOR WCL FULL FLOW TESTS, FORWARD

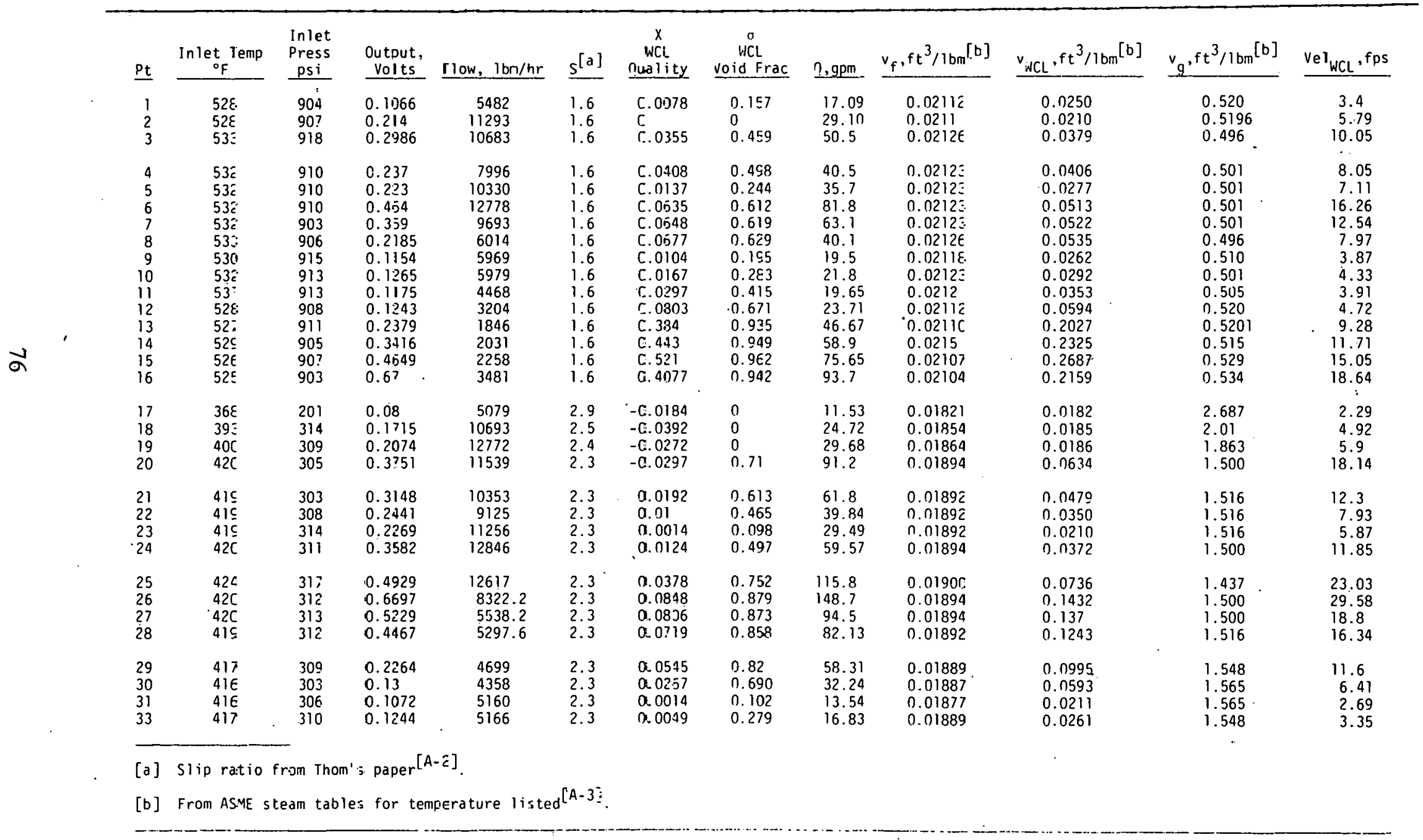


TABLE A-II

REDUCED DATA FOR WCL FULL FLOW TESTS, REVERSE

\begin{tabular}{|c|c|c|c|c|c|c|c|c|c|c|}
\hline$\underline{p_{t}}$ & $\begin{array}{l}\text { WCL } \\
\text { Void Fraction } \\
\text { a } \\
\end{array}$ & $\begin{array}{c}\text { Inlet Press } \\
\text { psi }\end{array}$ & $\begin{array}{c}\text { In let Temp } \\
\mathrm{F}\end{array}$ & $\begin{array}{r}V_{g}[a] \\
f t^{3} / 1 \mathrm{bm}\end{array}$ & $\begin{array}{r}v_{f}[a] \\
f t^{3} / 1 b m \\
\end{array}$ & $\underline{v_{g} / v_{f}}$ & $s(b)$ & $\begin{array}{l}\text { Output } \\
\text { volts } \\
\end{array}$ & $\mathrm{Vel}_{\mathrm{WCL}}, \mathrm{fpS}$ & $v_{W C L}, \mathrm{ft}^{3} / 1 \mathrm{bm}$ \\
\hline 57 & 0 & & & & & & & 0.1131 & 3.11 & \\
\hline 58 & 0 & . & & & & & & 0.2079 & 5.7 & 0.01885 \\
\hline 59 & 0 & 323 & 414 & 1.5991 & 0.01884 & 84.5 & 2.3 & 0.2065 & 5.67 & 0.01885 \\
\hline 60 & $0.372-.395$ & 310 & 417 & 1.548 & 0.01588 & 82 & 2.3 & 0.3275 & 9.38 & 0.0299 \\
\hline 62 & 0.764 & 319 & 423 & 1.. 452 & 0.01898 & 76.6 & 2.3 & 0.4943 & 12.76 & 0.0771 \\
\hline 63 & 0.868 & 317 & 422 & 1.4682 & 0.01897 & 77.4 & 2.3 & 0.6291 & 15.33 & 0.1327 \\
\hline 64 & 0.862 & 317 & 422 & 1.4682 & 0.01897 & 77.4 & 2.3 & 0.5598 & 13.70 & 0.1273 \\
\hline 65 & 0.866 & 315 & 419 & 1.516 & 0.01892 & 80 & 2.3 & 0.5148 & 12.61 & 0.1304 \\
\hline 66 & 0.867 & 310 & 417 & 1.548 & 0.01888 & 82 & 2.3 & 0.3049 & 21.25 & 0.1322 \\
\hline 67 & 0.825 & 310 & 417 & 1.548 & 0.01888 & 82 & 2.3 & 0.2215 & 5.59 & 0.1022 \\
\hline 68 & 0.8 & 312 & 418 & 1.532 & 0.01890 & 81.3 & 2.3 & 0.3291 & 8.40 & 0.0903 \\
\hline 69 & 0.726 & 311 & 417 & 1.548 & 0.01888 & 82 & 2.3 & 0.219 & 5.77 & 0.067 \\
\hline 71 & 0.763 & $311]$ & 417 & 1.548 & 0.01888 & $8 \hat{c}$ & 2.3 & 0.1037 & 2.70 & 0.0768 \\
\hline 72 & 0.214 & $31 ?$. & 417 & 1.548 & 0.01888 & $8 \varepsilon$ & 2.3 & 0.1310 & 3.87 & 0.024 \\
\hline 73 & 0.143. & $31 ?$ & 417 & 1.548 & 0.18888 & $8 \hat{c}$ & 2.3 & 0.1931 & 5.77 & 0.0221 \\
\hline 74 & 0.170 & 313 & 417 & 1.548 & 0.18888 & $8 i$ & 2.3 & 0.2388 & 7.10 & 0.0228 \\
\hline 75 & 0 & 314 & 418 & 1.532 & 0.01890 & 81.3 & 2.3 & 0.2194 & 4.78 & 0.018 \\
\hline 76 & 0.147 & 312 & 418 & 1.532 & -0.01890 & 81.3 & 2.3 & 0.1484 & 4.44 & 0.0222 \\
\hline 77 & 0.380 & 311 & 418 & 1.532 & 0.01890 & 81.3 & 2.3 & 0.1576 & 4.59 & 0.2062 \\
\hline 78 & 0.111 & 597 & 482 & 0.8015 & 0.02004 & 40 & 1.9 & 0.1293 & 3.90 & 0.2254 \\
\hline 79 & 0.412 & 609 & 485 & 0.778 & 0.02011 & 38.8 & 1.9 & 0.1631 & 4.65 & 0.0337 \\
\hline 80 & 0.655 & 589 & 589 & 0.8015 & 0.02004 & 40 & 1.9 & 0 & 7.17 & 0.0337 \\
\hline $\begin{array}{l}{[\mathrm{a}]} \\
{[\mathrm{b}]}\end{array}$ & \multicolumn{9}{|c|}{$\begin{array}{l}\text { Based on temperature from ASME steam tables } 1967: \text { Table } 1, p \text { 8 } 8{ }^{[A-3]} \text {. } \\
\text { Slip ratio from Thom's paper }{ }^{[A-2]} \text {. }\end{array}$} & - \\
\hline
\end{tabular}




\section{REFERENCES}

A-1. Internal Report.

A-2. J. R. S. Thom, "Prediction of Pressure Drop During Forced Circulation Boiling of Water," International Journal of Heat Mass Transfer, 7 (1964) pp. 709-724.

A-3. C. A. Meyer (ed.), 1967 ASME Steam Tables, 2nd edition, New York: American Society of Mechanical Engineers, 1967. 
APPENDIX B

LEGRAND/SILVERMAN THEORY FOR A TURBINE IN STEADY DISPERSED, TWO-PHASE FLOW 
THIS PAGE

WAS INTENTIONALLY

LEFT BLANK 


\section{APPENDIX B \\ LEGRAND/SILVERMAN THEORY FOR A TURBINE IN STEADY DISPERSED, TWO-PHASE FLOW}

The present theory is based upon ideas evolved while considering Aya's theory for turbine response ${ }^{[B-1]}$. As discussed in Section III-5, results predicted with Aya's theory agree reasonably well with experimental results. It was, therefore, felt that Aya's theory was heading in the correct direction. However, the aerodynamic aspects of Aya's theory seemed technically incomplete. The present theory assumes that the turbine is rotating at some nominal speed due to steady, dispersed, two-phase flow moving at some nominal flow velocity. The gas is assumed to be moving faster than the nominal flow velocity while the fluid is moving slower. It is assumed that the lift force of the gas tends to speed up the turbine while the lift and drag forces due to the liquid, and the drag force due to the gas, tend to slow it down. For steady flow, the resultant forces must be balanced and must result in the turbine turning at the nominal turbine speed. This force balance occurs if the velocity vector of the gas is on one side of the blade while the velocity vector of the fluid is on the other side (see Figure B-1). The force vectors are shown in Figure B-2. The notation used in the figures is defined as follows:

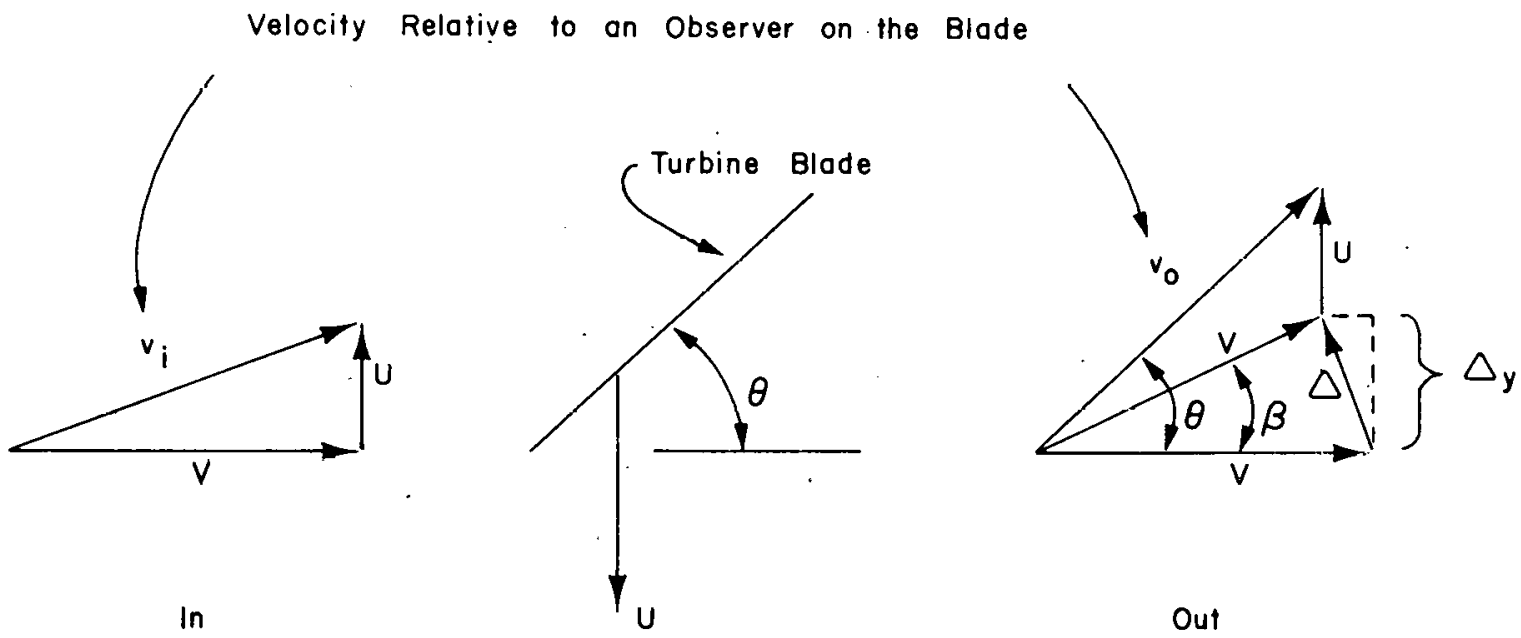

ANC - A- 7008

Fig. B-1 Velocity vectors for turbine blade and liquid.
$\mathrm{V}=$ absolute velocities
$v \quad=\quad$ velocities relative to an observer on the blade
$\mathrm{g}=$ gas
f $=$ water
Subscripts 




AnC A A T ToOT

Fig. B-2 Force vectors for turbine blade and liquid.

$\mathrm{t}=$ nominal velocity of flow $\} \quad$ Subscripts

$\mathrm{u}=$ turbine speed

$a=$ angle of attack relative to an observer on the blade

$\delta=$ blade angle of attack, absolıter

$\mathrm{F}_{\mathrm{Lg}}=\quad$ lift due to gas

$\mathrm{F}_{\mathrm{Dg}}=$ drag due to gas

$\mathrm{F}_{\mathrm{Lf}}=$ lift due to water

$\mathrm{F}_{\text {Dt }}=$ drag due to water.

From Figure B-2, the gas force acting normal to the turbine axis is

$$
F_{g}=F_{L g} \cos \left(\delta-\alpha_{g}\right)-F_{D g} \sin \left(\delta-\alpha_{g}\right)
$$


The lift and drag forces may be written as

$$
\begin{aligned}
& F_{L g}=(1 / 2) \rho_{g} \nu_{g}^{2} R C_{L g} A \\
& F_{D g}=(1 / 2) \rho_{g} \nu_{g}^{2} R C_{D g} A
\end{aligned}
$$

where

$$
\begin{array}{lll}
\mathrm{R} & = & \text { void fraction } \\
\rho_{\mathrm{g}} & = & \text { mass density of gas } \\
\mathrm{A} & = & \text { platform area of blade }=\text { chord } \mathrm{x} \text { length } \\
\mathrm{C}_{\mathrm{Lg}, \mathrm{G}_{\mathrm{Dg}}}= & \text { lift and drag coefficients for the gas. }
\end{array}
$$

By substituting Equation (B-2) and (B-3) into (B-1), $\frac{\mathrm{V}_{\mathrm{g}}}{\nu \mathrm{g}}$ for $\cos \left(\delta-\alpha_{\mathrm{g}}\right)$, and $\frac{\mathrm{u}}{\nu \mathrm{g}}$ for $\sin$ $\left(\delta-\alpha_{\mathrm{g}}\right)$ (See Figure B-1), the following is obtained

$$
F_{g}=K_{1} C_{L g} \nu_{g} v_{g}-K_{1} C_{D g} \nu_{g} u
$$

where

$$
K_{1}=(1 / 2) \dot{\rho}_{g} R A \text {. }
$$

From Figure B-1

$$
v_{g}^{2}=v_{g}^{2}+u^{2}
$$

Substituting Equation (B-5) into (B-4) yields for the expression $\mathrm{F}_{\mathrm{g}}$

$$
F_{g}=k_{1}\left(v_{g}^{2}+u^{2}\right)^{1 / 2}\left[C_{L g} v_{g}-C_{D g} u\right]
$$

The liquid force acting normal to the turbine axis is

$$
F_{f}=F_{L f} \cos \left(\delta+u_{f}\right)+F_{D f} \sin \left(\delta+u_{f}\right) .
$$

This expression may be simplified in the same manner as Equation $(\overline{\mathrm{B}}-1)$ yielding

$$
F_{f}=k_{2}\left(v_{f}^{2}+u^{2}\right)^{1 / 2}\left[c_{L f} v_{f}+c_{D f} u\right]
$$


where

$$
K_{2}=(1 / 2) \rho_{f}(1-R) A .
$$

For steady operation of the turbine, $F_{f}$ must equal $F_{g}$. This yields one equation with the following unknowns:

$$
V_{g}, V_{f}, R, u, C_{L}, C_{D}, \rho_{f}, \rho_{g} \cdot
$$

For a given test, the slip can be estimated from Reference $\mathrm{B}-2 ; \rho_{\mathrm{f}}$ and $\rho_{\mathrm{g}}$ can be obtained from Reference B-3 once temperature is known; $R$ must be obtained from a gamma densitometer; $C_{L}$ and $C_{D}$ are functions of $\alpha_{g}$ and $\alpha_{f}$ (see Figure B-1) and must be obtained from experiment or open literature, such as Reference B-4; and $u$ will be proportional to the turbine output. Thus, there is one equation and two unknowns, $V_{g}$ and $V_{f}$. It appears that another equation is required.

By equating Equations (B-7) and (B-8), dividing by $V_{f}^{2}$, and letting $y=\frac{V_{f}}{u}$, the following is obtained

$\frac{\rho_{g}}{\rho_{f}} \frac{R}{1-R}\left[\left(s^{2}+\frac{1}{y^{2}}\right)\right]^{1 / 2}\left[C_{L g} S-C_{D g} \frac{1}{y}\right]=\left[\left(1+\frac{1}{y^{2}}\right)\right]^{1 / 2}\left[C_{L f}+C_{D f} \frac{1}{y}\right]$

where $S$ is the slip ratio. Thus, by taking ratios of velocities, one equation and one unknown are obtained; Equation (B-9) is the governing lurbine equation. It is nonlinear and will become even more complex once expressions are substituted for $C_{L}$ and $C_{D}$.

From Reference B-4, the formulas obtained experimentally for lift and drag coefficients for flat plates in air are

$$
\begin{gathered}
C_{L}=\frac{\alpha}{\sqrt{6+54 \lambda}} \\
C_{D}=0.004+0.3 \frac{d}{a}+C_{L}(\sin \alpha)
\end{gathered}
$$

where $\alpha \leqslant 8$ is the angle of attack in degrees, $\mathrm{d}$ is the plate thickness (normal to flow for zero angle of attack), $a$ is the plate depth dimension in the flow direction for zero angle of attack, $\lambda=a / b$ is the plate depth to length ratio, and $b$ is the plate length normal to the flow.

The experimental data for air must be reevaluated for validity in water. In particular, the Reynolds number range for the tests must be established. If the range is not sufficiently wide to cover the liquid flow, then further tests are required.

It appears that an iterative technique is required to solve Equation (B-9) for $y$. The angles of attack for liquid and gas must be assumed. Lift and drag coefficients can then be calculated from Equations (B-10) and (B-11) and then substituted into Equation (B-9) 
which can then be solved for $y$. Knowing the gas and liquid velocities, the drag coefficients can be computed and checked against the assumed drag coefficients.

A considerable amount of work is required to apply the foregoing theory. In view of the present state-of-the-art of two-phase flow measurement, the additional effort is probably not justified unless the other three models are shown to be unacceptably poor for blowdown conditions.

\section{REFERENCES}

B-1. I. Aya, A Model to Calculate Mass Flow Rates and Other Quantities of Two-Phase Flow in a Pipe with a Densitometer, a Drag Disc, and a Turbine Meter, ORNL TM-47591 (November 1975).

B-2. J. R. S. Thom, "Prediction of Pressure Drop During Forced Circulation Boiling of Water," International Journal of Heat Mass Transfer, 7 (1964) pp 709-724.

B-3. C. A. Meyer (ed.), 1967 ASME Steam Tables, 2nd Edition, New York: American Society of Mechanical Engineers, 1967.

B-4. O. Foeppl, "Wind Forces on Flat and Cambered Plates" (German), Jahrbuch für Motorluftschiffstudiengesllschaft, Vol. 4, p 51, (1910-1911) (Cited in Applied Hydro and Aeromechanics, L. Prandtl and O. G. Tietjens, Dover 1957, p 144). 


\section{THIS PAGE WAS INTENTIONALLY LEFT BLANK}


APPENDIX C

ARA TESTS, PRE-WCL 
-

THIS PAGE

WAS INTENTIONALLY

LEFT BLANK 


\section{APPENDIX C}

\section{ARA TESTS, PRE-WCL}

In Table C-I, both raw and reduced test data are presented for the ARA tests run prior to the WCL tests. The raw data are presented in Reference C-1, Appendix D. 


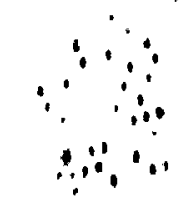

TABLE C-I

ARA TESTS, PRE-WCL, FULL FLOW, ALL WATER

\begin{tabular}{|c|c|c|c|c|c|c|c|c|c|c|}
\hline $\begin{array}{c}\text { Flow } \\
\text { Direction }\end{array}$ & $\underline{p t}$ &  & $\begin{array}{c}\text { Calcuiated } \\
\text { Momentum } \\
\text { Flux Based on } \\
V_{L}, \text { lbm/(ft } \sec ^{2}: \\
\end{array}$ & $\begin{array}{c}67.5 v^{2} \\
1 \mathrm{br} /\left(\mathrm{ft} \sec ^{2}\right) \\
\end{array}$ & $\begin{array}{l}\text { Turtin } \\
\mathrm{Hz}\end{array}$ & $\frac{\text { Eutpiut }}{\text { Volts }[\mathrm{c}]}$ & $E=$ volts $\times 3.6^{[\mathrm{d}]}$ & $\begin{array}{r}\begin{array}{r}\text { Jras } \\
\text { Outp }\end{array} \\
\text { Volts Volt } \\
\end{array}$ & $\begin{array}{l}\text { Oisc } \\
\text { out } \\
\text { s/Gain[e] }\end{array}$ & $\begin{array}{l}\text { Average Velocity }[\mathrm{f}] \\
\mathrm{V}_{\mathrm{av}}=1.2936 \mathrm{~V}_{\mathrm{L}}, \mathrm{fps}\end{array}$ \\
\hline $\begin{array}{l}\text { Reverse } \\
\text { Tiurbine } \\
\text { stream }\end{array}$ & $\begin{array}{r}1 \\
2 \\
3 \\
4 \\
5 \\
6 \\
7 \\
8 \\
9 \\
10 \\
11 \\
12 \\
13 \\
14\end{array}$ & $\begin{array}{l}0 \\
4.0 \\
6.0 \\
7.97 \\
10.0 \\
12.0 \\
12.76 \\
12.76 \\
12.0 \\
10.0 \\
8.0 \\
6.0 \\
4.0 \\
0\end{array}$ & $\begin{array}{r}0 \\
984 \\
2214 \\
3907 \\
6151 \\
8856 \\
10013 \\
10013 \\
8856 \\
6151 \\
3936 \\
2214 \\
984 \\
0\end{array}$ & $\begin{array}{c}0 \\
1646.0 \\
3704.9 \\
65.37 .2 \\
10291.4 \\
14819.6 \\
16756.2 \\
76756.2 \\
14619.6 \\
10291.4 \\
6586.5 \\
3704.9 \\
\mathbf{1 6 4 6 . 6} \\
0\end{array}$ & $\begin{array}{c}0 \\
55.7 \\
81.8 \\
111.8 \\
139.8 \\
168.0 \\
174.0 \\
175.0 \\
165.5 \\
137.5 \\
110.7 \\
81.8 \\
53.6 \\
0\end{array}$ & $\begin{array}{l}0 \\
0.1474 \\
0.2164 \\
0.2958 \\
0.3698 \\
0.4444 \\
0.4603 \\
0.463 \\
0.4378 \\
0.3638 \\
0.2929 \\
0.2164 \\
0.1418 \\
0\end{array}$ & $\begin{array}{l}0 \\
0.5306 \\
0.779 \\
1.0649 \\
1.3313 \\
1.6 \\
1.6571 \\
1.6667 \\
1.5762 \\
1.3095 \\
1.0544 \\
0.779 \\
0.5105 \\
0\end{array}$ & $\begin{array}{l}0.2311 \\
1.05 \\
1.92 \\
3.38 \\
3.51 \\
{[9]} \\
{[9]} \\
{[9]} \\
69] \\
{[9]} \\
3.37 \\
1.97 \\
1.04 \\
0.22\end{array}$ & $\begin{array}{c}0.058 \\
0.268 \\
0.481 \\
g]_{0.865}^{0.878} \\
{[g]} \\
{[g]} \\
{[g]} \\
{[g]} \\
{[g]} \\
0.842 \\
0.493 \\
0.261 \\
0.054\end{array}$ & $\begin{array}{c}0 \\
5.17 \\
7.76 \\
10.31 \\
12.94 \\
15.52 \\
16.51 \\
16.51 \\
15.52 \\
12.94 \\
10.35 \\
7.76 \\
5.17 \\
0\end{array}$ \\
\hline $\begin{array}{l}\text { Forward } \\
\text { Drag Dis: } \\
\text { strear }\end{array}$ & $\begin{array}{l}15 \\
16 \\
17 \\
18 \\
19 \\
20 \\
21 \\
22 \\
23 \\
24 \\
25 \\
26 \\
27 \\
28 \\
29\end{array}$ & $\begin{array}{c}0 . \\
4.0 \\
6.0 \\
7.97 \\
9.96 \\
12.0 \\
14.0 \\
16.0 \\
14.0 \\
12.0 \\
10.0 \\
8.0 \\
6.0 \\
4.0 \\
0\end{array}$ & $\begin{array}{r}0 \\
984 \\
2214 \\
3907 \\
6101 \\
8856 \\
12054 \\
15744 \\
12054 \\
8856 \\
6150 \\
3936 \\
2214 \\
984 \\
0\end{array}$ & $\begin{array}{c}0 \\
i 646.6 \\
3704.9 \\
6537.2 \\
10209.2 \\
14819.6 \\
20171.2 \\
26346.0 \\
20171.2 \\
1<\varepsilon 19.6 \\
10291.4 \\
6586.5 \\
3704.9 \\
1646.6 \\
0\end{array}$ & $\begin{array}{r}0 \\
79 \\
102 \\
106 \\
153 \\
180 \\
203 \\
226 \\
200 \\
178 \\
148 \\
101 \\
81 \\
79 \\
0\end{array}$ & $\begin{array}{l}0 \\
0.2090 \\
0.2698 \\
0.2804 \\
0.4048 \\
0.4762 \\
0.537 \\
0.5979 \\
0.5291 \\
0.4709 \\
0.3915 \\
0.2672 \\
0.2143 \\
0.2090 \\
0\end{array}$ & $\begin{array}{l}0 \\
0.7524 \\
0.9713 \\
1.0094 \\
1.4571 \\
1.7143 \\
1.9333 \\
2.1524 \\
1.9048 \\
1.6952 \\
1.4095 \\
0.9619 \\
0.7115 \\
0.7524 \\
0\end{array}$ & $\begin{array}{c}-0.034 \\
-1.13 \\
-2.20 \\
-3.80 \\
{[9]} \\
{[g]} \\
{[g]} \\
{[g]} \\
{[9]} \\
{[9]} \\
{[9]} \\
{[9]} \\
-2.40 \\
-1.12 \\
-0.056\end{array}$ & $\begin{array}{c}-0.008 \\
-0.284 \\
-0.550 \\
-0.950 \\
{[g]} \\
{[g]} \\
{[g]} \\
{[g]} \\
{[g]} \\
{[g]} \\
{[g]} \\
{[g]} \\
-0.600 \\
-0.281 \\
-0.014\end{array}$ & $\begin{array}{c}0 \\
5.1744 \\
7.7616 \\
10.31 \\
12.8843 \\
15.523 \\
18.1104 \\
20.6976 \\
18.1104 \\
15.5232 \\
.12 .936 \\
10.348 \\
7.7616 \\
5.1744 \\
0\end{array}$ \\
\hline
\end{tabular}

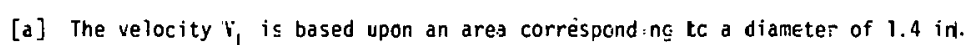

[b] All data taker at $p<15 \mathrm{psia}$ and $70^{\circ} \mathrm{F}<T<1: 5^{\circ} \mathrm{F}$ therefore, ave $=61.5 \mathrm{1b} / \mathrm{ft}^{3}$.

[c] Volis $=\frac{\mathrm{Hz}}{378}$.

[d] $E$ is equivalert Wyle volts.

[e] Gain Ratio $=4$.

[i] The velocity $\mathrm{d}_{\mathrm{a} . \mathrm{y}}$ is based upon an area of $1.19 \mathrm{ir.}^{2}$. This is the minimum flow area in the turbine and occurs at she drag disc.

[g] Beyond drag disc meter ranged; meter saturated. 


\section{REFERENCE}

C-1. Internal Report. 


\section{THIS PAGE}

\section{WAS INTENTIONALLY}

LEFT BLANK 
APPENDIX் D

EQUIVALENCY BETWEEN WYLE AND WCL TURBINE VOLTS 
THIS PAGE

\section{WAS INTENTIONALLY LEFT BLANK}




\section{APPENDIX D \\ EQUIVALENCY BETWEEN WYLE AND WCL TURBINE VOLTS}

For a given turbine speed, the turbine output volts were not the same for all test series. In the following Table D-I, the basis is presented for converting ARA (pre-WCL) and WCL turbine volts to equivalent Wyle volts. The equivalency is required for comparing data from the various test series. The present electronics is slightly different from the Wyle set up. 
TABLE D-I

EQUIVALENT TURBINE VOLTS BETWEEN ARA TESTS

(PRE-WCL), WCL TESTS, AND WYLE TESTS ${ }^{[b]}$

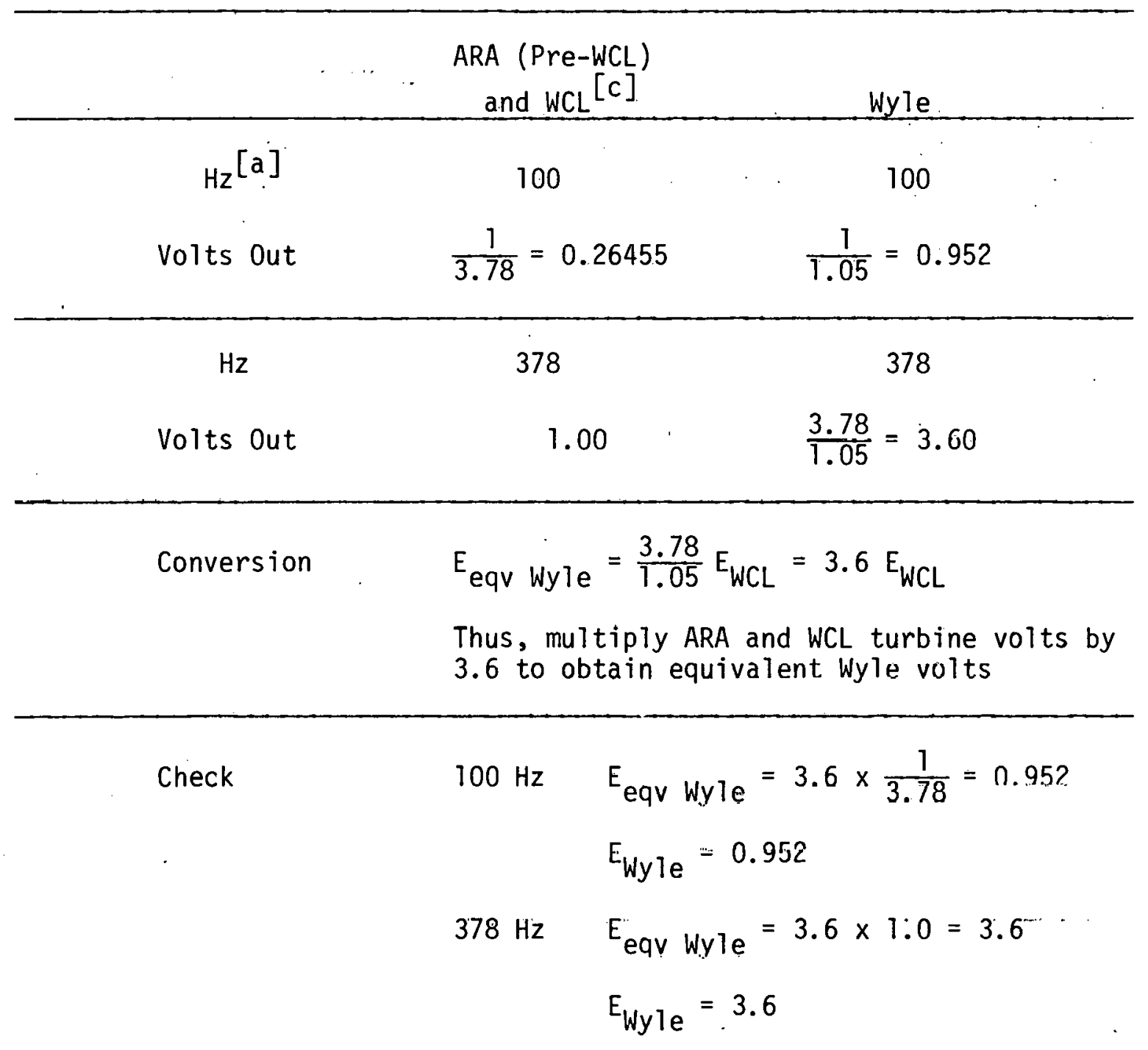

[a] $6 \mathrm{~Hz}=1$ RPS of turbine since turbine has six blades.

[b] Present setup is such that $\mathrm{Hz} /$ volts $=100$.

[c] For the WCL free field all water calibration tests (pump simulator tests) the ratio $\mathrm{Hz} /$ volts varied as $309<\mathrm{Hz} /$ volts $<378$. 
APPENDIX E

WCL ALL-WATER FREE FIELD TESTS 
THIS PAGE

\section{WAS INTENTIONALLY LEFT BLANK}




\section{APPENDIX E \\ WCL ALL-WATER FREE FIELD TESTS}

Table E-I contains raw and reduced data from the WCL all-water free field tests. The data are taken from Reference E-1 and previously unreported test data. 
TABLE E-I

WCL FREE FIELD, ALL-WATER (PUMP SIMULATOR TESTS) FORWARD (DRAG DISC UPSTREAM) AND REVEFSE

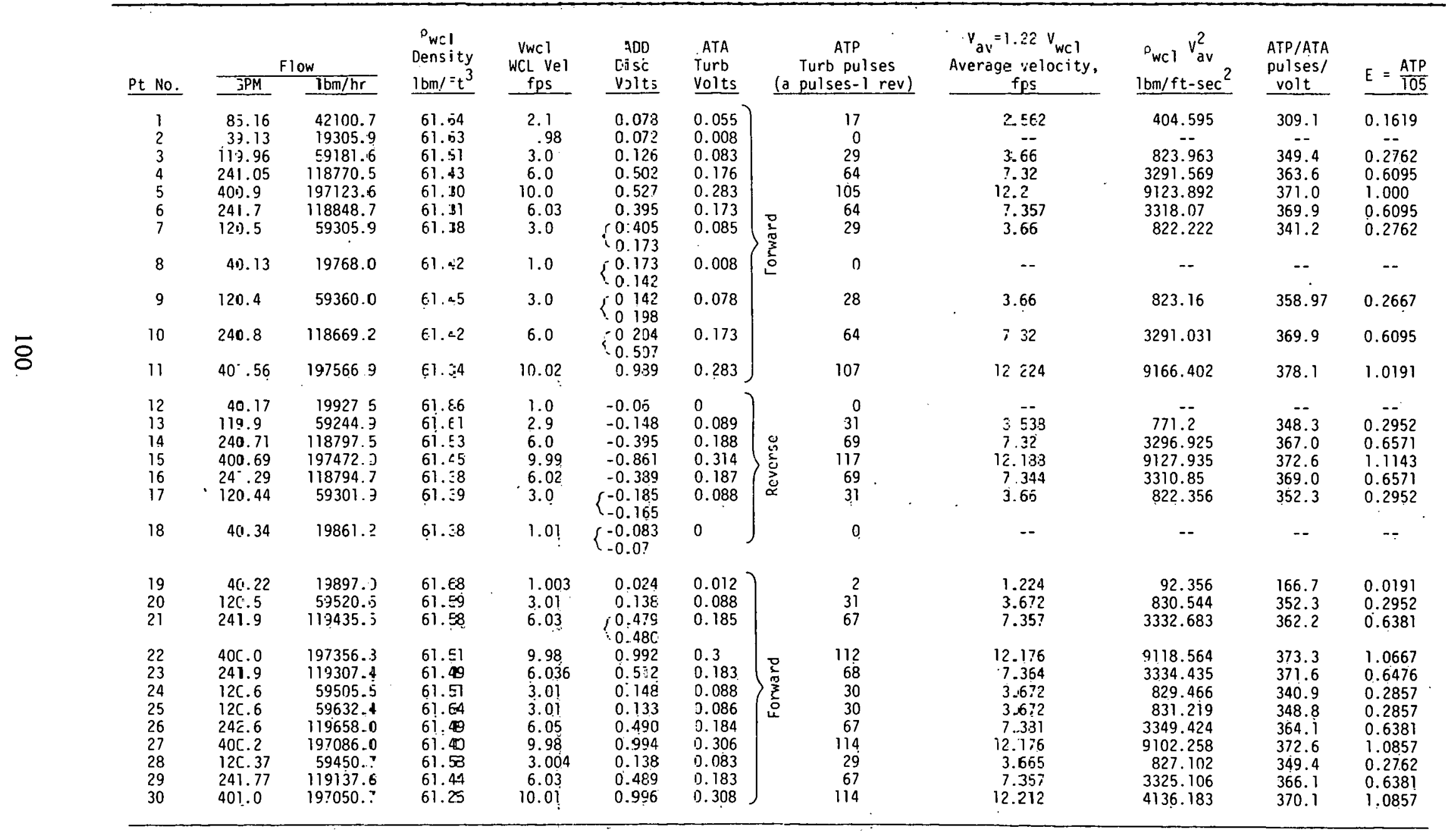




\section{REFERENCE}

E-1. C. B. Parsons, ANC Pump Simulator and LOFT Flow Meter [sic] Tests, Mod-2, CWAPD-251 (July 1974) pp 1-5. 
THIS PAGE

\section{WAS IN'TENTIONALLY \\ LEFT BLANK}




\section{APPENDIX F}

ARA TESTS, POST-WCL, AND COMPPARISONS WITH WYLE 


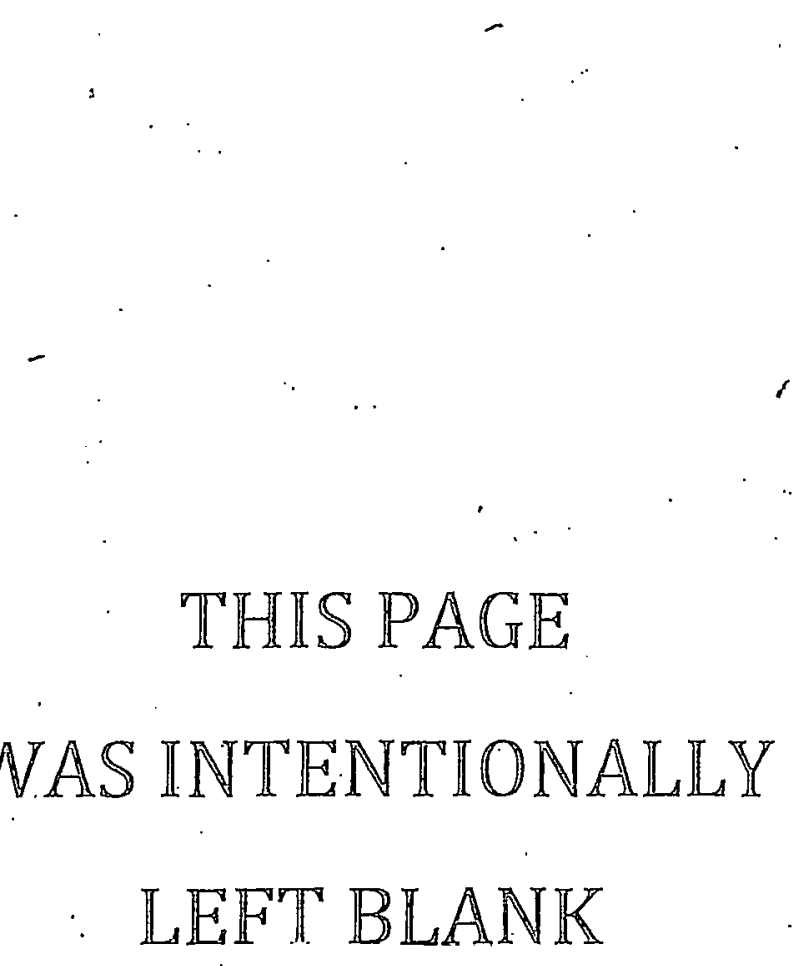




\section{APPENDIX F \\ ARA TESTS, POST-WCL, AND COMPARISONS WITH WYLE}

\section{WYLE TESTS}

Wyle calibration equations are reported in Reference F-1. The tests involved placing the DTT in a horizontal probe configuration in a 12-in. ID pipe. Volumetric flow (in gpm) and DTT output (in volts) were recorded. A rake of pitot tubes was employed to obtain a curve relating volumetric flow to velocity at the meter location but with no meter present at the rake location. The calibration equations of Reference F-1 relate the velocity obtained from the pitot tube to the output volts. Unfortunately, chlorine present in the city water caused corrosion in the DTTs. New turbines were installed in DTTs 13,54 , and 57, and new VRTs and cores were installed in DTTs 54, 57, and 60. A new drag disc was installed in DTT 60. All the other meters were cleaned by operating in an ARA flow loop until they operated satisfactorily. 


\section{ARA TEST}

To verify that the Wyle calibration. was not affected by the corrosion, further tests were conducted by EG\&G Idaho, Inc., at ARA III. Their tests were for a full flow condition (all flow through the meter) with the water temperature between 70 and $200^{\circ} \mathrm{F}$. The biggest unknown factor was the amount of air in the test loop. Air may effectively reduce the water density below $62.4 \mathrm{lb} / \mathrm{ft}^{3}$ as well as directly influence by means of cavitation, both the drag disc and turbine outputs and the reference turbine output. It was assumed that no air was present in the loop and that the water density could be obtained from the tempcrature of the water. 


\section{MODIFICATION OF ARA AND WYLE VELOCITIES}

The initial calibration of the ARA data using nominal flow velocity yielded curves significantly different from the Wyle curves. (See Figure 2 of this report). For the same output voltage, the Wyle curve yielded approximately a 1.5 times greater velocity.

Because of this initial poor agreement between the Wyle and ARA data, further studies were conducted. For the Wyle tests, the velocity through the meter was assumed to be the average flow vclocity through the pipe with both the blockage caused by the DTT support and the DTT itself accounted for. For the plenum and piping meters, the flow area was about 106.5 in. ${ }^{2}$. See Section II-4 for further details on calculating the average flow velocity.

For the ARA tests, the flow area was based upon the minimum flow area anywhere in the meter. For the piping meter, this is at the shroud and has a value of about 1.37 in. ${ }^{2}$. The minimum flow area for the plenum meter is at the drag disc and is about 1.19 in. ${ }^{2}$. 


\section{COMPARISON OF WYLE AND ARA DATA}

The ARA and Wyle data, based upon average velocity through the meter, are summarized in Table F-I and F-II and presented in Figures F-1 through F-27. Most of the differences observed initially, but not all, are eliminated by carefully accounting for the flow areas as discussed previously. The turbine data, in general, agree better than the drag disc data.

The following unknown variables may affect the results and comparisons:

(1) Air in the ARA loop

(2) Swirl in the ARA loop

(3) The DTT calibrations could possibly have really changed, especially the calibration for DTT 13

(4) From the figures, it is seen that the ARA data for the turbines y.ield different calibration for forward and reverse. This was not evident at Wy:le. 


\section{TABLE F-I}

\section{COMPARISON OF ARA AND WYLE TURBINE DATA}

\begin{tabular}{|c|c|c|c|c|c|}
\hline \multicolumn{2}{|c|}{ DTT No. } & Notes & $\begin{array}{l}\text { Calibration Slope }[\mathrm{a}] \\
\text { ARA Data of } 9 / 5 / 75\end{array}$ & \multicolumn{2}{|c|}{$\begin{array}{c}\text { Calibration Slope }{ }^{[a]}, \\
\text { Wyle } \\
\end{array}$} \\
\hline 13 & & $\begin{array}{l}\text { Forward and reverse different } \\
\text { Wyle high by about } 3 \%\end{array}$ & 9.02 & 9.23 & \\
\hline 14 & & $\begin{array}{l}\text { Forward and reverse different } \\
\text { Wyle high by about } 6 \% \text {. ARA data } \\
\text { of } 9 / 1 \text { and } 9 / 5 \text { agree well for } \\
\text { forward and reverse }\end{array}$ & 8.56 & 9.14 & \\
\hline 15 & & $\begin{array}{l}\text { Forward and reverse different } \\
\text { Wyle low by about } 6 \%\end{array}$ & 9.72 & 9.14 & \\
\hline 16 & & $\begin{array}{l}\text { Forward and reverse different } \\
\text { excellent agreement between Wyle } \\
\text { and ARA. ARA data of } 9 / 1 \text { and } 9 / 5 \\
\text { differ by about } 4 \%\end{array}$ & 9.98 & 10.08 & \\
\hline 18 & & $\begin{array}{l}\text { Forward and reverse agree well } \\
\text { Wyle high by } 8 \%\end{array}$ & 9.36 & 10.13 & \\
\hline 55 & & $\begin{array}{l}\text { Forward and reverse different } \\
\text { wyle high by about } 9 \%\end{array}$ & 28.0 & 32.06 & \\
\hline 56 & & $\begin{array}{l}\text { Forward and reverse different } \\
\text { Wyle high by } 10 \%\end{array}$ & 26.01 & 29.55 & \\
\hline 57 & & $\begin{array}{l}\text { Forward and reverse different } \\
\text { Wyle high by } 13 \%\end{array}$ & 27.10 & 29.72 & \\
\hline 58 & & $\begin{array}{l}\text { Forward and reverse ahnut the } \\
\text { same Wyle low by } 3 \%\end{array}$ & 27.63 & 26.93 & \\
\hline 59 & & $\begin{array}{l}\text { Forward and reverse different } \\
\text { Wyle high by } 13 \%\end{array}$ & 24.56 & 27.9 & \\
\hline \multicolumn{6}{|c|}{$\begin{array}{l}\text { [a] } V_{a v}=\text { slope *E + offset, fps } \\
\text { where } E \text { is the turbine output volts }(0.952 \text { volts } " 100 \mathrm{~Hz}, 6 \mathrm{H}=1 \mathrm{RPS} \text { of turbine) and } \\
V_{\mathrm{av}} \text { is the average velocity through the turbine based on the minimum flow area. Except } \\
\text { for Numbers } 18 \text { and } 55 \text {, slope obtained from least squares fit to data, these two obtained } \\
\text { from "eycball fit". }\end{array}$} \\
\hline$[b]$ & & $\begin{array}{l}e \text { is obtained by multiplying } V_{W y} \\
r \text { and } 0.772 \text { piping meter. Refer }\end{array}$ & $\begin{array}{l}\text { e Reference } F-1 \text {, Tabl } \\
\text { ction II-4 for deriva }\end{array}$ & $\begin{array}{l}\text { by } 0.812 \\
\text { f the constanls. }\end{array}$ & \\
\hline
\end{tabular}




\section{TABLE F-II}

\section{COMPARISON OF ARA AND WYLE DRAG DISC DATA}

\begin{tabular}{|c|c|c|c|c|c|c|c|}
\hline \multirow{2}{*}{\multicolumn{2}{|c|}{ DTT No: }} & \multirow{2}{*}{$\begin{array}{l}\text { Notes } \\
\text { Forward } \\
\end{array}$} & \multirow{2}{*}{$\begin{array}{c}\text { Notes } \\
\text { Reverse }\end{array}$} & \multicolumn{2}{|c|}{$\begin{array}{l}\text { ARA Data } \\
\text { Calibration Slope } \\
\text { [a] }\end{array}$} & \multicolumn{2}{|c|}{$\begin{array}{l}\text { Wyle Data } \\
\text { Calibration Slope }\end{array}$} \\
\hline & & & & Forward & Reverse & Forward & Reverse \\
\hline 13 & & Wyle high by $33 \%$ & Wyle high by $32 \%$ & 1044 & 1752 & 1516 & 2395 \\
\hline \multirow{2}{*}{\multicolumn{2}{|c|}{14.}} & wyle high by $12.5 \%$ & Wyle high by $2.5 \%$ & 1129 & 2105 & 1273 & 2125 \\
\hline & & $\begin{array}{l}\text { Not enough data, } \\
\text { but it appears. } \\
\text { data of } 9 / 1 \text { and } \\
9 / 5 \text { agree }\end{array}$ & $\begin{array}{l}\text { Not enough data, } \\
\text { too much scatter in } \\
\text { available data }\end{array}$ & & & . & \\
\hline 15 & & $\begin{array}{l}\text { Wyle low by } 4 \% \text {, not } \\
\text { enough data }\end{array}$ & $\begin{array}{l}\text { Wyle high by } 13 \% \text {, not } \\
\text { enough data }\end{array}$ & 1440 & 2026 & \multicolumn{2}{|l|}{1500} \\
\hline \multicolumn{2}{|l|}{16} & $\begin{array}{l}\text { Much scatter Wyle } \\
\text { low by } 8 \% \text { ARA data } \\
\text { of gil arid } 9 / 5 \\
\text { differ considerably }\end{array}$ & $\begin{array}{l}\text { Wyle high by } 23 \%, \text { ARA } \\
\text { data of } 9 / 1 \text { and } 9 / 5 \\
\text { agree Well }\end{array}$ & 1664 & 2183 & 1573 & 2680 \\
\hline \multicolumn{2}{|l|}{18} & $\begin{array}{l}\text { Wyle hiyh by } 5 \% \text {, not } \\
\text { enough data }\end{array}$ & $\begin{array}{l}\text { Wyle high by } 25 \% \text {, not } \\
\text { enough data }\end{array}$ & 1227 & 1621 & 1291 & 221.3 \\
\hline \multicolumn{2}{|l|}{55} & $\begin{array}{l}\text { Wyle high by } 17 \% \text { not } \\
\text { enough. data }\end{array}$ & $\begin{array}{l}\text { Wyle high by } 29 \% \text { not } \\
\text { enough data }\end{array}$ & 1600 & 2056 & 1895 & 2800 \\
\hline \multicolumn{2}{|l|}{56} & Wyle low by $9 \%$ & Wyle high by $22 \%$ & 29,717 & 42,075 & 26,598 & 52,119 \\
\hline \multicolumn{2}{|l|}{57} & Wyle high by $5 \%$ & Wyle high by $35 \%$ & 25,705 & 33,607 & 26,862 & 53,41 \\
\hline \multicolumn{2}{|l|}{58} & Wyle low by $11.5 \%$ & Wyle high by $17.5 \%$ & 28,758 & 44,509 & 25,659 & 52,570 \\
\hline \multicolumn{2}{|l|}{59} & Excellent agreement & Wyle high by $12 \%$ & 31,272 & 51,386 & 31,375 & 57,466 \\
\hline \multicolumn{8}{|c|}{$\begin{array}{l}\text { [a] } \rho v_{a v}^{2}=S l o p e{ }^{*} E+\text { offset, } 1 \mathrm{bm} /\left(\mathrm{ft}-\mathrm{sec}^{2}\right) \\
\text { where } E \text { is the drag disc voltage output for a gain of } 8 x \text { and } v_{a v} \text { is the avcraga velocily lhrough the } \\
\text { turbine based on the minimum flow area (see fontnotes Tahle } F-I) \text {. Except for plumbers } 15,18 \text {, and } 5 b \text {, } \\
\text { slope obtained from least square fit the data; those three obtained from "eyebal! fit". }\end{array}$} \\
\hline
\end{tabular}




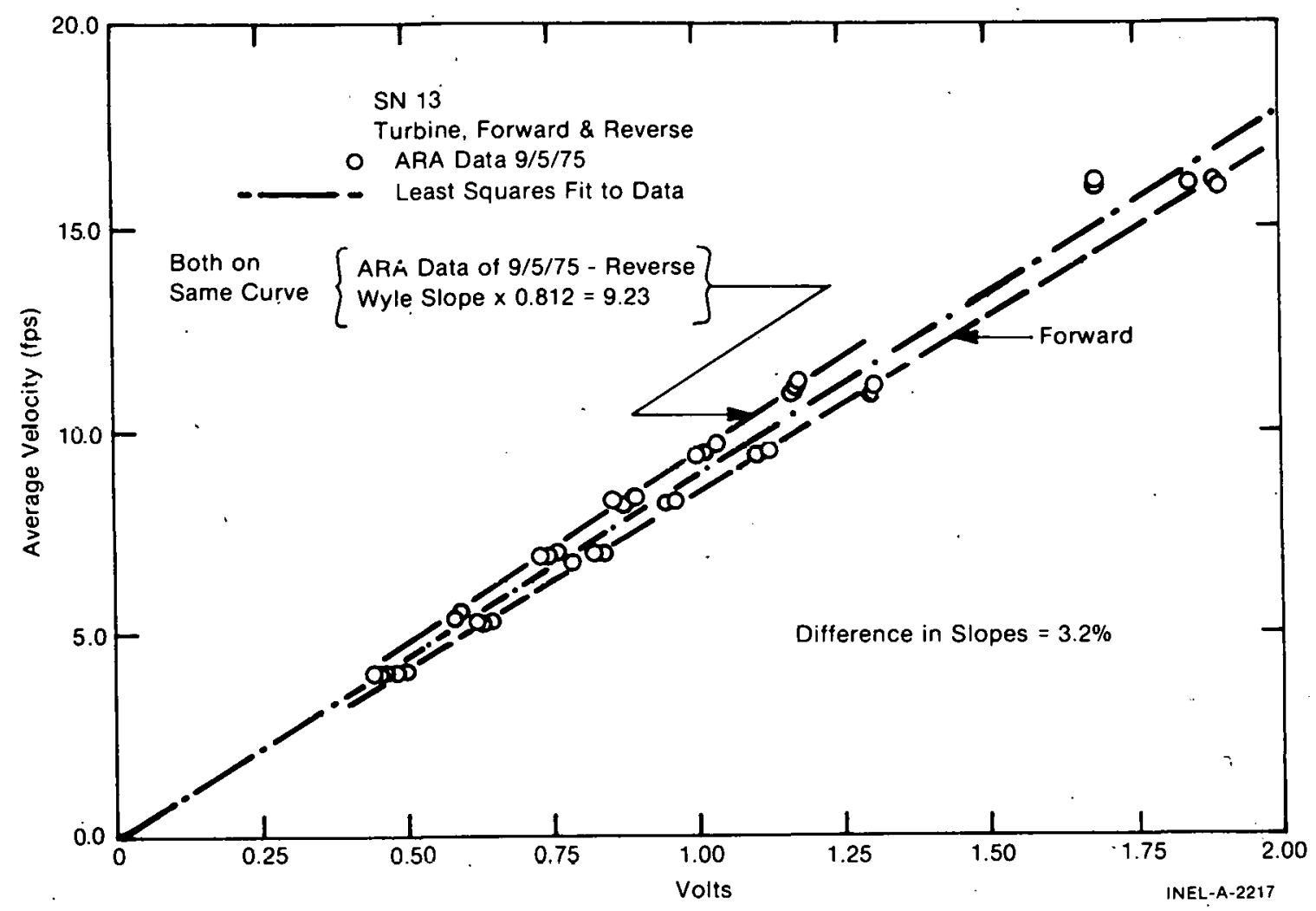

Fig. F-1 Average velocity versus turbine volts, ARA tests, SN 13.

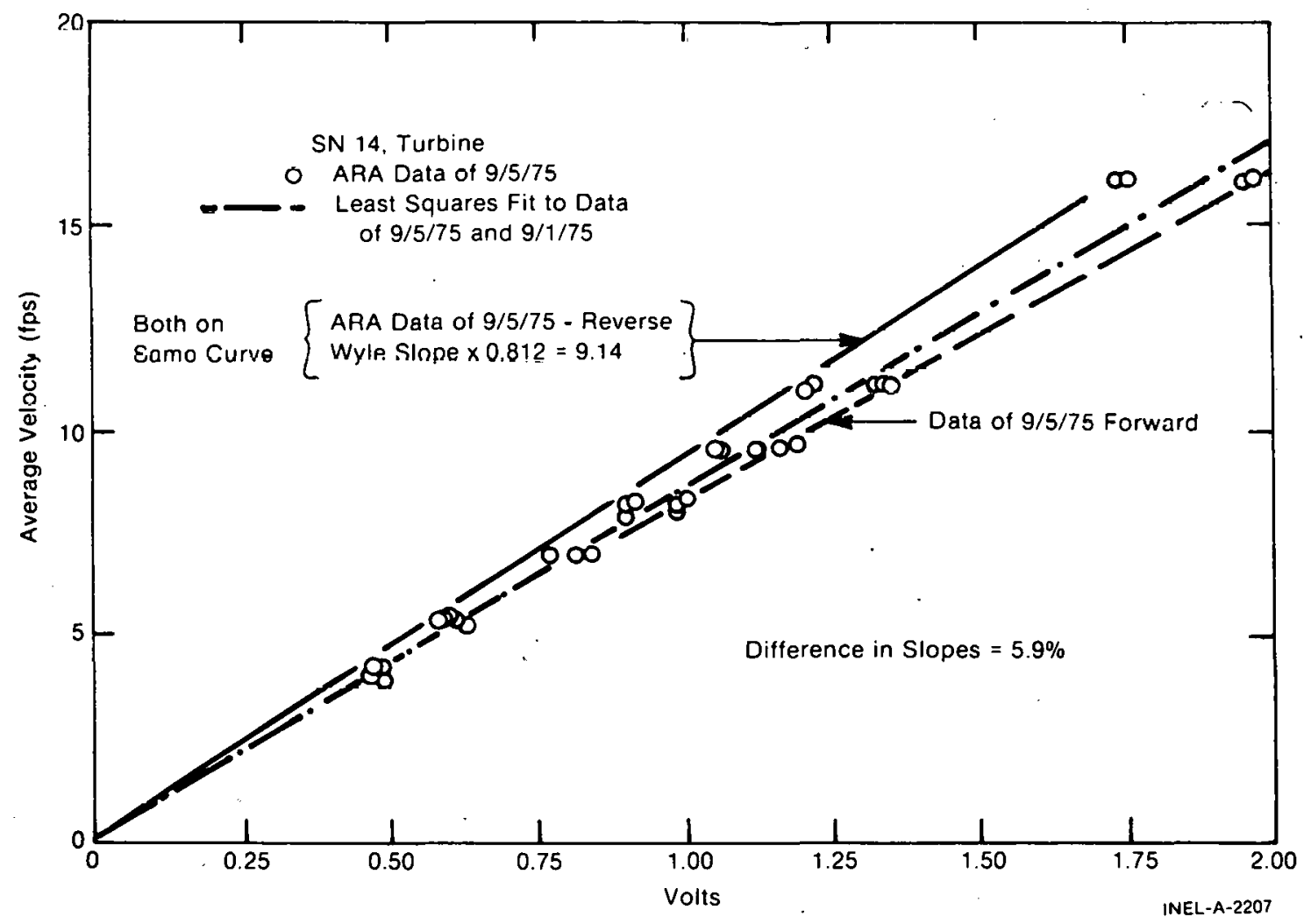

Fig. F-2 Average velocity versus turbine volts, ARA tests, SN.14. 


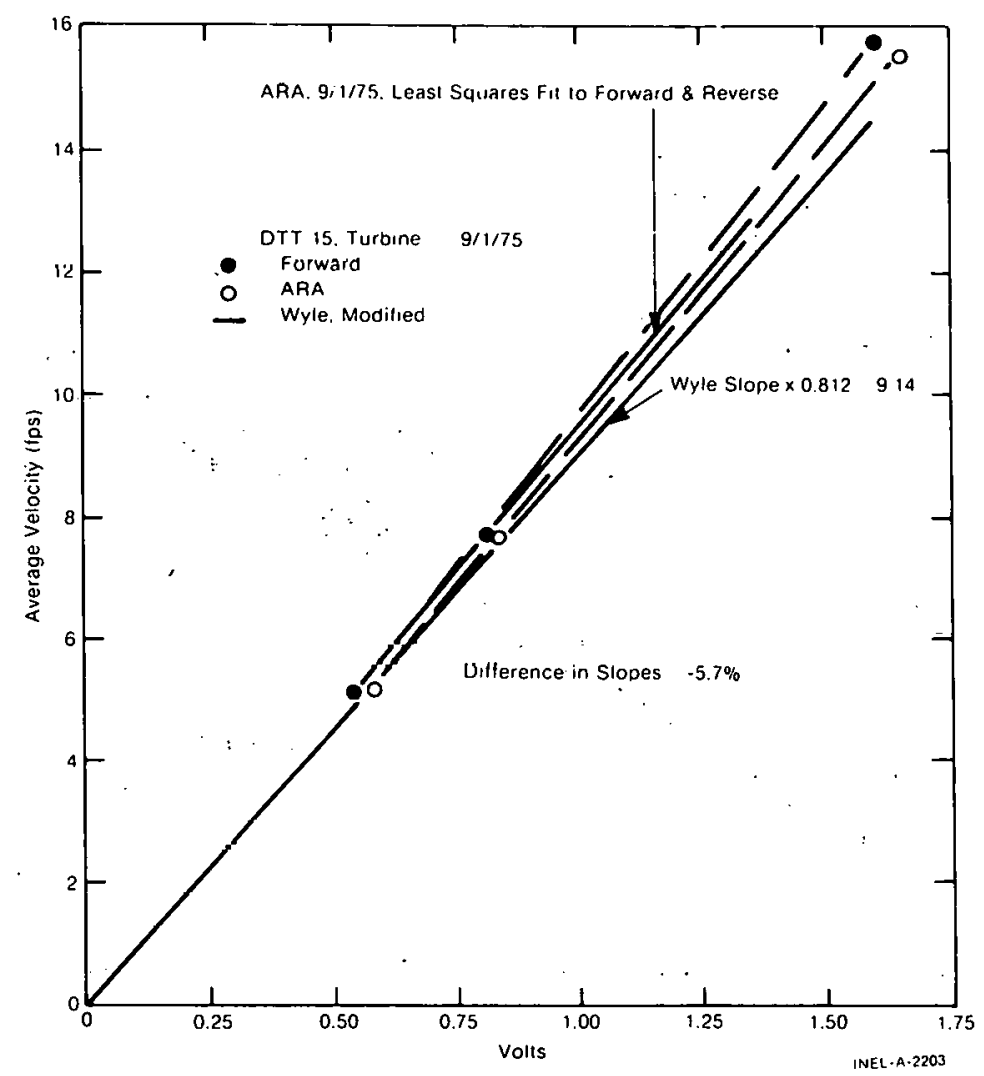

Fig. F-3 Average velocity versus turbine volts, ARA tests, SN 15.

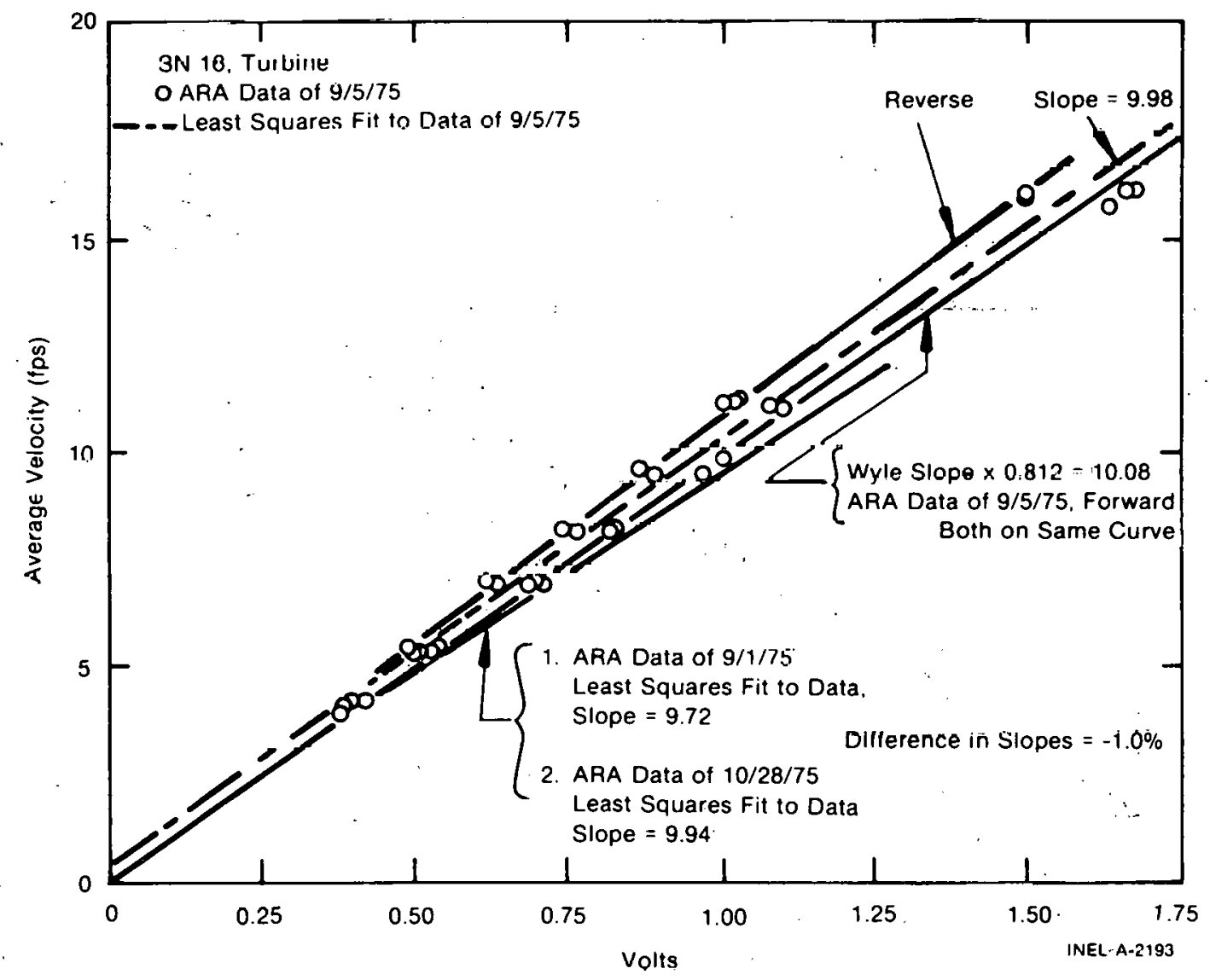

Fig. F-4 Average velocity versus turbine volts; ARA tests, SN 16 . 


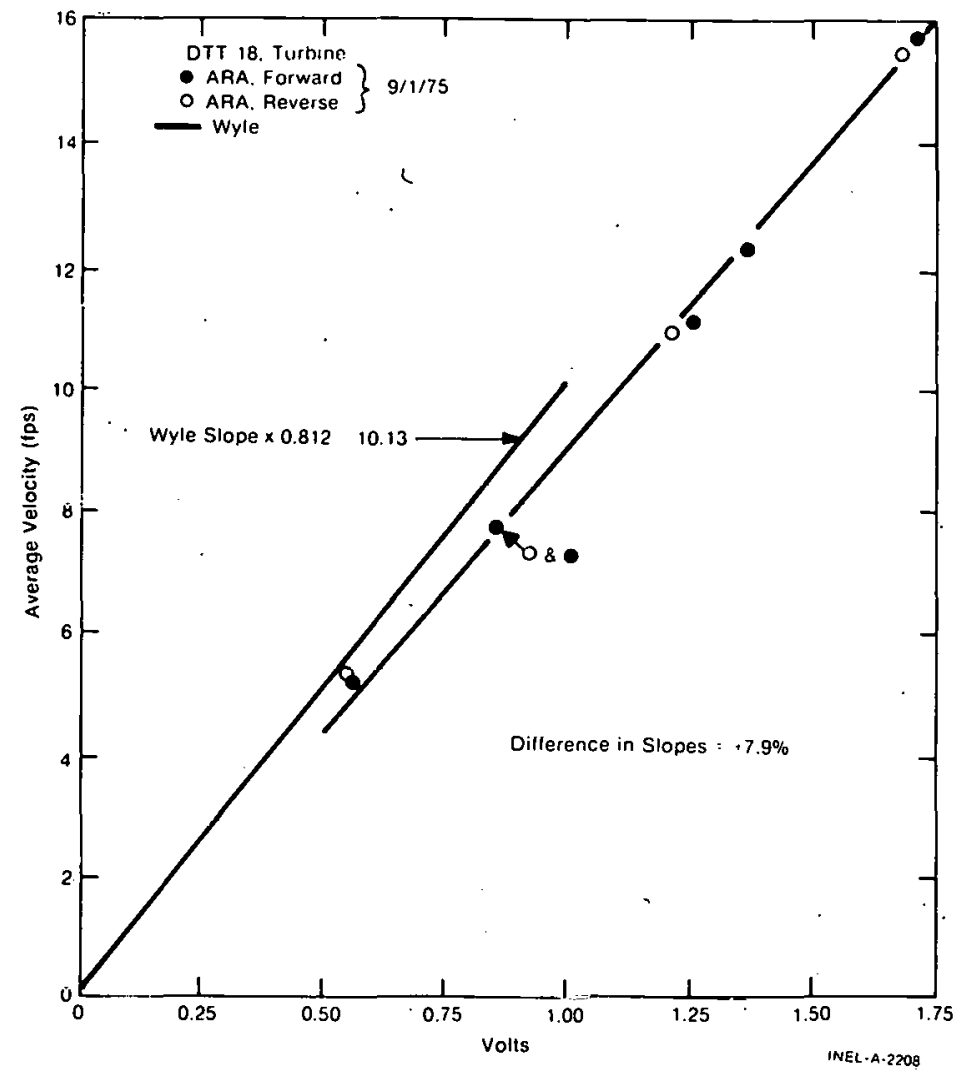

Fig. F-5 Average velocity versus turbine volts, ARA tests, SN 18.

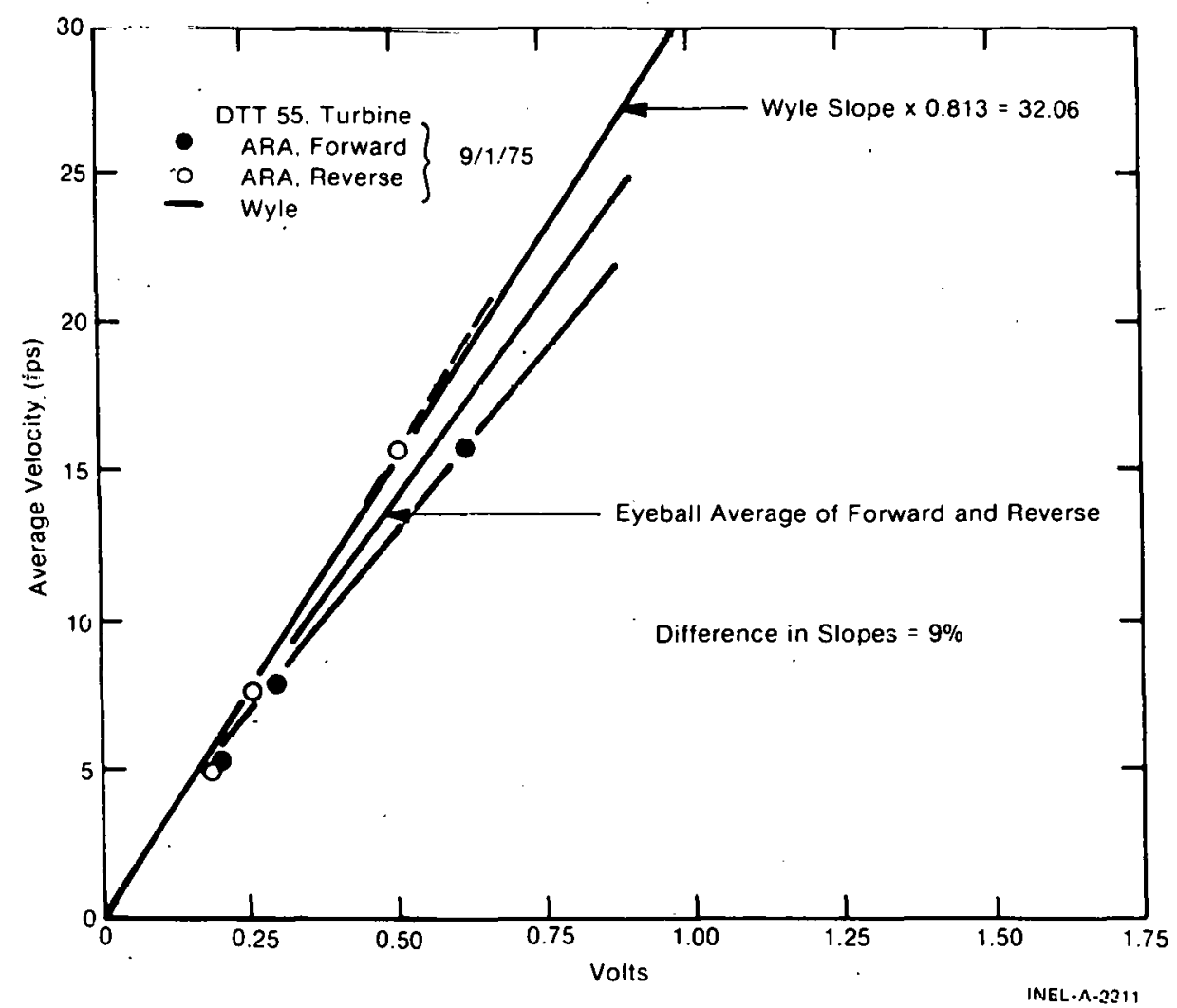

Fig. F-6 Avcrage velocity versus turbine volts, ARA tests, SN 55. 


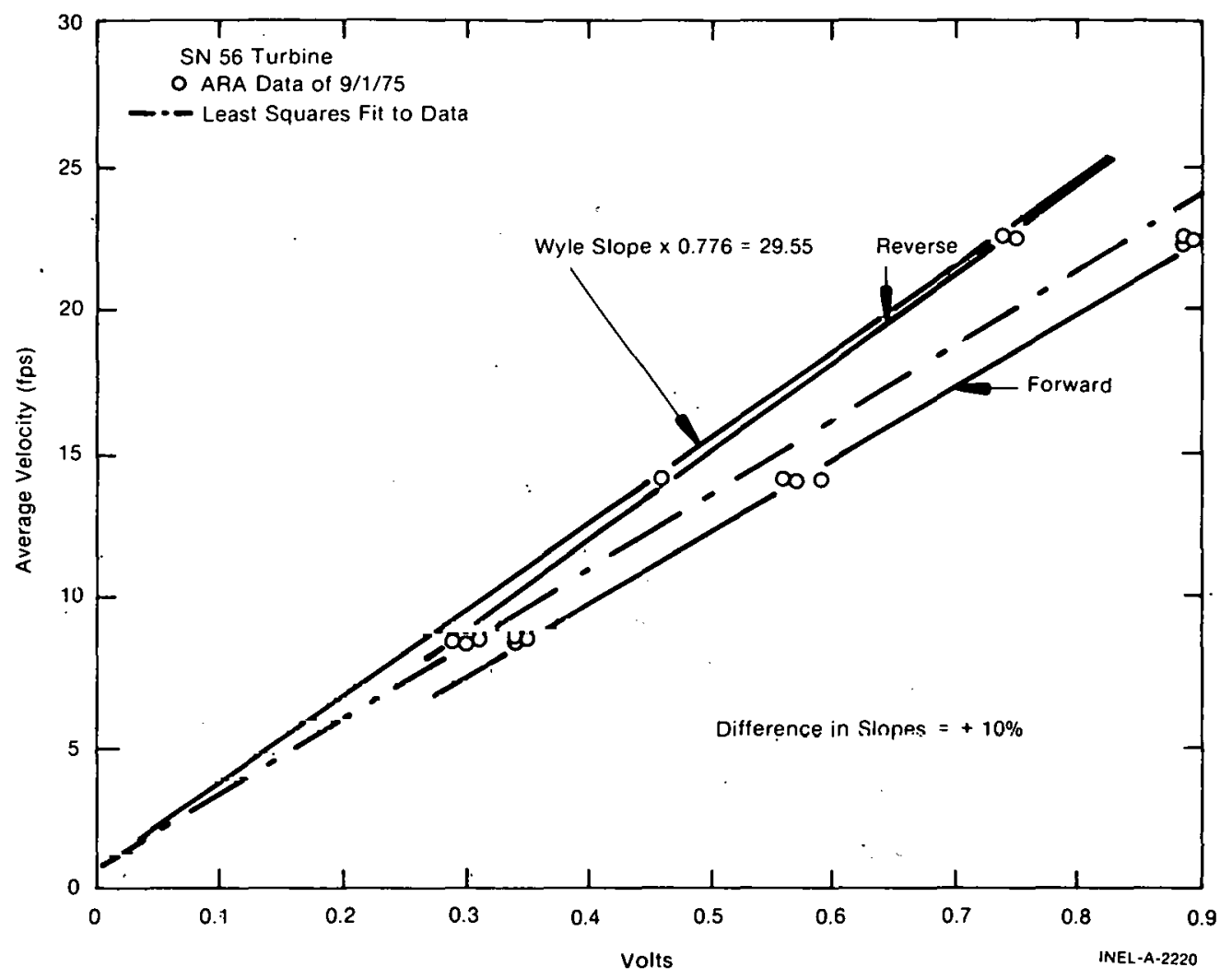

Fig. F-7 Average velocity versus turbine volts, ARA tests, SN 50.

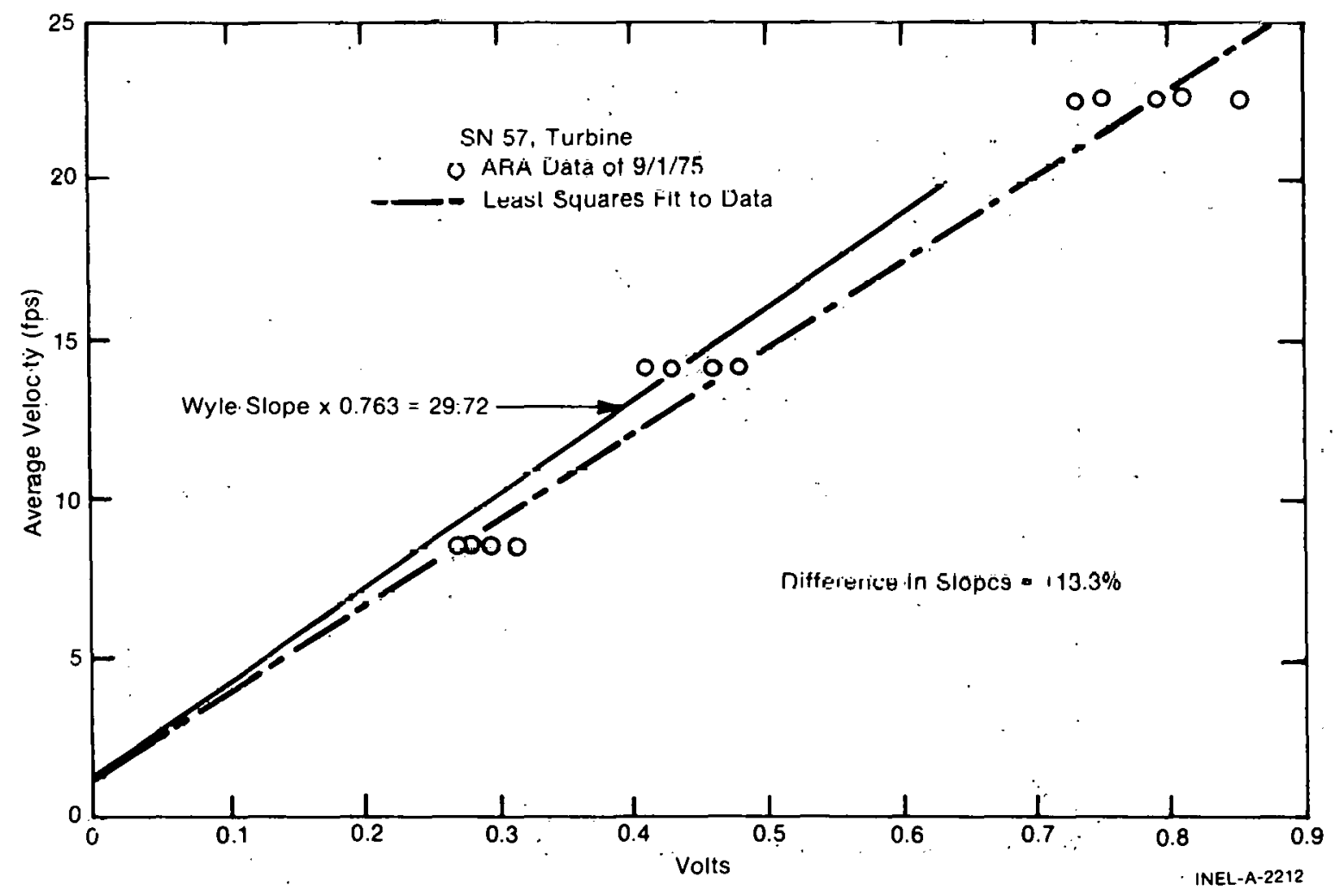

Fig. F-8 Average velocity versus turbine volts, ARA tests, SN 57. 


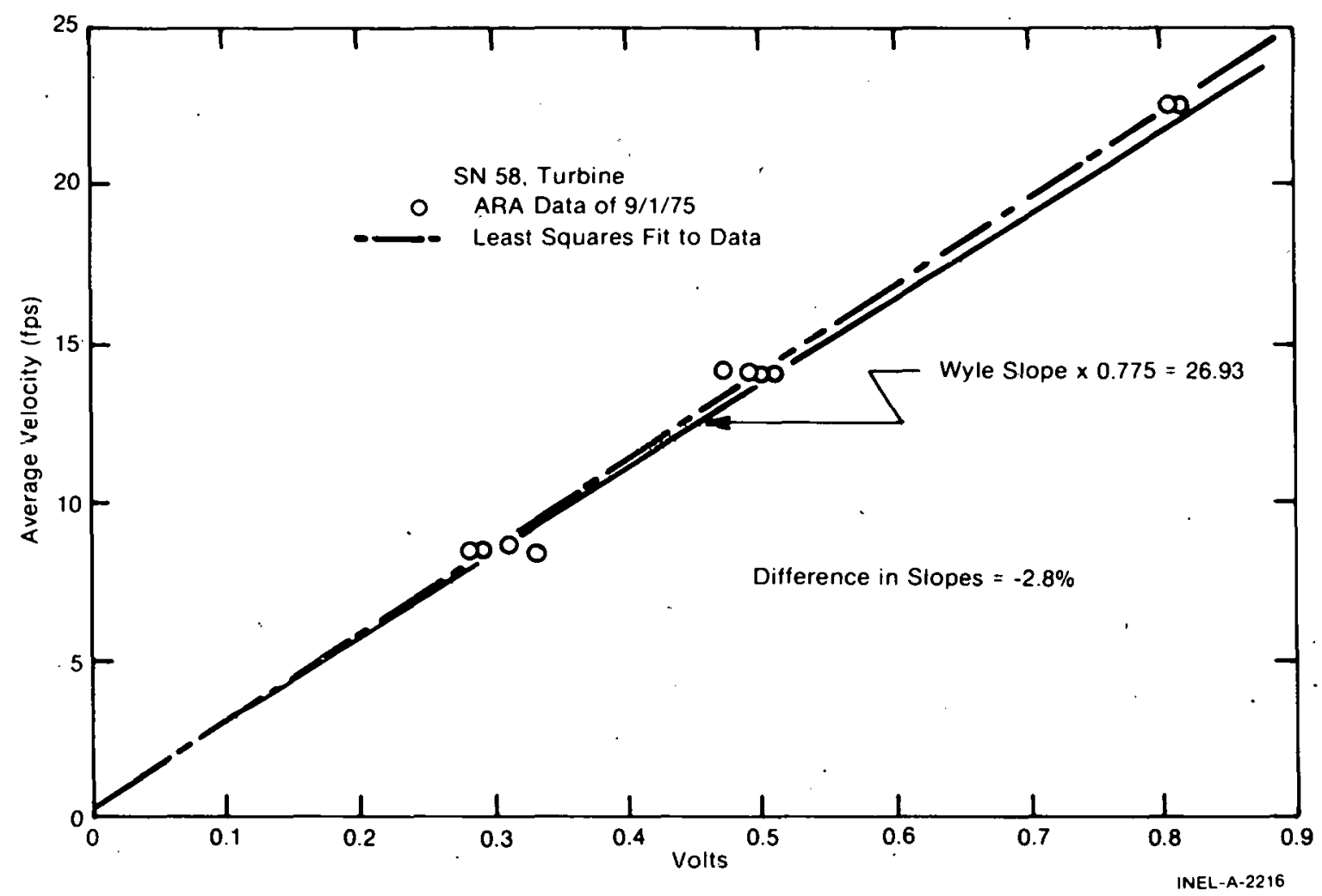

Fig. F-9 Average velocity versus turbine volts, ARA tests, SN 58.

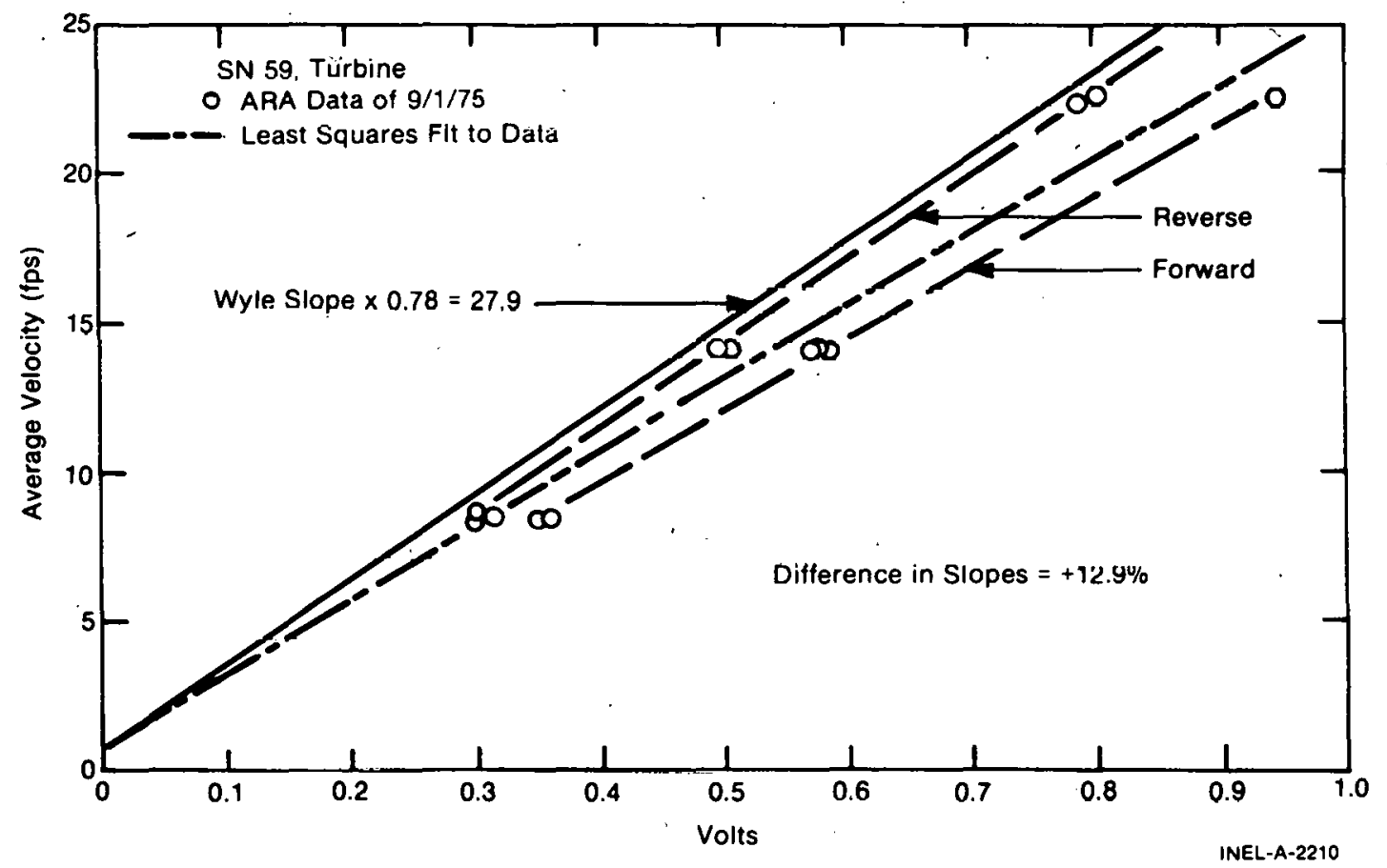

Fig. F-10 Average velocity versus turbine volts, ARA tests, SN 59. 


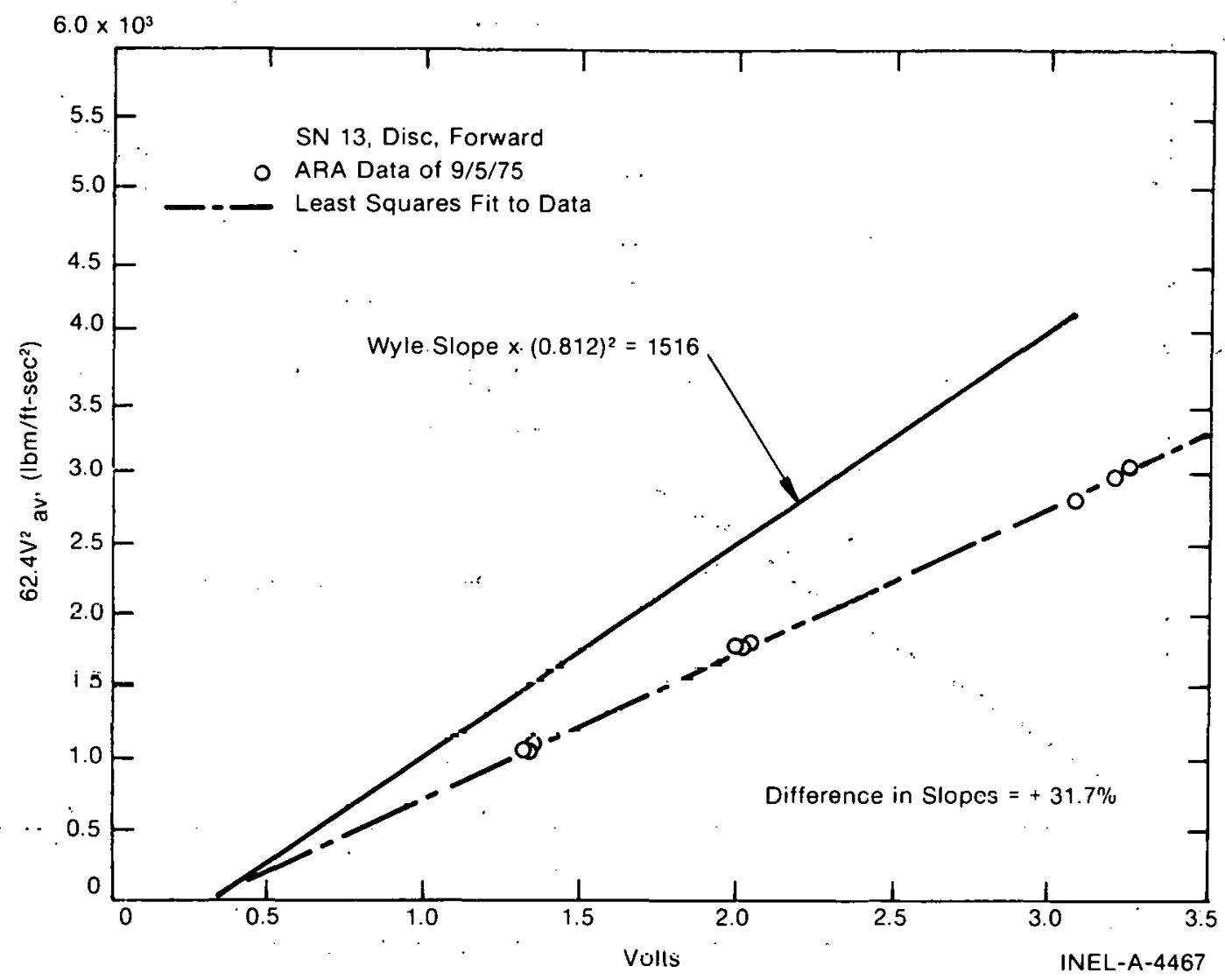

Fig. F-11 Momentum flux using average velocity versus drag disc volts, ARA tcsts, SN 13, forward.

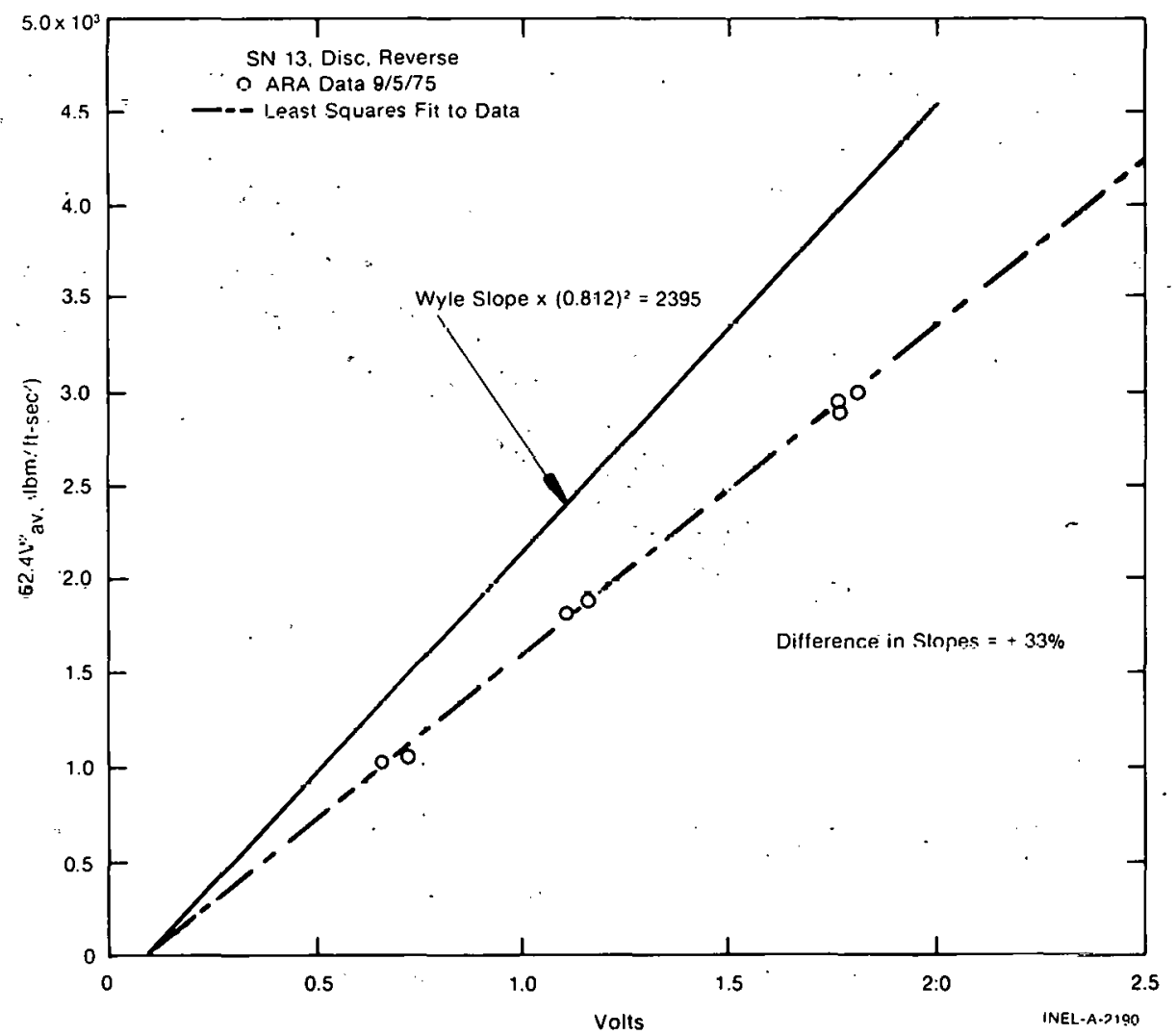

Fig. F-12 Momentum flux using average velucity versus drag disc volts, ARA tests, SN 13, reverse. 


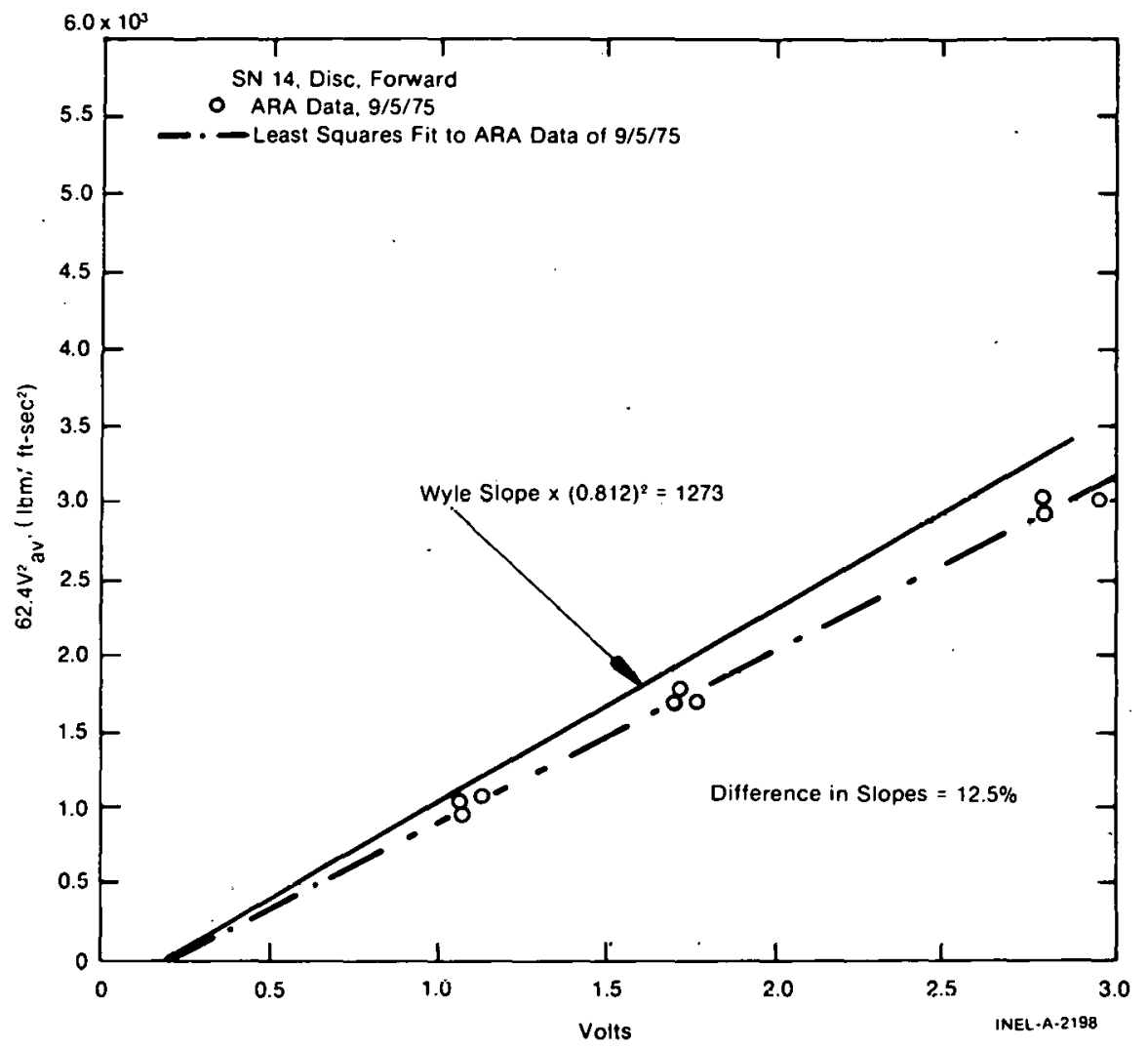

Fig. F-13 Momentum flux using average velocity versus drag disc volts, ARA tests, SN 14, forward.



Fig. F-14 Momentum flux using average velocity versus drag disc volts, ARA tests, SN 14, reverse. 


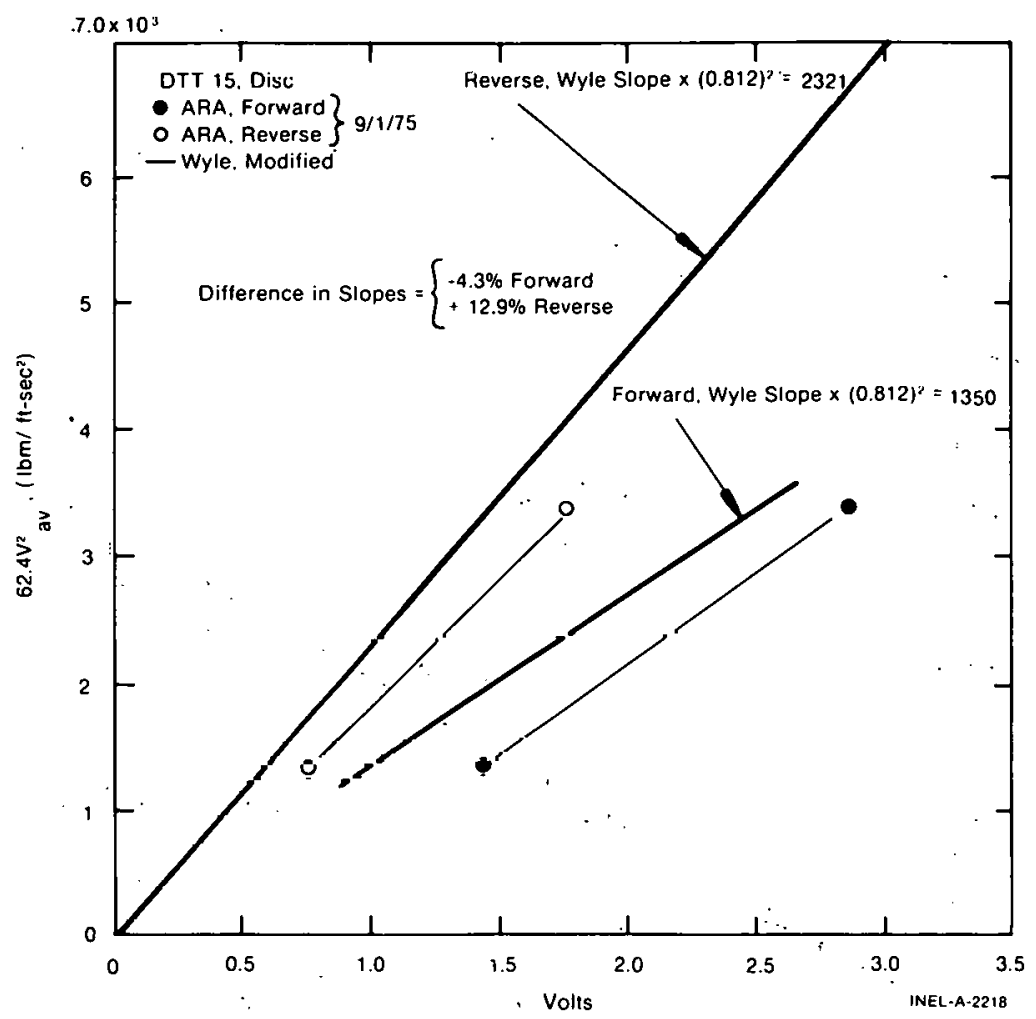

Fig. F-15 Momentum flux using average velocity versus drag disc volts, ARA tests, SN 15, forward and reverse.

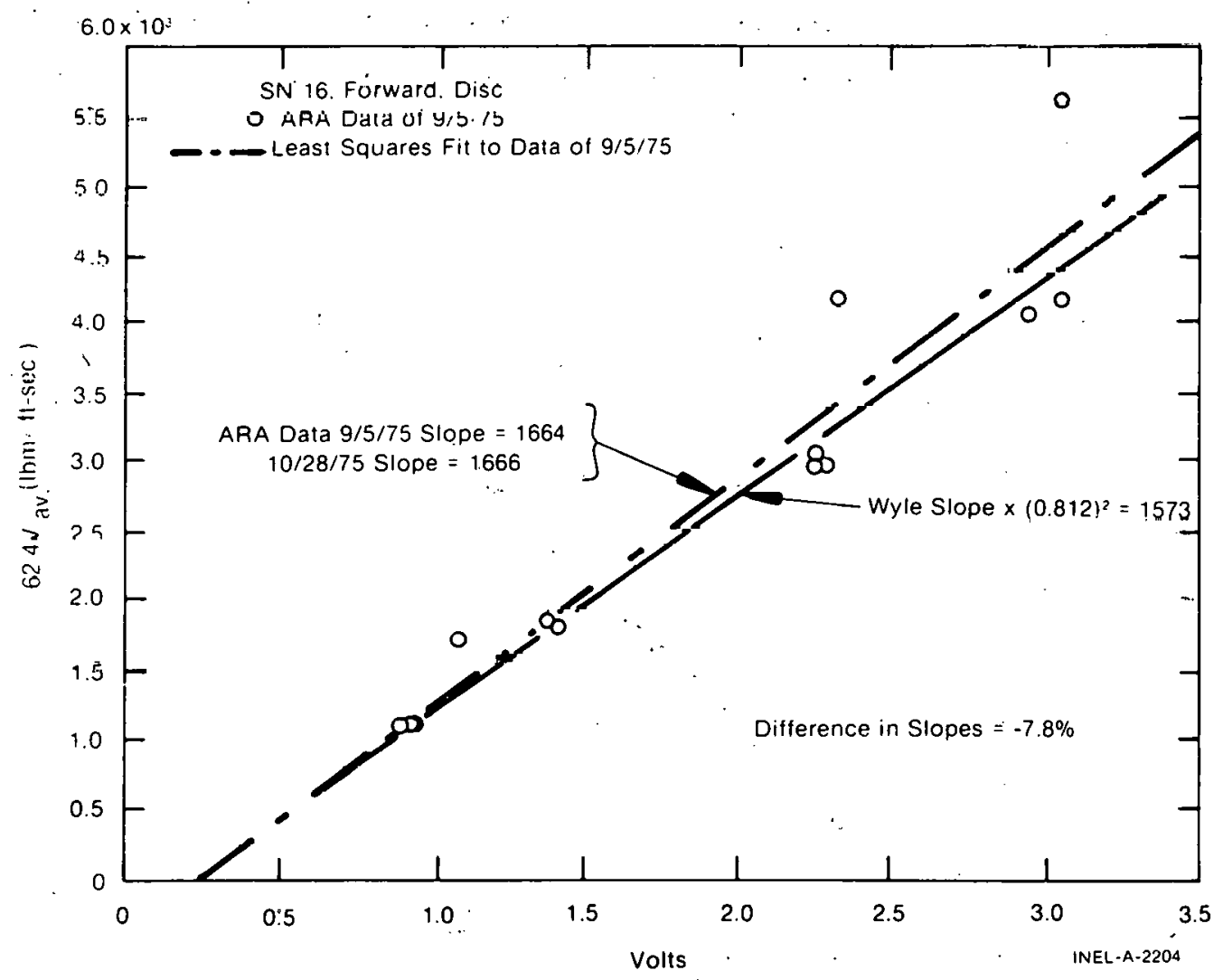

Fig. F-16 Momentum flux using average velocity versus drag disc volts, ARA tests, SN 16, forward. 


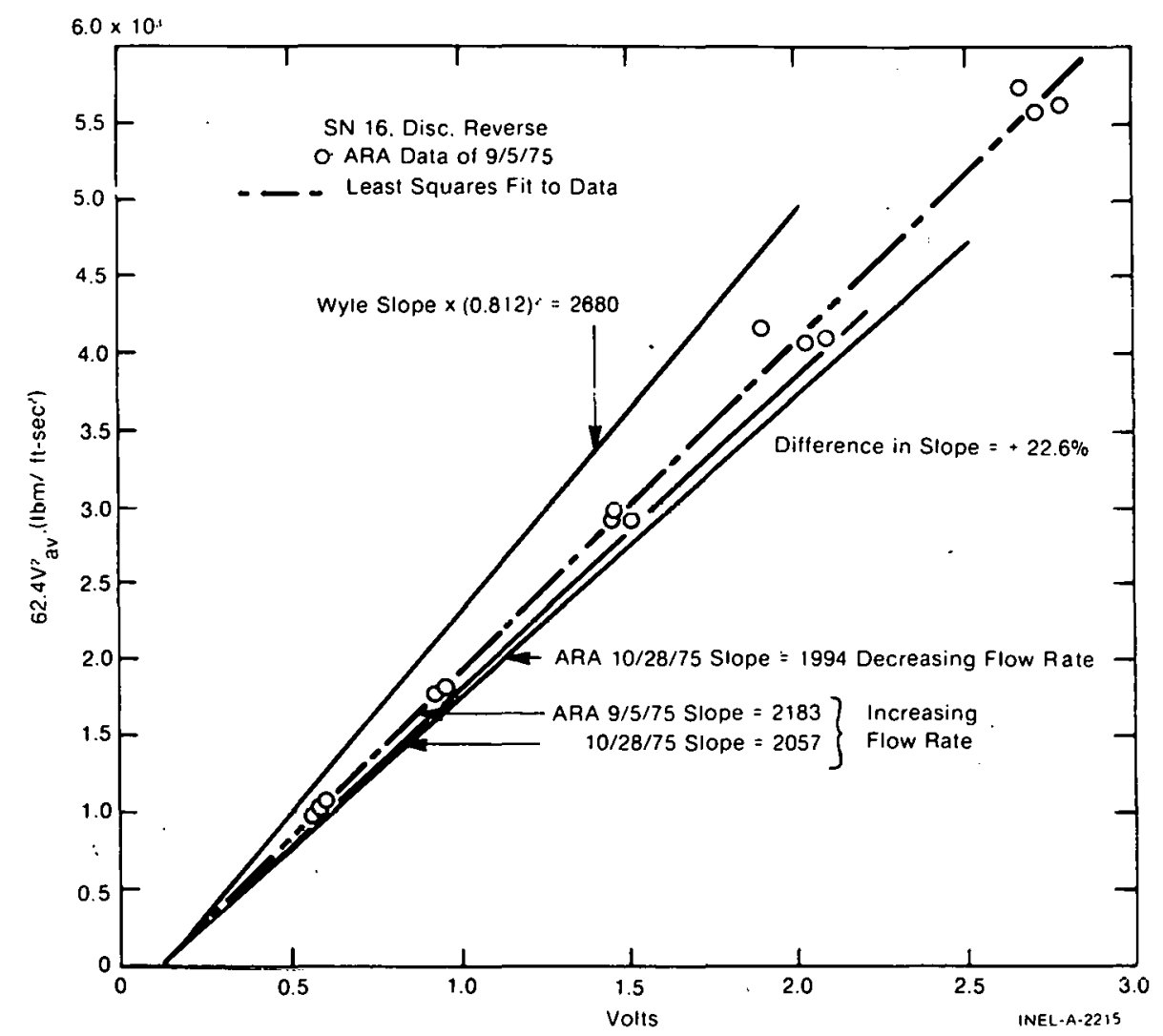

Fig. F-17 Momentum flux using average velocity versus drag disc volts, ARA tests, SN 16, reverse.

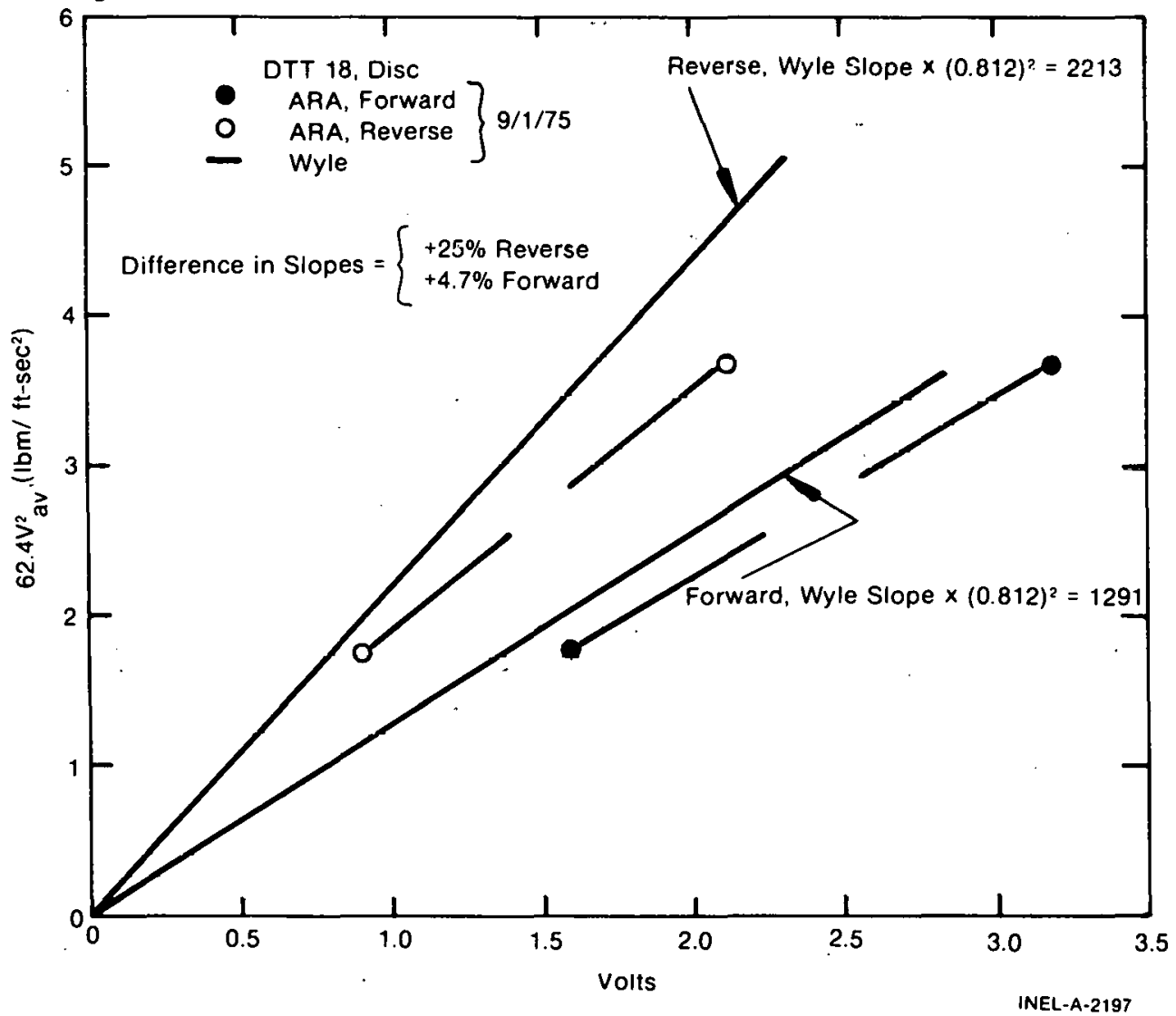

Fig. F-18 Momentum flux using average velocity versus drag disc volts, ARA tests, SN 18, forward and reverse. 




Fig. F-19 Momentum flux using average velocity versus drag disc volts, ARA tests, SN 55, forward and reverse.

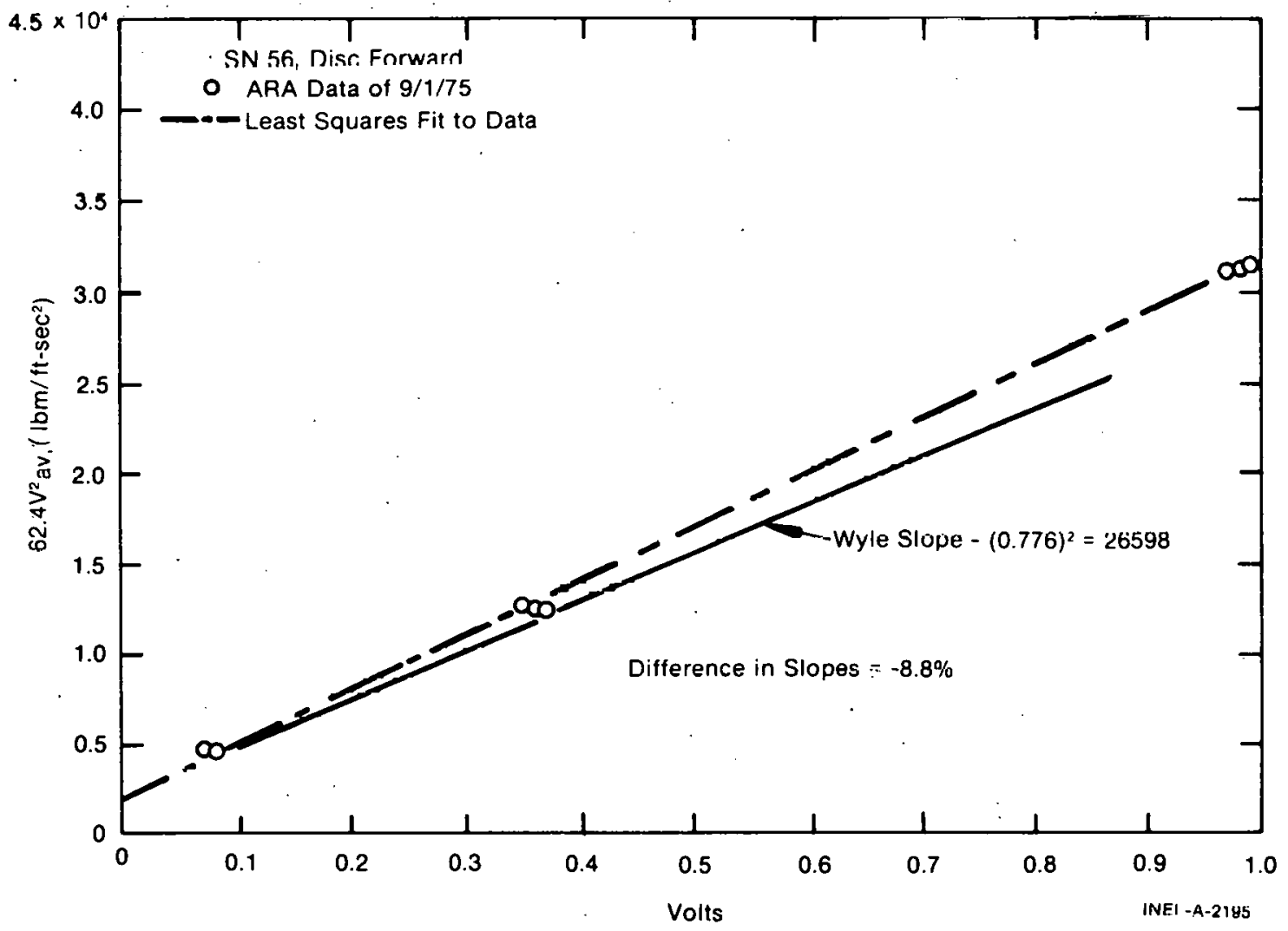

Fig. F-20 Momentum flux using average velocity versus drag disc volts, ARA tests, SN 56, forward. 




Fig. F-21 Momentum flux using average velocity versus drag disc volts, ARA tests, SN 56, reverse.

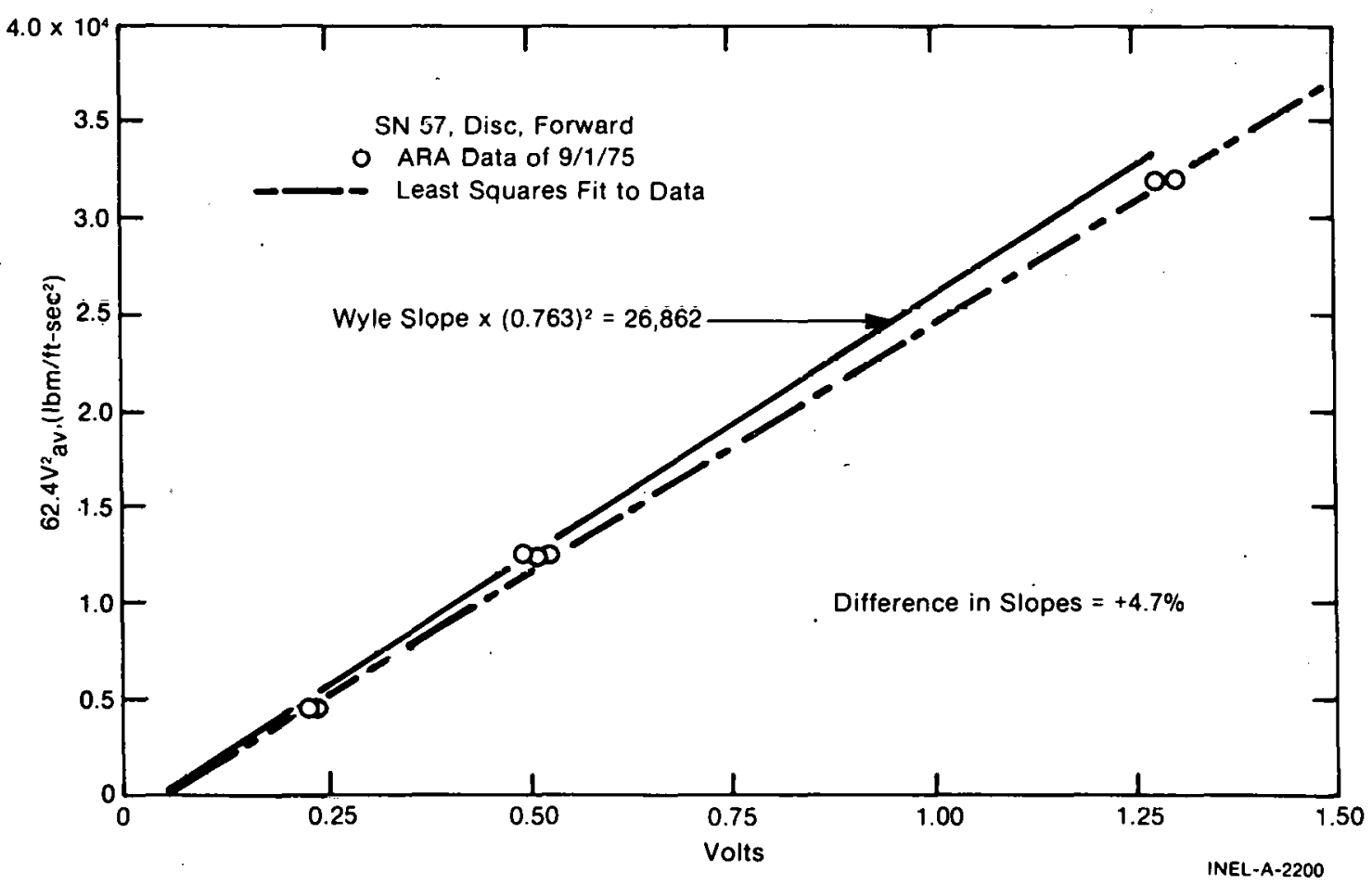

Fig. F-22 Momentum flux using average velocity versus drag disc volts, ARA tests, SN 57, forward. 




Fig. F-23 Momentum flux using average velocity versus drag disc volts, ARA tests, SN 57, reverse.

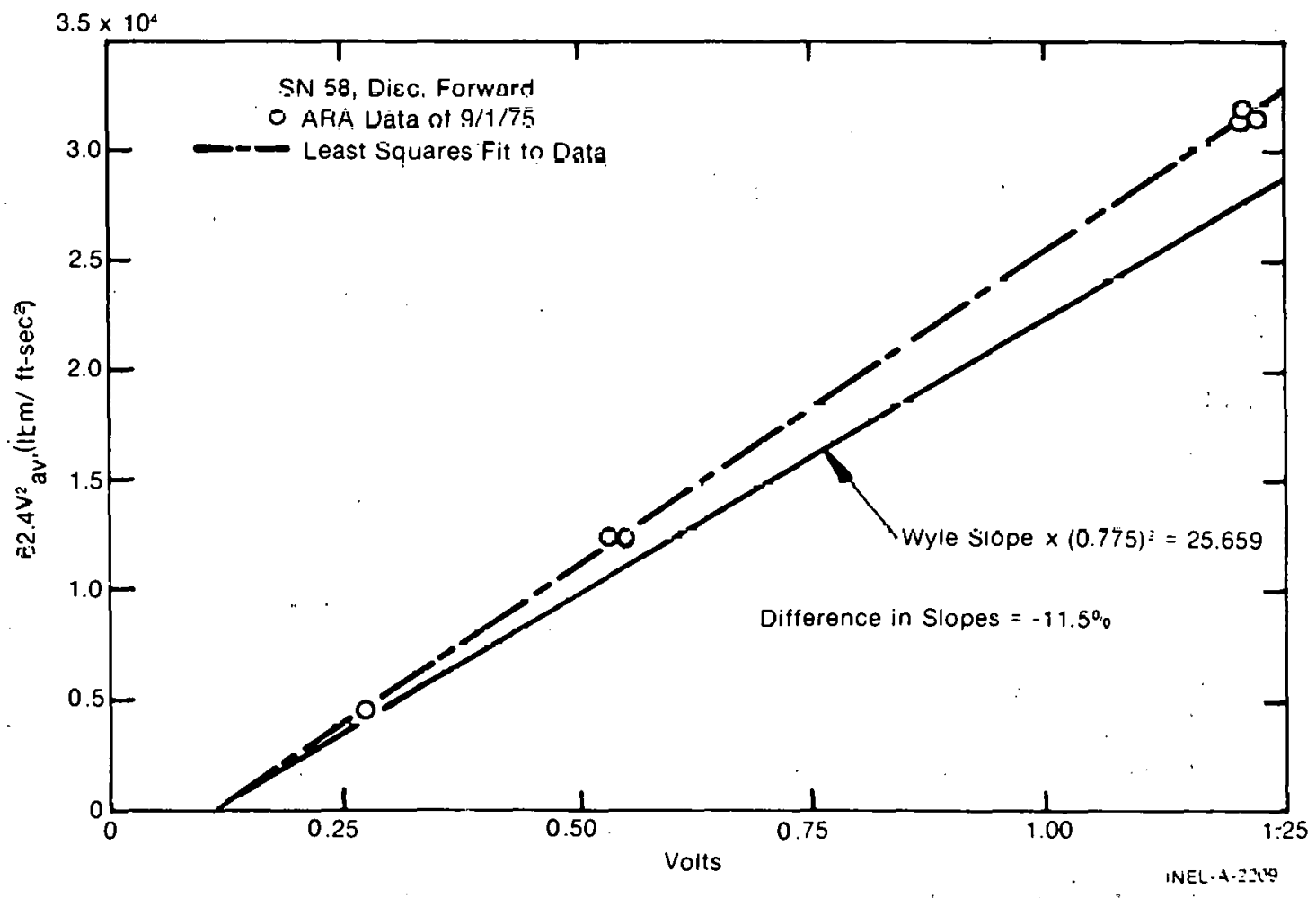

Fig. F-24 Momentum flux using average velocity versus drag disc volts, ARA tests, SN 58, forward. 




Fig. F-25 Momentum flux using average velocity versus drag disc volts, ARA tests, SN 58, reverse.

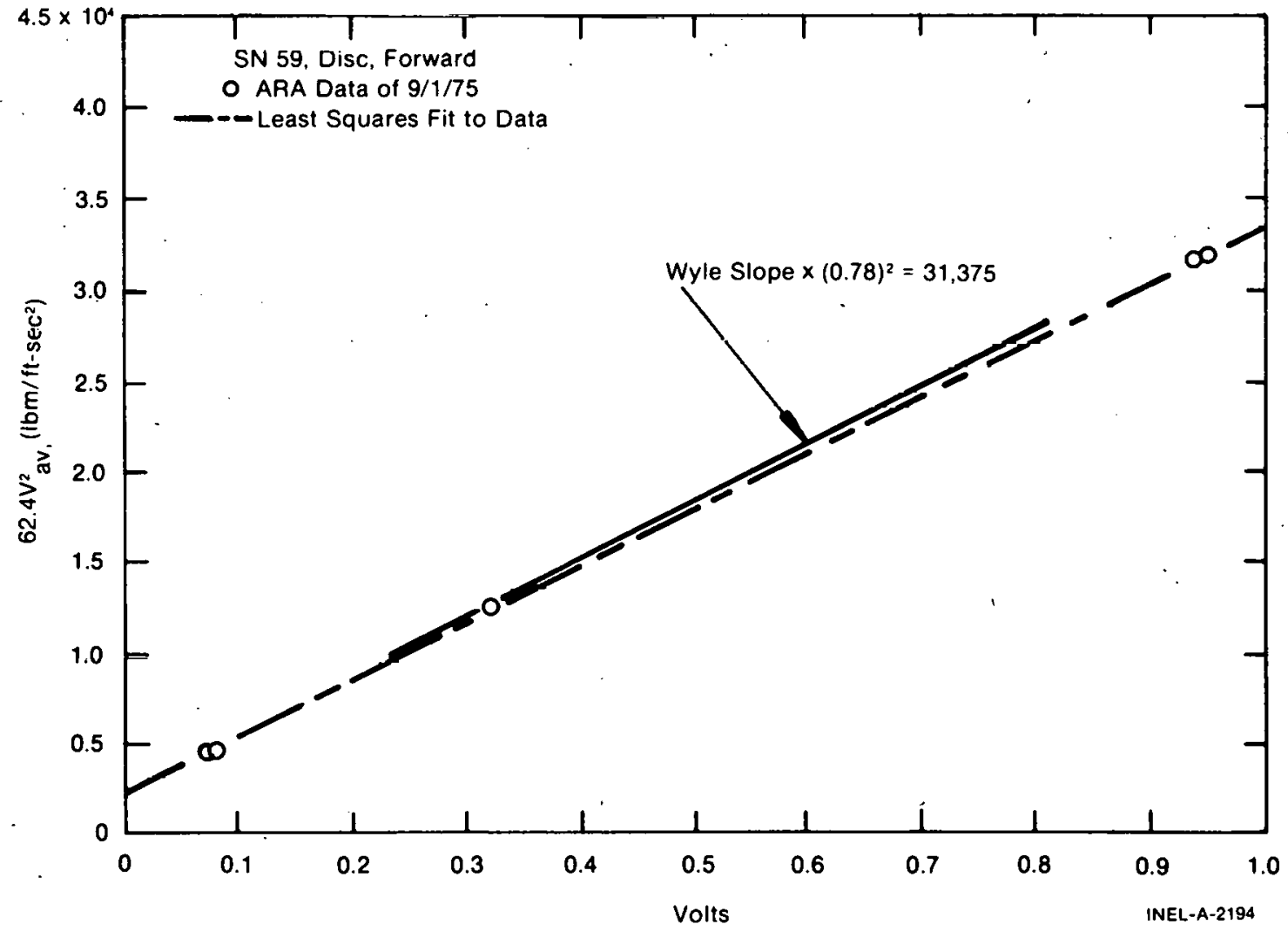

Fig. F-26 Momentum flux using average velocity versus drag disc volts, ARA tests, SN 59, forward. 


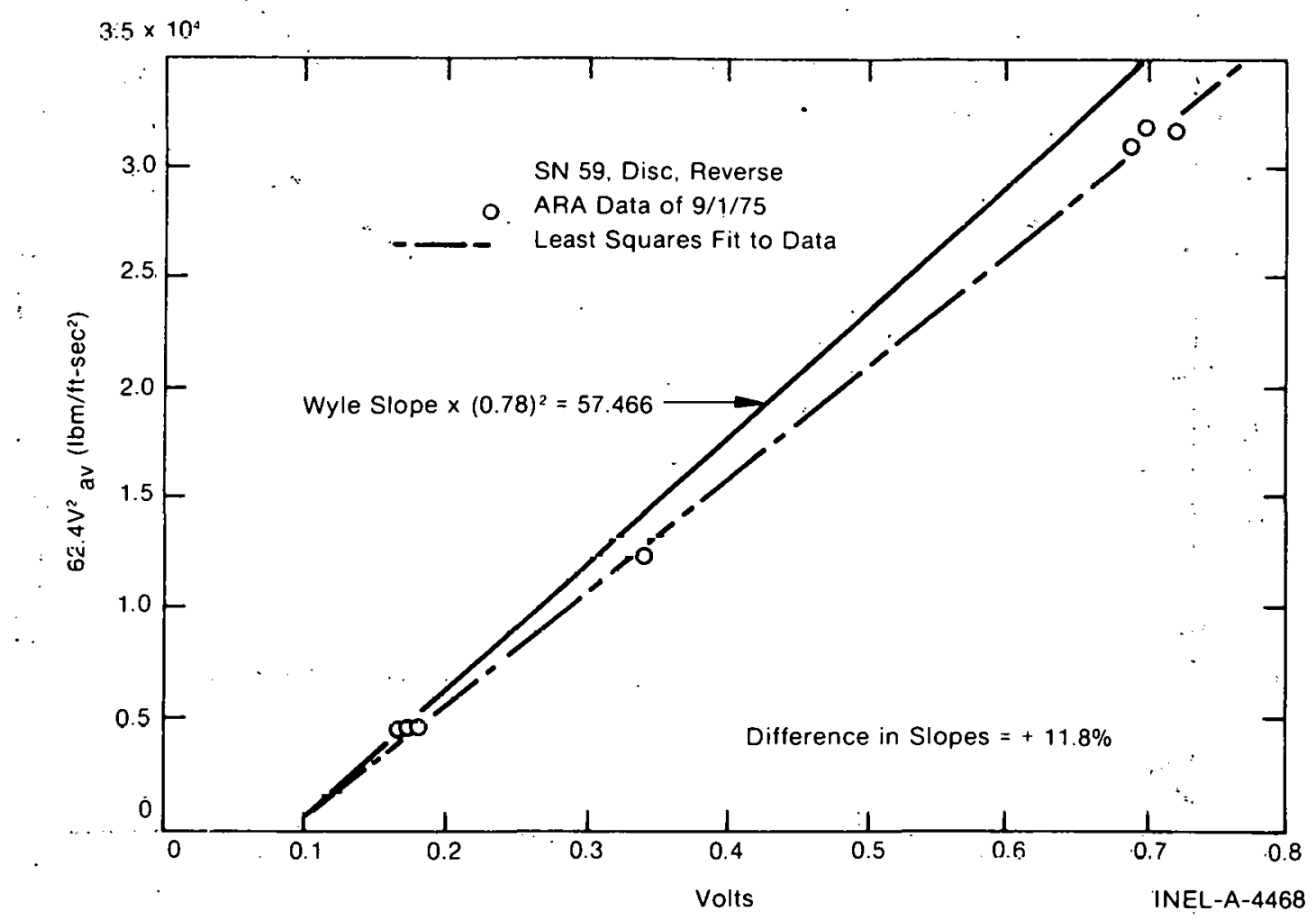

Fig. F-27 Momentum flux using average velocity versus drag disc volts, ARA tests, SN 59, reverse.

A study of the data indicates that most usually (but not always) the modified Wyle velocity and momentum flux are larger than those nhtained from the $\Lambda R \Lambda$ data for the same voltage output. In summary, the turhine and drag disc data for differcnt flow geometries agree reasonably well when the data are corrected for actual flow area. However, differences between the corrected data do exist, indicating that other variables enter the problem.

\section{REFERENCE}

F-1. Internal Report. 


\section{APPENDIX G}

FLOW MAP FOR WCL FULL FLOW TESTS 
THIS PAGE

\section{WAS INTENTIONALLY \\ LEFT BLANK}




\section{APPENDIX G}

\section{FLOW MAP FOR WCL FULL FLOW TESTS}

This appendix contains Table G-I, which has raw and reduced data used to obtain a flow map for the WCL full flow data. The map of Reference G-1 was used. 
TABLE G-I

WCL FULL FLOW TESTS, CALCULATIONS FOR FLOW REGIME MAP

\begin{tabular}{|c|c|c|c|c|c|c|c|c|c|c|c|c|c|}
\hline$\underline{p t}$ & $\underline{\mathrm{I},{ }^{\circ} \mathrm{F}}$ & ${ }^{D} \mathrm{~L} \frac{\mathrm{lbm}}{\mathrm{ft}^{3}}$ & $\frac{\rho_{L}}{\rho_{W}}$ & $\frac{\frac{\sigma}{w a}}{\sigma}$ & $Y=\frac{\rho_{L} \sigma_{W}}{\rho_{W} \sigma_{A}}$ & ${ }^{\circ} \mathrm{G}, \frac{\mathrm{lbm}}{\mathrm{ft}^{3}}$ & 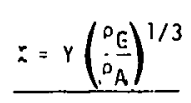 & $\dot{M_{g}, \frac{1 \mathrm{bm}}{\mathrm{hr}}}$ & $v_{s g}=\frac{M^{[a]}}{29.750}, f$ fos & $M_{L}, \frac{\mathrm{lbm}}{h r}$ & $v_{\text {s! }}=\frac{M_{\mathrm{L}}[\mathrm{b}]}{29.75 \rho_{\mathrm{L}}}$ & $\mathrm{YV}_{\mathrm{sL}}, \mathrm{fps}$ & $x v_{s g}, f p s$ \\
\hline 1 & 528 & 47.35 & 0.760 & 3.616 & 1.2876 & 1.925 & 3.868 & 300.6 & 5.249 & $\leq 181.4$ & 3.678 & 4.736 & 20.30 \\
\hline 2 & 528 & 47.39 & 0.761 & 3.616 & 1.2878 & 1.925 & 3.868 & 274.9 & $\begin{array}{r}4.800 \\
1786\end{array}$ & 11017.9 & $\begin{array}{r}7.815 \\
7.120\end{array}$ & $\begin{array}{r}10.064 \\
0.210\end{array}$ & 18.569 \\
\hline 3 & 533 & 47.04 & 0.755 & $\begin{array}{r}3.739 \\
3\end{array}$ & $\begin{array}{l}1.2962 \\
1.2944\end{array}$ & $\begin{array}{l}2.016 \\
\text { 1996 }\end{array}$ & $\begin{array}{l}3.954 \\
3.935\end{array}$ & $\begin{array}{l}706.9 \\
626.8\end{array}$ & $\begin{array}{l}11.786 \\
10.556\end{array}$ & $\begin{array}{l}5976.2 \\
5369.4\end{array}$ & $\begin{array}{l}7.129 \\
5\end{array}$ & $\begin{array}{l}9.240 \\
6.808\end{array}$ & $\begin{array}{l}46.603 \\
41.541\end{array}$ \\
\hline $\begin{array}{l}4 \\
5\end{array}$ & $\begin{array}{l}532 \\
553\end{array}$ & $\begin{array}{l}47.10 \\
47.10\end{array}$ & 0.756 & $\begin{array}{l}3.713 \\
3.713\end{array}$ & $\begin{array}{l}1.2944 \\
1.2944\end{array}$ & 1.996 & $\begin{array}{l}3.935 \\
3\end{array}$ & $\begin{array}{l}626.8 \\
495 ?\end{array}$ & $\begin{array}{r}10.556 \\
8.339\end{array}$ & $\begin{array}{l}3.369 .4 \\
6834.4\end{array}$ & $\begin{array}{r}5.259 \\
7.018\end{array}$ & $\begin{array}{l}0.8086 \\
9.085\end{array}$ & $\begin{array}{l}41.541 \\
32.819\end{array}$ \\
\hline $\begin{array}{l}5 \\
6\end{array}$ & $\begin{array}{l}532 \\
532\end{array}$ & $\begin{array}{l}47.10 \\
47.10\end{array}$ & $\begin{array}{l}0.756 \\
0.756\end{array}$ & $\begin{array}{l}3.713 \\
3.713\end{array}$ & $\begin{array}{l}1.29944 \\
1.2944\end{array}$ & 1.996 & $\begin{array}{l}\text { 3. } \\
\text { 3. } 9355 \\
\text { a }\end{array}$ & 1201.6 & $\begin{array}{r}80.235 \\
20.235\end{array}$ & $\begin{array}{r}5854.4 \\
11575.9\end{array}$ & 8.261 & $\begin{array}{r}9.065 \\
10.694\end{array}$ & 79.636 \\
\hline 7 & $\begin{array}{l}532 \\
532\end{array}$ & 47.10 & 0.756 & 3.713 & $\begin{array}{l}1.2944 \\
1.2944\end{array}$ & 1.996 & $\begin{array}{l}3.935 \\
3.935\end{array}$ & 923.1 & $\begin{array}{l}15.545 \\
15\end{array}$ & 8769.4 & $\begin{array}{l}6.258 \\
6.258\end{array}$ & 8.101 & $\begin{array}{l}1.030 \\
61.178\end{array}$ \\
\hline 8 & 533 & 47.04 & 0.755 & 3.739 & $\begin{array}{l}1.2444 \\
1.2962\end{array}$ & 8.016 & $\begin{array}{l}3.954 \\
3.94\end{array}$ & 630.3 & 10.509 & 5384.1 & 3.847 & 4.987 & 41.553 \\
\hline $\begin{array}{l}8 \\
9\end{array}$ & 530 & $\begin{array}{l}47.04 \\
47.21\end{array}$ & 0.758 & 3.664 & 1.2909 & 1.961 & 3.902 & 328.8 & 5.636 & 5639.7 & 4.015 & 5.183 & 21.989 \\
\hline 10 & 532 & 47.10 & 0.756 & 3.713 & 1.2944 & 1.996 & 3.935 & 377.4 & 6.356 & 5601.5 & 3.998 & 5.175 & 25.012 \\
\hline 11 & 531 & 47.17 & 0.757 & 3.689 & 1.2927 & T. 930 & 3.920 & 368.8 & 6.261 & $\$ 99.0$ & 2.921 & 3.776 & 24.542 \\
\hline 12 & 528 & $\begin{array}{l}47.35 \\
\end{array}$ & 0.760 & $\begin{array}{r}3.616 \\
3\end{array}$ & 1.2876 & $\begin{array}{l}1.925 \\
1023\end{array}$ & $\begin{array}{l}3.868 \\
3.866\end{array}$ & $\begin{array}{l}401.9 \\
788\end{array}$ & $\begin{array}{r}7.018 \\
\end{array}$ & 2802.1 & 1.989 & 2.561 & 27.142 \\
\hline 13 & 527 & $\begin{array}{l}47.62 \\
46.51\end{array}$ & 0.764 & 3.593 & $\begin{array}{l}1.2873 \\
1.2839\end{array}$ & $\begin{array}{l}1.923 \\
1.912\end{array}$ & $\begin{array}{l}3.866 \\
3.886\end{array}$ & $\begin{array}{l}788.3 \\
944.7\end{array}$ & $\begin{array}{l}13.799 \\
16.35\end{array}$ & 1057.6 & $\begin{array}{l}.747 \\
785\end{array}$ & .961 & $\begin{array}{r}53.264 \\
63.248\end{array}$ \\
\hline $\begin{array}{l}14 \\
15\end{array}$ & $\begin{array}{l}529 \\
526\end{array}$ & $\begin{array}{l}46.51 \\
47.46\end{array}$ & $\begin{array}{l}0.747 \\
0.762\end{array}$ & $\begin{array}{l}3.540 \\
3.570\end{array}$ & $\begin{array}{l}1.2839 \\
1.2841\end{array}$ & $\begin{array}{l}1.942 \\
1.839\end{array}$ & $\begin{array}{l}\begin{array}{l}3.868 \\
3.833\end{array} \\
3\end{array}$ & $\begin{array}{r}944.7 \\
1196.0\end{array}$ & $\begin{array}{l}16.352 \\
21.282\end{array}$ & 1086.4 & $\begin{array}{l}.785 \\
752\end{array}$ & $\begin{array}{l}1.008 \\
.966\end{array}$ & $\begin{array}{l}63.248 \\
81.577\end{array}$ \\
\hline $\begin{array}{l}15 \\
16\end{array}$ & $\begin{array}{l}526 \\
525\end{array}$ & $\begin{array}{l}47.46 \\
4753\end{array}$ & $\begin{array}{l}0.162 \\
0.763\end{array}$ & $\begin{array}{l}3.510 \\
3.547\end{array}$ & $\begin{array}{l}1.2841 \\
1.285\end{array}$ & $\begin{array}{r}1.839 \\
1.872\end{array}$ & $\begin{array}{l}3.853 \\
3.817\end{array}$ & 1392.9 & $\begin{array}{l}1.888 \\
25.011\end{array}$ & 2088.1 & 1.477 & $\begin{array}{l}.960 \\
1.894\end{array}$ & $\begin{array}{l}8.571 \\
95.463\end{array}$ \\
\hline $\begin{array}{l}10 \\
17\end{array}$ & $\begin{array}{l}535 \\
368\end{array}$ & 54.91 & 0.881 & $\begin{array}{l}3.747 \\
1.784\end{array}$ & $\begin{array}{l}1.5060 \\
1.1197\end{array}$ & $0.3 \div 2$ & 1.945 & 0 & 0 & $\begin{array}{r}5079.4 \\
50.4\end{array}$ & 3.109 & 3.482 & 0.400 \\
\hline 18 & 393 & 53.74 & 0.866 & 1.931 & 1.1371 & 0.498 & 2.176 & 0 & 0 & 10693.3 & 6.664 & 7.577 & \\
\hline 19 & 400 & 53.55 & $0.8 \in-1$ & 0.977 & 1.1423 & 0.537 & 2.242 & 0 & 0 & 12571.9 & 8.002 & 9.141 & 0 \\
\hline 20 & 420 & 52.30 & 0.848 & 2.124 & 1. 1583 & 0.66 .7 & 2.444 & 710.0 & 35.785 & 10329.3 & 6.894 & 7.985 & 87.453 \\
\hline 21 & 419 & $\begin{array}{l}52.35 \\
5.25\end{array}$ & 0.848 & 2.116 & $\begin{array}{l}1.1575 \\
1.1575\end{array}$ & $\begin{array}{l}0.660 \\
0.660\end{array}$ & $\begin{array}{l}2.434 \\
2.434\end{array}$ & 495.7 & $\begin{array}{r}25.246 \\
21\end{array}$ & $\begin{array}{l}9357.3 \\
8012 ?\end{array}$ & $\begin{array}{l}6.269 \\
5.51\end{array}$ & 7.257 & $\begin{array}{l}61.437 \\
51\end{array}$ \\
\hline 22 & 419 & $\begin{array}{l}52.35 \\
52.35\end{array}$ & $\begin{array}{l}0.848 \\
0.848\end{array}$ & $\begin{array}{l}2.116 \\
2.116\end{array}$ & $\begin{array}{l}.1555 \\
1.1555\end{array}$ & $\begin{array}{l}0.660 \\
0.6 \in 0\end{array}$ & $\begin{array}{l}2.434 \\
2.434\end{array}$ & $\begin{array}{l}472.6 \\
376.5\end{array}$ & 21. (1938. & $\begin{array}{r}8712.2 \\
103993\end{array}$ & $\begin{array}{l}5.541 \\
6.919\end{array}$ & $\begin{array}{l}6.414 \\
8.009\end{array}$ & $\begin{array}{l}5.137 \\
49676\end{array}$ \\
\hline $\begin{array}{l}23 \\
24\end{array}$ & $\begin{array}{l}4199 \\
420\end{array}$ & $\begin{array}{l}52.35 \\
52.30\end{array}$ & $\begin{array}{l}0.848 \\
0.848\end{array}$ & 2.124 & $\begin{array}{l}1.15 / 5 \\
1.1583\end{array}$ & $\begin{array}{l}0.6 t 0 \\
0.6 \varepsilon 7\end{array}$ & $\begin{array}{l}\text {. } 2.434 \\
2.444\end{array}$ & $\begin{array}{l}370.0 \\
388.2\end{array}$ & 19.563 & $12=5.4$ & $\begin{array}{l}6.919 \\
7.931\end{array}$ & $\begin{array}{l}8.009 \\
9.185\end{array}$ & $\begin{array}{l}4.6 \% 6 \\
47.809\end{array}$ \\
\hline $\begin{array}{l}<4 \\
25\end{array}$ & $\begin{array}{l}400 \\
424\end{array}$ & 52.53 & $\begin{array}{l}.0 .046 \\
0.845\end{array}$ & 2.156 & 1.1617 & 0.696 & 2.486 & 531.6 & 25.674 & $12 j E 5.1$ & 7.718 & 8.967 & 63.827 \\
\hline 26 & 420 & 52.80 & 0.848 & 2.124 & 1.1583 & 0.667 & 2.444 & 678.9 & 34.213 & $7 \equiv 43.2$ & 4.866 & 5.636 & 83.611 \\
\hline 27 & 420 & 52.80 & 0.848 & 2.124 & 1.1583 & 0.667 & 2.444 & 453.5 & 22.854 & $5] \in 4.7$ & 3.237 & 3.749 & 55.851 \\
\hline 28 & 419 & 52.35 & 0.848 & 2.116 & 0.1575 & 0.660 & 2.434 & 400.0 & 20.377 & 4397.5 & 3.115 & 3.605 & 49.588 \\
\hline 29 & 417 & 52.94 & 0.850 & 2. 100 & $\begin{array}{l}1.1588 \\
1 \\
15550\end{array}$ & 0.646 & $\begin{array}{l}2.413 \\
2.00\end{array}$ & $\begin{array}{l}294.4 \\
177.0\end{array}$ & $\begin{array}{r}15.319 \\
0.250\end{array}$ & $47 C 5.0$ & $\begin{array}{l}2.797 \\
2.565\end{array}$ & 3.233 & 36.960 \\
\hline 30 & 416 & $\begin{array}{r}52.99 \\
52\end{array}$ & $\begin{array}{r}0.851 \\
7.851\end{array}$ & $\begin{array}{r}2.093 \\
2.093\end{array}$ & $\begin{array}{l}1.1550 \\
\end{array}$ & $\begin{array}{l}0.639 \\
0\end{array}$ & $\begin{array}{l}2.402 \\
2.402\end{array}$ & $\begin{array}{l}177.9 \\
225.8\end{array}$ & $\begin{array}{r}9.358 \\
11.878\end{array}$ & 4080.1 & $\begin{array}{l}2.652 \\
3.3130\end{array}$ & 3.063 & $\begin{array}{l}22.482 \\
28\end{array}$ \\
\hline 32 & $\begin{array}{l}417 \\
417\end{array}$ & 52.94 & 3.850 & $\begin{array}{l}2.093 \\
2.100\end{array}$ & $\begin{array}{l}0.150 \\
1.1558\end{array}$ & $\begin{array}{l}0.039 \\
0.646\end{array}$ & 2.413 & 254.3 & $\begin{array}{l}13.232 \\
13.23\end{array}$ & $\begin{array}{l}4.8 \\
4 \equiv 11.8\end{array}$ & $\begin{array}{l}3.130 \\
3.119\end{array}$ & $\begin{array}{l}3.015 \\
3.605\end{array}$ & 31.926 \\
\hline [a] & \multicolumn{13}{|c|}{$\dot{M}_{g}=c_{g} \mathrm{AV}$} \\
\hline \multirow{2}{*}{\multicolumn{14}{|c|}{$v_{s g}=\frac{\dot{M}_{g}}{c_{g}^{A}}=\frac{\dot{n}_{j}}{29 . . \dot{5} \sigma_{g}}, f f s$}} \\
\hline & & & & & & & & & & & & & \\
\hline \multicolumn{14}{|c|}{ where $A=1.19$ aches $^{2}$. } \\
\hline & & & & & & & & & & & & & \\
\hline
\end{tabular}




\section{REFERENCE}

G-1. G. W. Govier and K. Aziz, The Flow of Complex Mixtures in Pipes, New York: Van Nostrand Reinhold, 1972. 
THIS PAGE

\section{WAS INTENTIONALLY \\ LEFT BLANK}


APPENDIX H

WEIGHT CALIBRATION OF DTT DRAG DISC 


\section{THIS PAGE}

\section{WAS INTENTIONALLY \\ LEFT BLANK}




\section{APPENDIX H}

\section{WEIGHT CALIBRATION OF DTT DRAG DISC}

This appendix consists of an Aerojet Nuclear Company ${ }^{[a]}$ letter from D. Goodrich and S. Silverman to J. R. Karvinen summarizing an investigation of ARA weight calibrations.

[a] Aerojet Nuclear Companny has been succeeded by EG\&G Idaho, Inc, as of October 1, 1976. 


\section{Aerojet nuclear Company}

Interoffice Correspondence

June 30,1975

J.. R. Karvinen

Roqers 310

WEIGHT CALIBRATION OF DTT DRAG DISC - LDG-9-75

Your request for an analys is of calibrating the drag disc using weights has been completed for plenum; typc-DTTs. (S/Ns 14, 15, 18, 19)

and piping types. (S/Ns $58,59,56$ ).. This technique does: appear to have merit:. A brief discussion of our analysis follows.

The: force seen by the drag disc is $F=1 / 2 \rho V^{2} A C_{d}$

$$
\begin{aligned}
& F=\text { force } \text { on drag disc } \\
& p=\text { density of fluid } \\
& V=\text { velocity of fluid. } \\
& C_{d}=\text { drag coefficient } \\
& A=\text { Area }
\end{aligned}
$$

If the weight calibration is valid then the Wyle calibration should agree. with the weight calibration technique. The romparison is accomplished by converting the weight calibration to an equivalent ov2 and plotting with the Wyle data. To perform this calculation the following assumptions were made:

1. The effective: drag area was assumed. to be the area of the drag disc plus the area of the support arm between the DTT housing and the disc (see Figure 1).

The areas were determined to be:

\section{Plenum}

Diameter of drag disc

Area of drag disc

Distance suppurl rud is

in the flow stream

Diameter of support rod:

Effective support rod area

Total. effective area
.595 tn . $6 n n$ in. dia. $.2827^{\circ}$ in 2

.28 in.

.155 to .156 in. dia. .0436

.3263 
J. R. Karvinen

June 30,1975

LDG-8-75

Page 2

\section{Piping}

Diameter of drag disc

Area of drag disc

Distance support rod is in the flow stream

Diameter of support rod

Effective support rod drag area

Total effective area

$$
\begin{aligned}
& .295 \text { to } 300 \text { in. dia. } \\
& .0707 \text { in } 2
\end{aligned}
$$

.50 in.

.155 to .156 in. dia.

$\frac{.070^{2} \mathrm{in}^{2}}{.1409 \mathrm{in}^{2}}$

2. The drag coefficient was assumed to be the same for Reynolds numbers from $10^{3}$ to $10^{5}$. The number used for the drag coefficient was 1.17 .

3. The weight of water was assumed to te $62.41 \mathrm{bs} / \mathrm{ft}^{3}$ and the conversion from pounds to grams used was $453.6 \mathrm{~g} / 1 \mathrm{~b}$.

4. The effective drag area is actually composed for two areas as shown in Figure 1 . In fluid flow these two areas have two different moment arms $d_{1}$ and $d_{2}$. Therefore, to relate the weight calibration to the Wyle tests, one must compensate for these moment arms. This is accomplished by a simple moment balance:

$$
F_{3} d_{1}=F_{1} d_{1}+F_{2} d_{2}
$$

where:

$$
\begin{aligned}
F_{1}= & \text { force on drag disc } \\
F_{2}= & \text { force on support arm } \\
F_{3}= & \text { equivalent force if both } F_{1} \text { and } F_{2} \text { were acting } \\
& \text { at the center of the drag disc } \\
d_{1}= & \text { distance to center of drag disc } \\
d_{2}= & \text { distance to center of support arm drag area }
\end{aligned}
$$

For the piping drag disc $d_{1}=1.85$ and $c_{2}=1.45$. Therefore, if $F_{1}$ and $F_{2}$ are equal (areas are equal) then

$$
F_{3}=F_{1} \quad\left(1+\frac{d_{2}}{d_{1}}\right) .
$$

If an equivalent force $F_{3}$ is applied, the output must be divided by

$$
1.7838=\left(1+\frac{d_{2}}{d_{1}}\right)
$$


J. R. Karvinen

June 30,1975

LDG-8-7.5

Page 3

to relate this force to flow conditions.

This effect for the plenum drag disc is smaller due to the larger disc and smaller support arm drag area. The support area is only $15.4 \%$ of the disc drag area, therefore,

$$
\frac{t_{3}}{d_{1}}
$$

must be reduced by .154 . Using the above and $a d_{1}=1.850$ inches and $d_{2}=$ 1.31 inches. The nit.put will he high by 1.1542 .

The force equation was rewritten to solve for $\rho v^{2}$ :

$$
\rho V^{2}=\frac{2 F}{A C_{d}} \text {. }
$$

Since

$$
\frac{2}{A C}
$$

is a constant this quantity was calculated and found to be .01869 for plenum types and .00808 for the fiping types. These quantities were then divided into the weight used for the weight test to obtain an equivalent $\rho V^{2}$. This calculation is satisfactory for forward flow but for reverse flow the equivalent $\rho \vee 2$ is not the same function as forward flow due to shadowing by the turbine. The weight calibration test assumes no shadowing. An effective drag disc area was calculated for reversc flow by ratioing drag disc output for the $! y$ yle tests. This value was .6010 for the plenum and .5147 for the piping DTT.

The above analysis was then applied to the weight calibration data supplied by you. To illustrate the technique piping transducer $S / N 58$ data will be used and the calculation procedure given here:

\section{Forward Flow}

1. Calculate equivalent $\rho v^{2}$ by dividing weight in grams by .00808 (see Table I).

2. Correct the VRT output for offset and divide by 1.7838 to correct for moment arm.

3. The $\rho V^{2}$ equivalent can now be plotted against the corrected VRT output (see Figure 2). This will be calibration curve for forward flow. 
Drag Area No. 1 . dcam $=0.6$ in. Plenum 0.3 in. Piping


$\begin{array}{cc}\text { Piping } & \text { Plenum } \\ 1.85 & 1.85 \\ 1.45 & 1.31\end{array}$

0

Fig. H-1 Drag disc, pertinent dimensions.

IABLE $\mathrm{H}-1$

FORWARD FLOW (S/N 58)

\begin{tabular}{|c|c|c|c|}
\hline $\begin{array}{c}\text { Weight } \\
\text { Gram }\end{array}$ & VRT Uutput & $\begin{array}{c}\rho v^{2} \\
\text { tquivalent }\end{array}$ & $\begin{array}{l}\text { Corrected } \\
\text { VRT Output }\end{array}$ \\
\hline 0 & .02 & 0 & $0 \cdots$ \\
\hline 147 & .80 & 18,193 & .44 \\
\hline 287 & 1.48 & 35,579 & .82 \\
\hline 427 & 2.24 & 52,846 & 1.25 \\
\hline 567 & 2.86 & 76,173 & 1.60 \\
\hline 707 & 3.17 & 87,500 & 1.78 \\
\hline
\end{tabular}




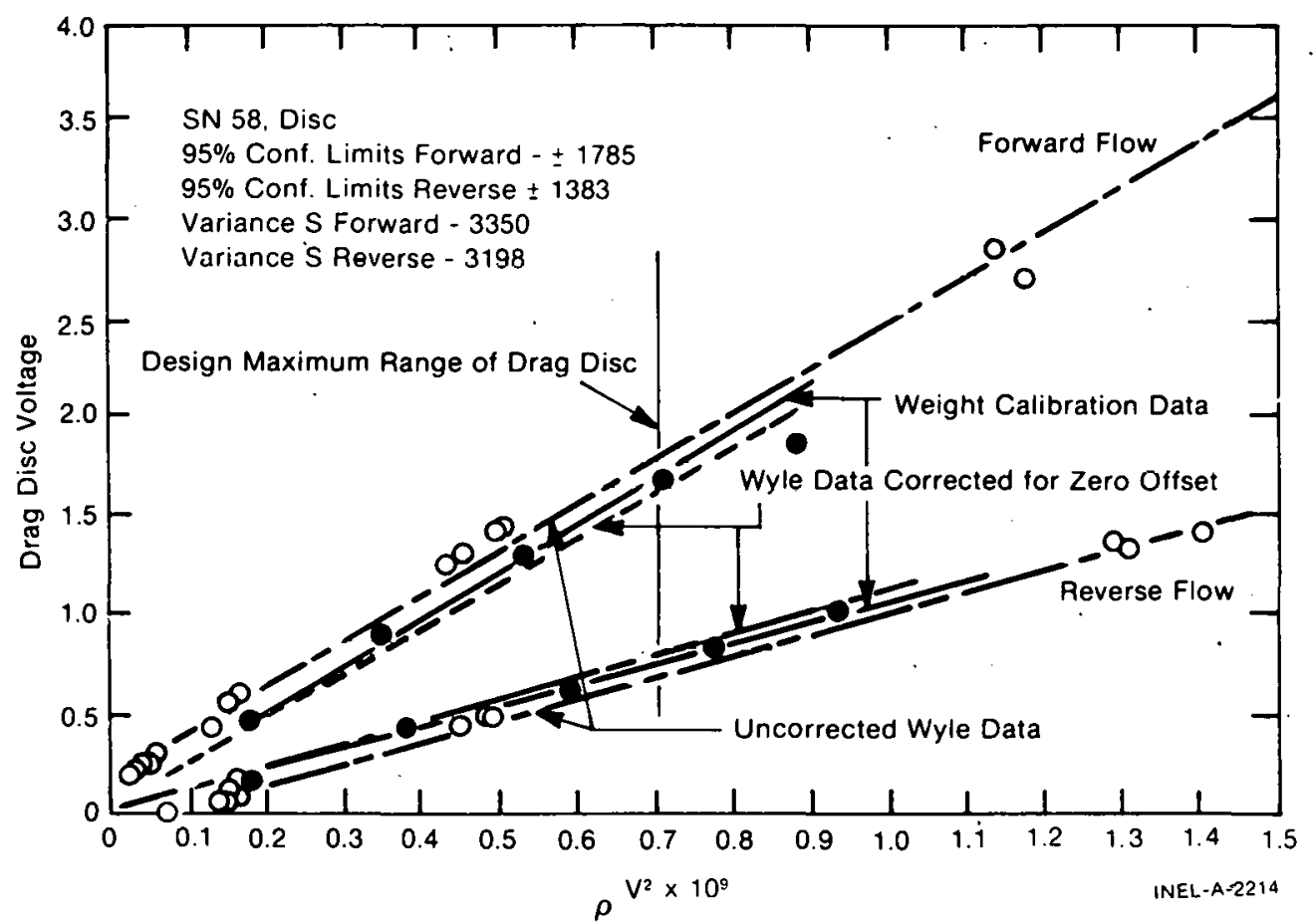

Fig. H-2 Drag disc volts versus momentum flux, from Wyle data and ARA weight calibration, SN 58.

\section{TABLE H-II}

\section{REVERSE FLOW (S/N 58)}

\begin{tabular}{rrrr}
$\begin{array}{c}\text { Weight } \\
\text { Grams }\end{array}$ & VRT Output & $\begin{array}{c}\rho V^{2} \\
\text { Equivalent }\end{array}$ & $\begin{array}{c}\text { Corrected } \\
\text { VRT Output }\end{array}$ \\
\cline { 2 - 2 } & .01 & 0 & 0 \\
157 & .81 & 19,430 & .23 \\
317 & 1.45 & 39,233 & .42 \\
477 & 2.10 & 59,035 & .60 \\
637 & 2.71 & 78,837 & .78 \\
927 & 3.31 & 114,728 & 1.96 \\
\hline
\end{tabular}




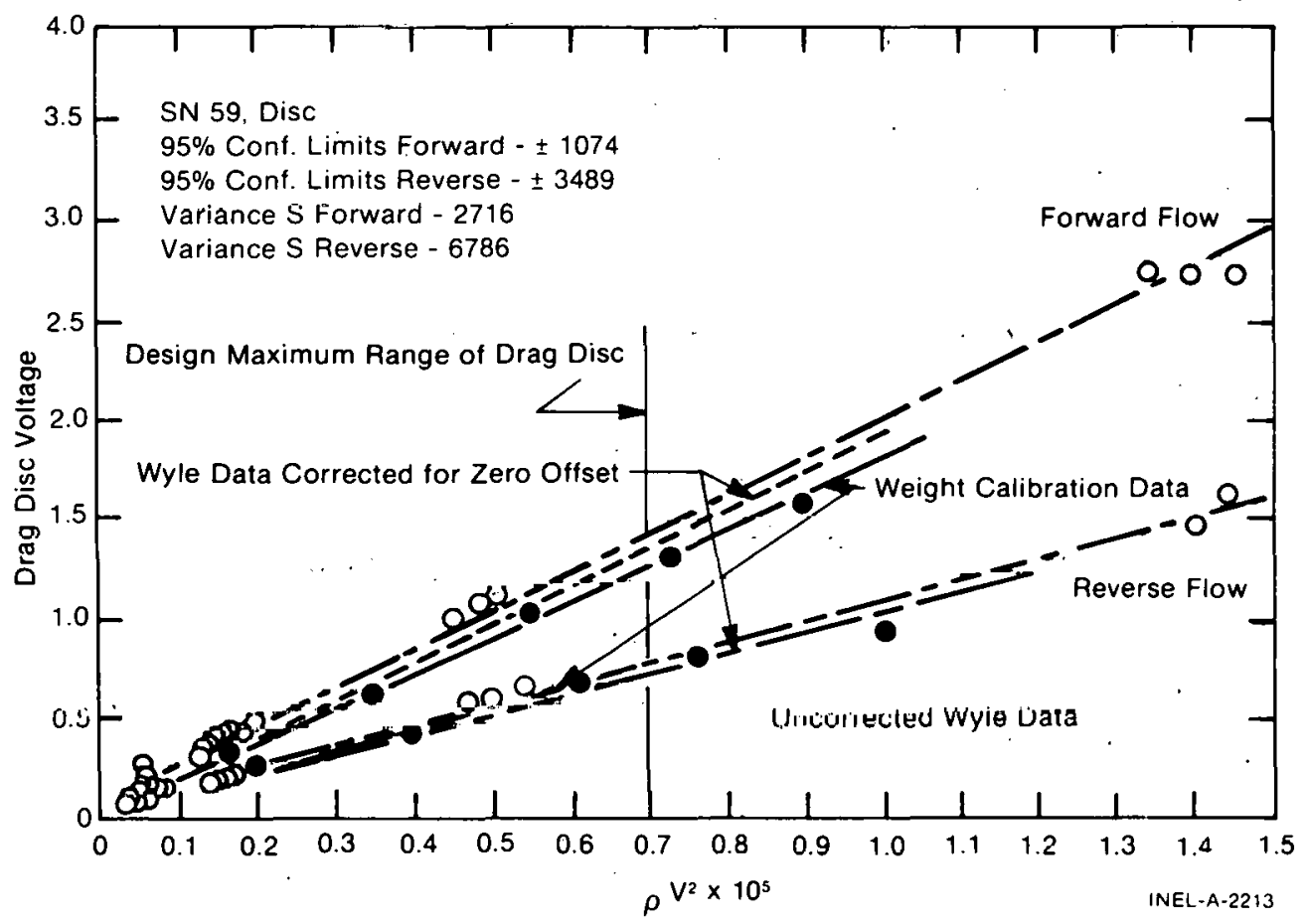

Fig. H-3 Drag disc volts versus momentum flux, from Wyle data and ARA weight calibration, SN 59.

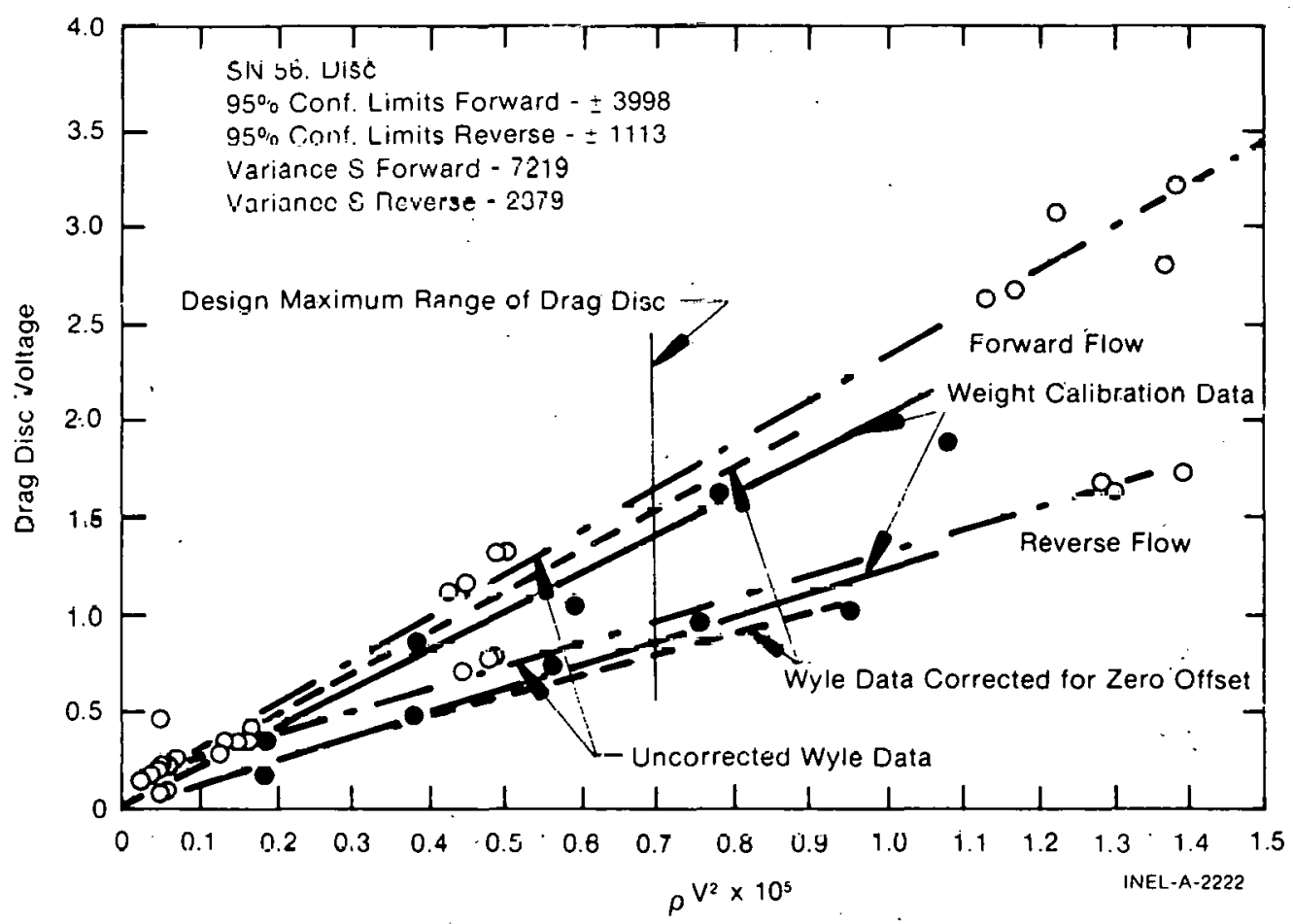

Fig. H-4 Drag disc volts versus momentum flux, from Wyle data and ARA weight calibration, SN 56. 


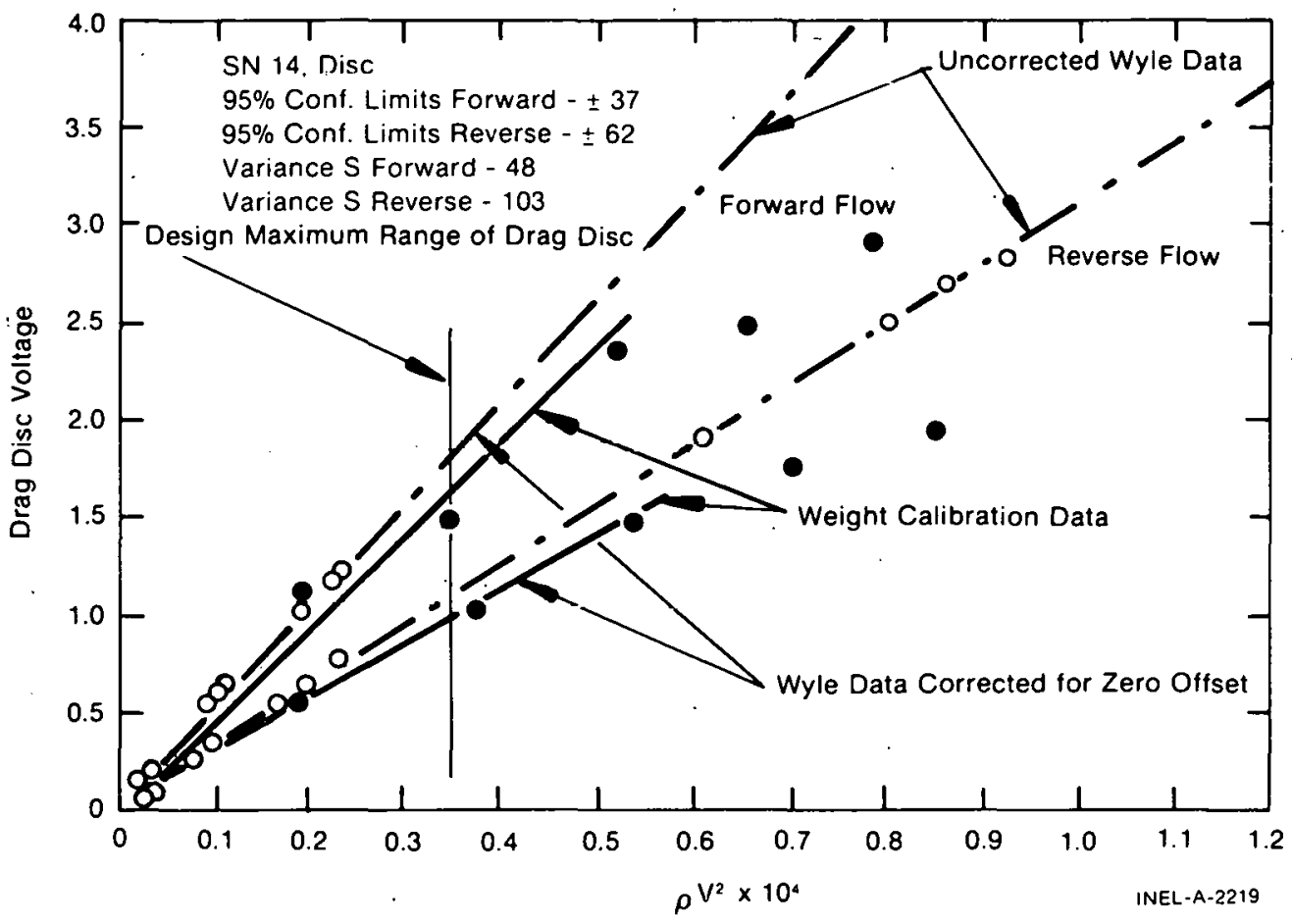

Fig. H-5 Drag disc volts versus momentum flux, from Wyle data and ARA weight calibration, SN 14.



Fig. H-6 Drag disc volts versus momentum flux, from Wyle data and ARA weight calibration, SN 15. 


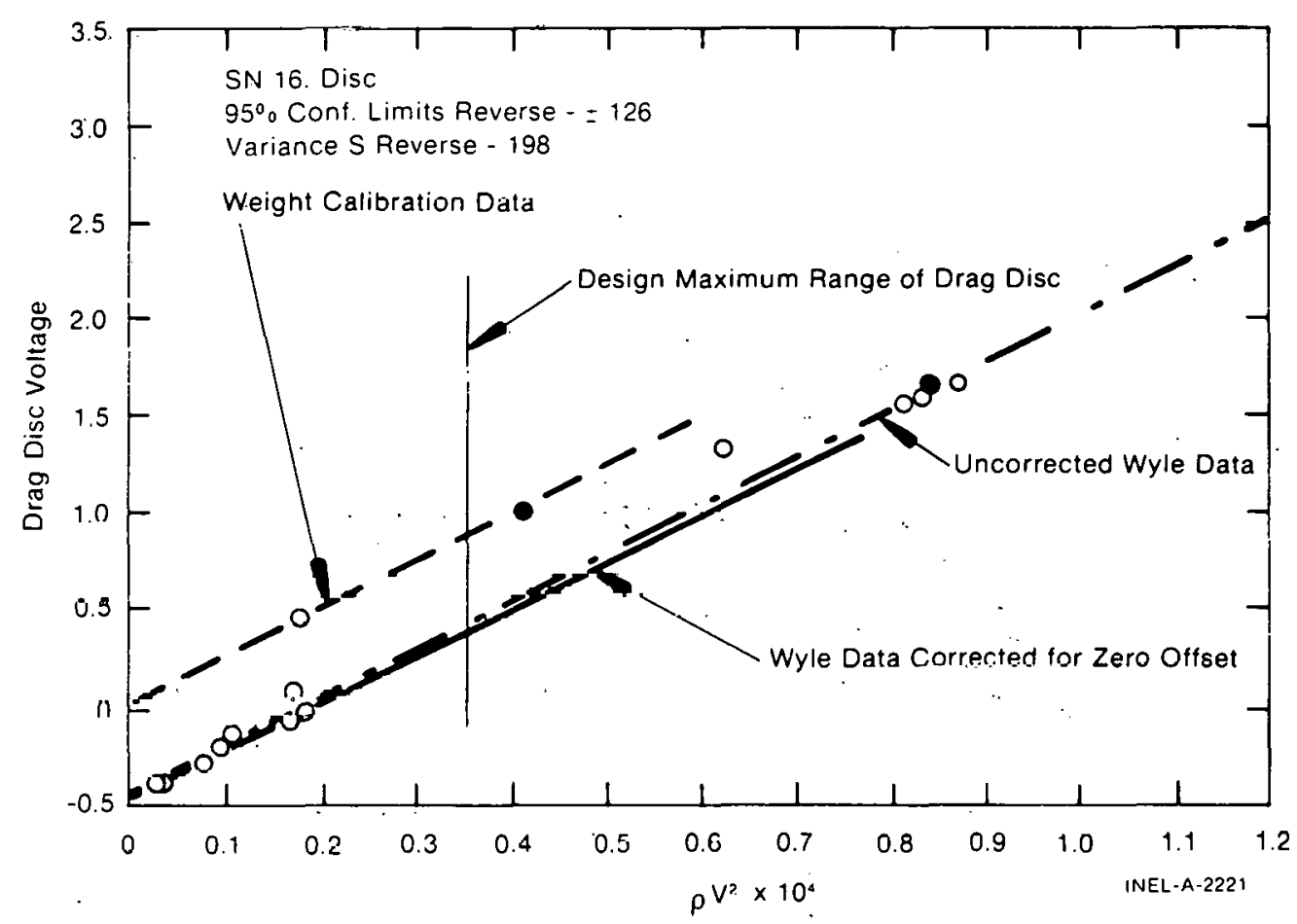

Fig. H-7 Drag disc volts versus momentum flux, from Wyle data and ARA weight calibration, SN 16, reverse.

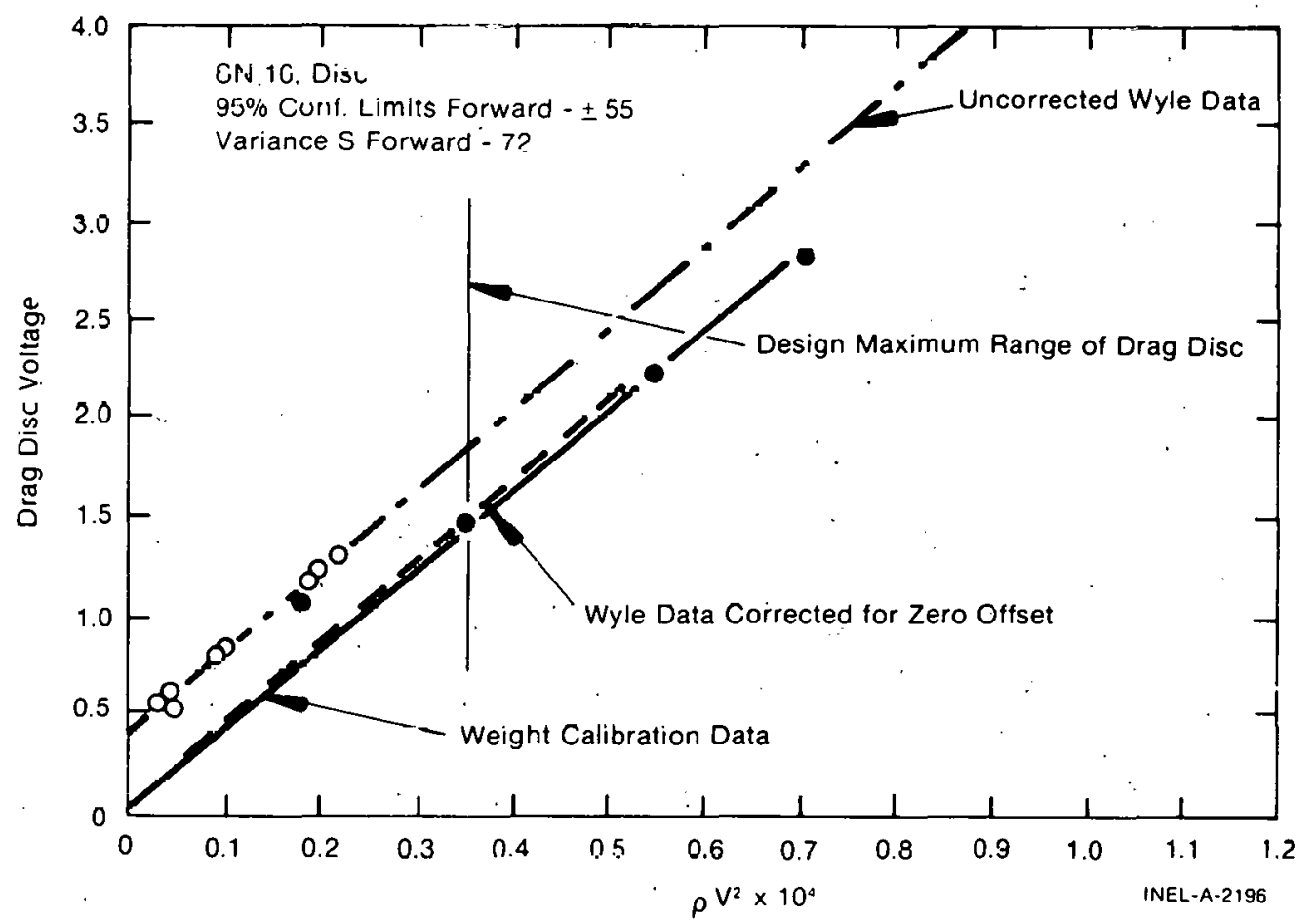

Fig. H-8 Drag disc volts versus momentum flux, from Wyle data and ARA weight calibration, SN 16, forward. 


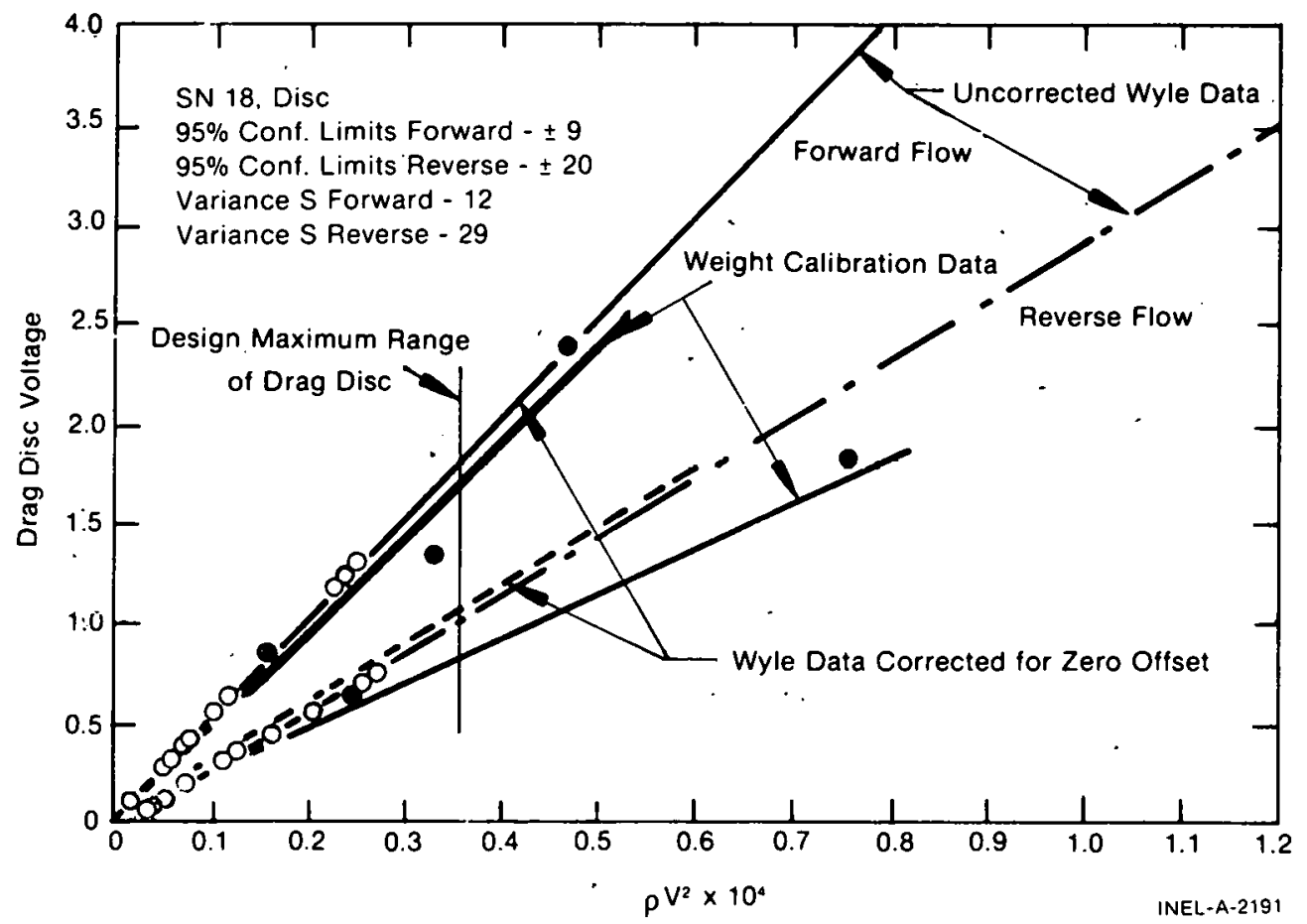

Fig. H-9 Drag disc volts versus momentum flux, from Wyle data and ARA weight calibration, SN 18.

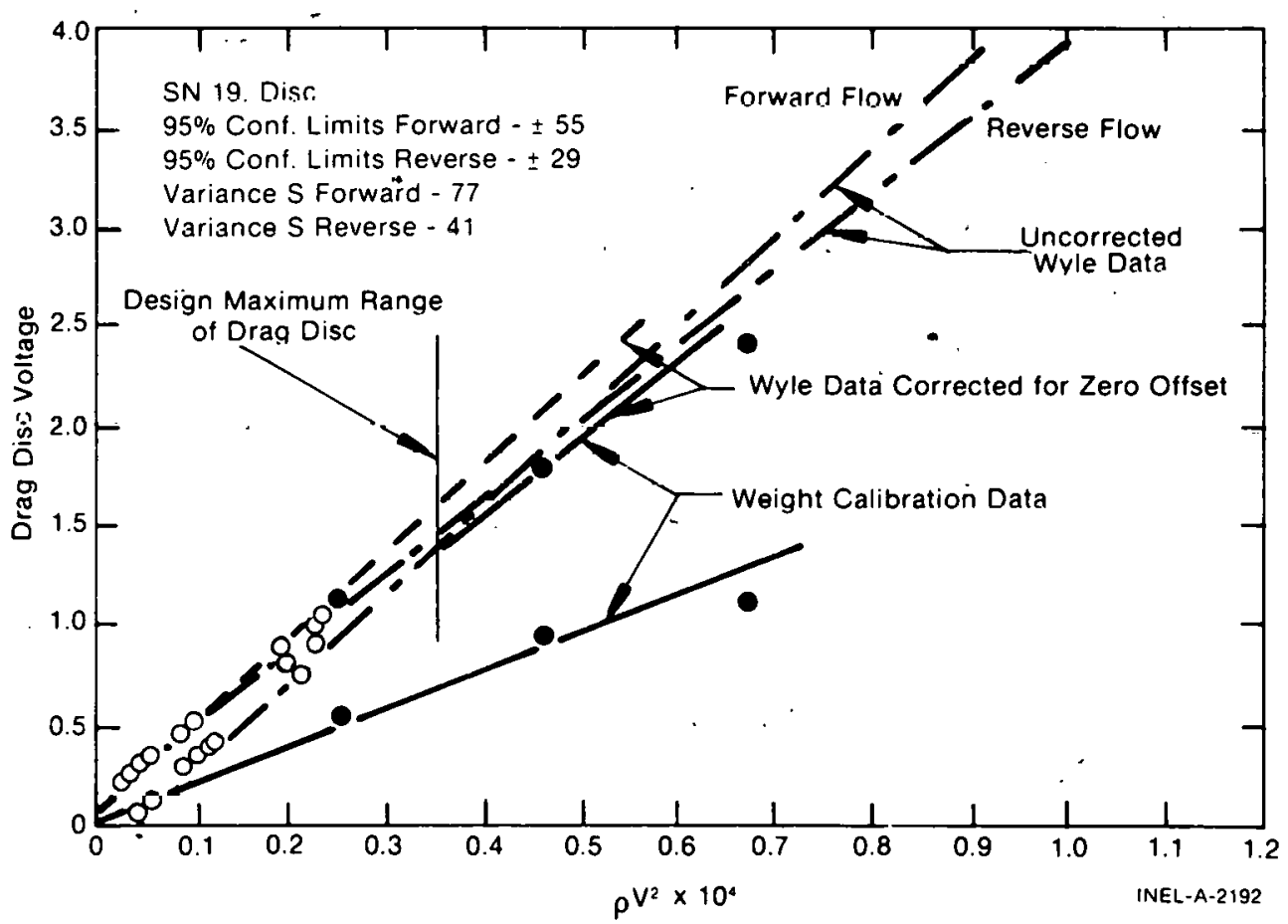

Fig. H-10 Drag disc volts versus momentum flux, from Wyle data and ARA weight calibration, SN 19. 